\title{
Self-Assembled Micro-Fibres by Oxime Connection of Linear Peptide Amphiphiles
}

\author{
Richard Booth, Ignacio Insua, Ghibom Bhak and Javier Montenegro*
}

Centro Singular de Investigación en Química Biolóxica e Materiais Moleculares (CIQUS), Departamento de Química Orgánica, Universidade de Santiago de Compostela, 15782 Santiago de Compostela, Spain. *E-mail: javier.montenegro@usc.es

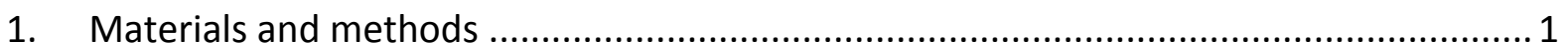

2. Characterisation of peptide heads (P1-6): ${ }^{1} \mathrm{H}-\mathrm{NMR}, \mathrm{HR}-\mathrm{MS}, \mathrm{HPLC}-\mathrm{MS}$.......................... 1

3. Characterisation of peptide amphiphiles: HR-MS, HPLC-MS.................................... 12

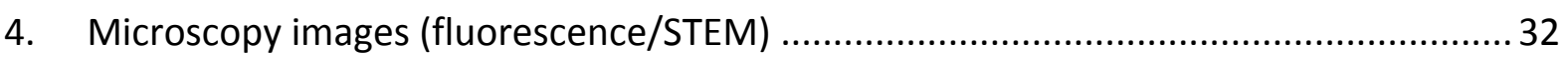

\section{Materials and methods}

Reagents were acquired from Sigma Aldrich, $\mathrm{TCl}$, Fluorochem, Iris Biotech or Fisher. Purified water was obtained from a Millipore Milli-Q integral 5 water purification system. Analytical HPLC was carried out using an Agilent 1260 Infinity II equipped with an Agilent SB-C18 column and connected to a 6120 Quadrupole LCMS. HR-MS was acquired using a Bruker MicroTOF instrument. ${ }^{1} \mathrm{H}$ NMR spectra were acquired using a Varian $300 \mathrm{MHz}$ spectrometer. Chemical shifts $(\delta)$ are reported in ppm relative to $D_{2} O(\delta=4.79 \mathrm{ppm})$. Epifluorescence microscopy was carried out using a Nikon eclipse Ti microscope equipped with an Andor Zyla sCMOS camera with images taken at either a magnification of $10 x$ or $60 x$.

\section{Characterisation of peptide heads (P1-6): ${ }^{1} \mathrm{H}-\mathrm{NMR}, \mathrm{HR}-\mathrm{MS}$, HPLC-MS}

P1 (RRRGAVV-ONH ${ }_{2}$ : ${ }^{1} \mathrm{H}-\mathrm{NMR}\left(300 \mathrm{MHz}, \mathrm{D}_{2} \mathrm{O}\right) \delta=4.68(\mathrm{~s}, 2 \mathrm{H}), 4.33-4.24(\mathrm{~m}, 4 \mathrm{H}), 4.15(\mathrm{~d}, \mathrm{~J}=$ $7.8 \mathrm{~Hz}, 1 \mathrm{H}), 4.08(\mathrm{~d}, J=8.3 \mathrm{~Hz}, 1 \mathrm{H}), 3.90(\mathrm{~s}, 2 \mathrm{H}), 3.20-3.14(\mathrm{~m}, 6 \mathrm{H}), 2.10-1.95(\mathrm{~m}, 2 \mathrm{H}), 1.89-$ $1.54(\mathrm{~m}, 12 \mathrm{H}), 1.37(\mathrm{~d}, J=7.1 \mathrm{~Hz}, 3 \mathrm{H}), 0.93-0.88(\mathrm{~m}, 12 \mathrm{H})$ ppm. HR-MS (ESI, +eV) m/z calculated for $\left[\mathrm{C}_{35} \mathrm{H}_{69} \mathrm{~N}_{18} \mathrm{O}_{9}\right]^{+}=885.5489 ; \mathrm{m} / \mathrm{z}$ found $=885.5485 . \boldsymbol{R}_{t} 8.5 \mathrm{~min}$ (Fig. S13) RPHPLC [Agilent SB-C18, $\mathrm{H}_{2} \mathrm{O}(0.1 \% \mathrm{TFA}) / \mathrm{MeCN}(0.1 \% \mathrm{TFA})$ 100:0 (0 $\left.\rightarrow 2 \mathrm{~min}\right)$, 100:0 $\rightarrow$ 5:95 ( $2 \rightarrow 22 \mathrm{~min}$ ), 0:100 (>22 $\mathrm{min})]$. Yield $=42.3 \mathrm{mg}(52 \%)$.

P2 (RRRGAVVV-ONH ${ }_{2}$ ): ${ }^{1} \mathrm{H}-\mathrm{NMR}\left(300 \mathrm{MHz}_{2} \mathrm{D}_{2} \mathrm{O}\right) \delta=4.70(\mathrm{~s}, 2 \mathrm{H})$, 4.36-4.26 (m, 4H), 4.17 (d, J $=7.7 \mathrm{~Hz}, 1 \mathrm{H}), 4.13(\mathrm{~d}, J=8.9 \mathrm{~Hz}, 1 \mathrm{H}), 4.08(\mathrm{~d}, J=8.3 \mathrm{~Hz}, 1 \mathrm{H}), 3.93(\mathrm{~s}, 2 \mathrm{H}), 3.22-3.17(\mathrm{~m}, 6 \mathrm{H})$, 2.10-1.94 (m, 2H), 1.92-1.58 (m, 12H), $1.39(\mathrm{~d}, J=7.2 \mathrm{~Hz}, 3 \mathrm{H}), 0.96-0.88(\mathrm{~m}, 18 \mathrm{H})$ ppm. HRMS $(E S I,+e V) m / z$ calculated for $\left[\mathrm{C}_{40} \mathrm{H}_{78} \mathrm{~N}_{19} \mathrm{O}_{10}\right]^{+}=984.6174 ; \mathrm{m} / \mathrm{z}$ found $=984.6176 . \boldsymbol{R}_{\boldsymbol{t}} \mathbf{9 . 5}$ 
$\min$ (Fig. S14) RP-HPLC [Agilent SB-C18, $\mathrm{H}_{2} \mathrm{O}(0.1 \% \mathrm{TFA}) / \mathrm{MeCN}(0.1 \% \mathrm{TFA})$ 100:0 (0 $\left.\rightarrow 2 \mathrm{~min}\right)$, 100:0 $\rightarrow 5: 95$ ( $2 \rightarrow 22 \mathrm{~min}), 0: 100$ (>22 $\mathrm{min})]$. Yield = $55.7 \mathrm{mg}(61 \%)$.

P3 (RRRGAAVV-ONH ${ }_{2}$ ): ${ }^{1} \mathrm{H}-\mathrm{NMR}\left(300 \mathrm{MHz}, \mathrm{D}_{2} \mathrm{O}\right) \delta=4.70(\mathrm{~s}, 2 \mathrm{H})$, 4.35-4.23 (m, 5H), 4.17 (d, J $=7.7 \mathrm{~Hz}, 1 \mathrm{H}), 4.09(\mathrm{~d}, J=8.2 \mathrm{~Hz}, 1 \mathrm{H}), 3.93(\mathrm{~s}, 2 \mathrm{H}), 3.22-3.17(\mathrm{~m}, 6 \mathrm{H}), 2.11-1.97(\mathrm{~m}, 2 \mathrm{H}), 1.92-$ $1.57(\mathrm{~m}, 12 \mathrm{H}), 1.38(\mathrm{t}, J=7.4 \mathrm{~Hz}, 6 \mathrm{H}), 0.95-0.90(\mathrm{~m}, 12 \mathrm{H})$ ppm. HR-MS (ESI, +eV) m/z calculated for $\left[\mathrm{C}_{38} \mathrm{H}_{74} \mathrm{~N}_{19} \mathrm{O}_{10}\right]^{+}=956.5861 ; \mathrm{m} / \mathrm{z}$ found $=956.5859 . \boldsymbol{R}_{\boldsymbol{t}} \mathbf{9} \min$ (Fig. S15) RPHPLC [Agilent SB-C18, $\mathrm{H}_{2} \mathrm{O}(0.1 \% \mathrm{TFA}) / \mathrm{MeCN}(0.1 \% \mathrm{TFA})$ 100:0 (0 $\left.\rightarrow 2 \mathrm{~min}\right)$, 100:0 $\rightarrow$ 5:95 ( $2 \rightarrow 22 \mathrm{~min}$ ), 0:100 (>22 $\mathrm{min})]$. Yield $=41.2 \mathrm{mg}(47 \%)$.

P4 (EEGAVV-ONH $\left.{ }_{2}\right):{ }^{1} \mathrm{H}-\mathrm{NMR}\left(300 \mathrm{MHz}, \mathrm{D}_{2} \mathrm{O}\right) \delta=4.66(\mathrm{~s}, 2 \mathrm{H}), 4.44-4.28(\mathrm{~m}, 3 \mathrm{H}), 4.21(\mathrm{~d}, \mathrm{~J}=$ $7.6 \mathrm{~Hz}, 1 \mathrm{H}), 4.15(\mathrm{~d}, J=8.1 \mathrm{~Hz}, 1 \mathrm{H}), 4.04-3.90(\mathrm{~m}, 2 \mathrm{H}), 2.54-2.47(\mathrm{~m}, 4 \mathrm{H}), 2.23-1.96(\mathrm{~m}, 6 \mathrm{H})$, $1.41(\mathrm{~d}, J=7.2 \mathrm{~Hz}, 3 \mathrm{H}), 0.97-0.93(\mathrm{~m}, 12 \mathrm{H}) \mathrm{ppm}$. HR-MS (ESI, +eV) m/z calculated for $\left[\mathrm{C}_{27} \mathrm{H}_{47} \mathrm{~N}_{8} \mathrm{O}_{12}\right]^{+}=675.3308 ; \mathrm{m} / \mathrm{z}$ found $=675.3311 . \boldsymbol{R}_{\boldsymbol{t}} \mathbf{9} \mathrm{min}$ (Fig. S16) RP-HPLC [Agilent SB$\mathrm{C} 18, \mathrm{H}_{2} \mathrm{O}(0.1 \% \mathrm{TFA}) / \mathrm{MeCN}(0.1 \% \mathrm{TFA})$ 100:0 (0 $\rightarrow 2 \mathrm{~min}$ ), 100:0 $\rightarrow 5: 95$ (2 $\rightarrow 32 \mathrm{~min}$ ), 0:100 (>32 $\mathrm{min})$ ]. Yield = $22.1 \mathrm{mg}(32 \%)$.

P5 (EEAAVV-ONH $\left.{ }_{2}\right):{ }^{1} \mathrm{H}-\mathrm{NMR}\left(300 \mathrm{MHz}, \mathrm{D}_{2} \mathrm{O}\right) \delta=4.56(\mathrm{~s}, 2 \mathrm{H}), 4.40-4.26(\mathrm{~m}, 4 \mathrm{H}), 4.20(\mathrm{~d}, J=$ $7.8 \mathrm{~Hz}, 1 \mathrm{H}), 4.13(\mathrm{~d}, J=8.2 \mathrm{~Hz}, 1 \mathrm{H}), 2.54-2.48(\mathrm{~m}, 4 \mathrm{H}), 2.23-1.95(\mathrm{~m}, 6 \mathrm{H}), 1.41(\mathrm{~d}, J=7.2 \mathrm{~Hz}$, 3H), $1.40(\mathrm{~d}, J=7.2 \mathrm{~Hz}, 3 \mathrm{H}), 0.98-0.94(\mathrm{~m}, 12 \mathrm{H}) \mathrm{ppm}$. HR-MS (ESI, +eV) m/z calculated for $\left[\mathrm{C}_{28} \mathrm{H}_{48} \mathrm{~N}_{8} \mathrm{NaO}_{12}\right]^{+}=711.3284 ; \mathrm{m} / \mathrm{z}$ found $=711.3288 . \boldsymbol{R}_{\boldsymbol{t}} \mathbf{9 . 5}$ min (Fig. S17) RP-HPLC [Agilent SB-C18, $\mathrm{H}_{2} \mathrm{O}(0.1 \% \mathrm{TFA}) / \mathrm{MeCN}(0.1 \% \mathrm{TFA})$ 100:0 (0 $\left.\rightarrow 2 \mathrm{~min}\right), 100: 0 \rightarrow 5: 95$ (2 $\left.\rightarrow 32 \mathrm{~min}\right), 0: 100$ (>32 $\mathrm{min})]$. Yield = $29.6 \mathrm{mg}(49 \%)$.

P6 (EEAAAVV-ONH $)_{2}:{ }^{1} \mathrm{H}-\mathrm{NMR}\left(300 \mathrm{MHz}, \mathrm{D}_{2} \mathrm{O}\right) \delta=4.55(\mathrm{~s}, 2 \mathrm{H}), 4.40-4.24(\mathrm{~m}, 5 \mathrm{H}), 4.20(\mathrm{~d}, J=$ $8.0 \mathrm{~Hz}, 1 \mathrm{H}), 4.13(\mathrm{~d}, J=8.1 \mathrm{~Hz}, 1 \mathrm{H}), 2.51(\mathrm{t}, J=7.3 \mathrm{~Hz}, 4 \mathrm{H}), 2.23-1.97(\mathrm{~m}, 6 \mathrm{H}), 1.41(\mathrm{~d}, J=6.9$ $\mathrm{Hz}, 3 \mathrm{H}), 1.40$ (d, J = 7.2 Hz, 3H), 1.40 (d, J=6.9 Hz, 3H), 0.98-0.93 (m, 12H) ppm. HR-MS (ESI, $+e V$ ) $\mathrm{m} / \mathrm{z}$ calculated for $\left[\mathrm{C}_{31} \mathrm{H}_{53} \mathrm{~N}_{9} \mathrm{NaO}_{13}\right]^{+}=782.3655 ; \mathrm{m} / \mathrm{z}$ found $=782.3646 . \boldsymbol{R}_{\boldsymbol{t}} 10 \mathrm{~min}$ (Fig. S18) RP-HPLC [Agilent SB-C18, $\mathrm{H}_{2} \mathrm{O}(0.1 \%$ TFA)/MeCN (0.1\% TFA) 100:0 (0 $\rightarrow 2 \mathrm{~min})$, $100: 0 \rightarrow 5: 95(2 \rightarrow 32 \mathrm{~min}), 0: 100(>32 \mathrm{~min})]$. Yield $=24.6 \mathrm{mg}(40 \%)$. 


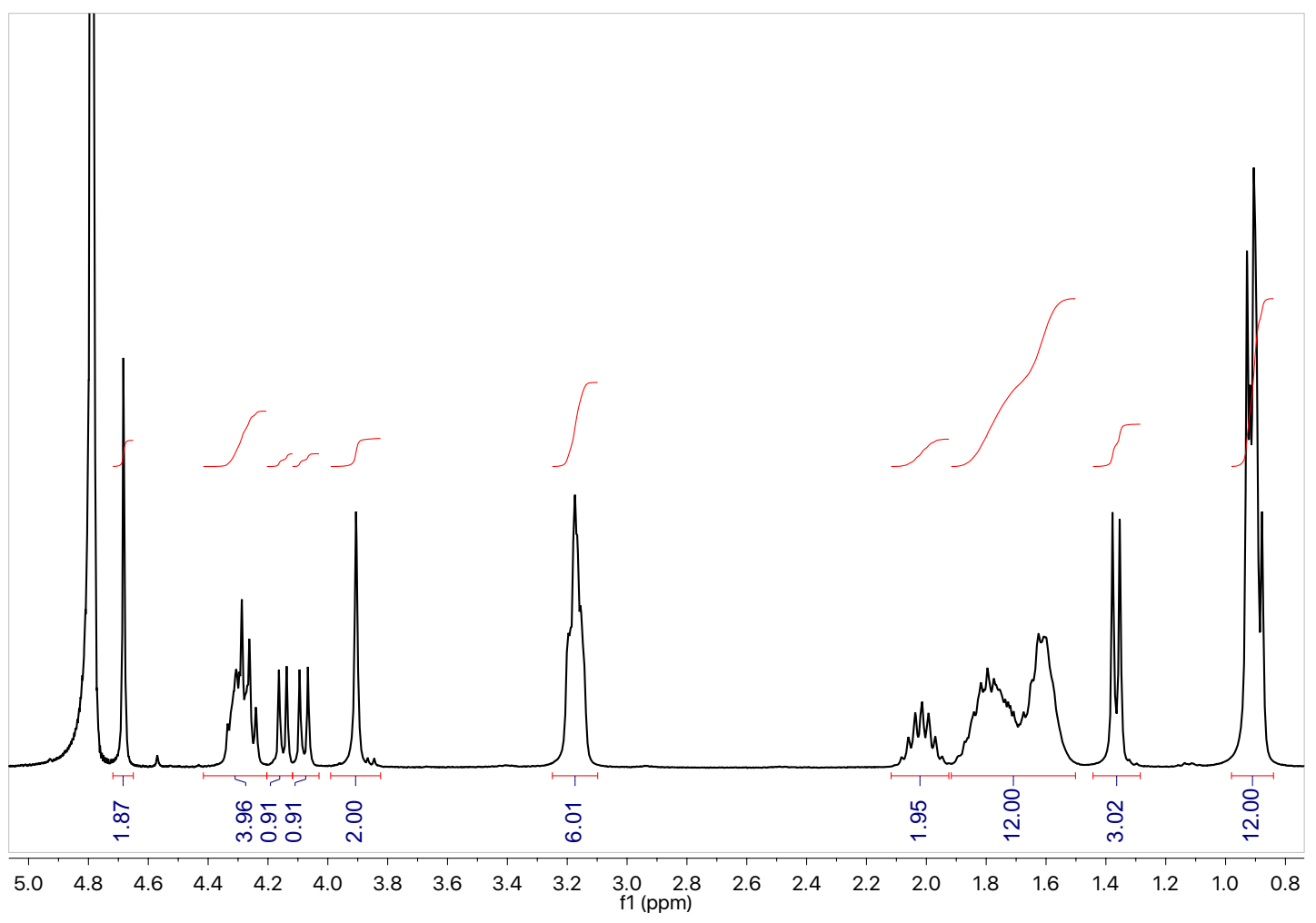

Figure $\mathrm{S} 1{ }^{1} \mathrm{H}-\mathrm{NMR}\left(300 \mathrm{MHz}, \mathrm{D}_{2} \mathrm{O}\right)$ of $\mathbf{P 1}\left(\mathrm{RRRGAVV}-\mathrm{ONH}_{2}\right)$.

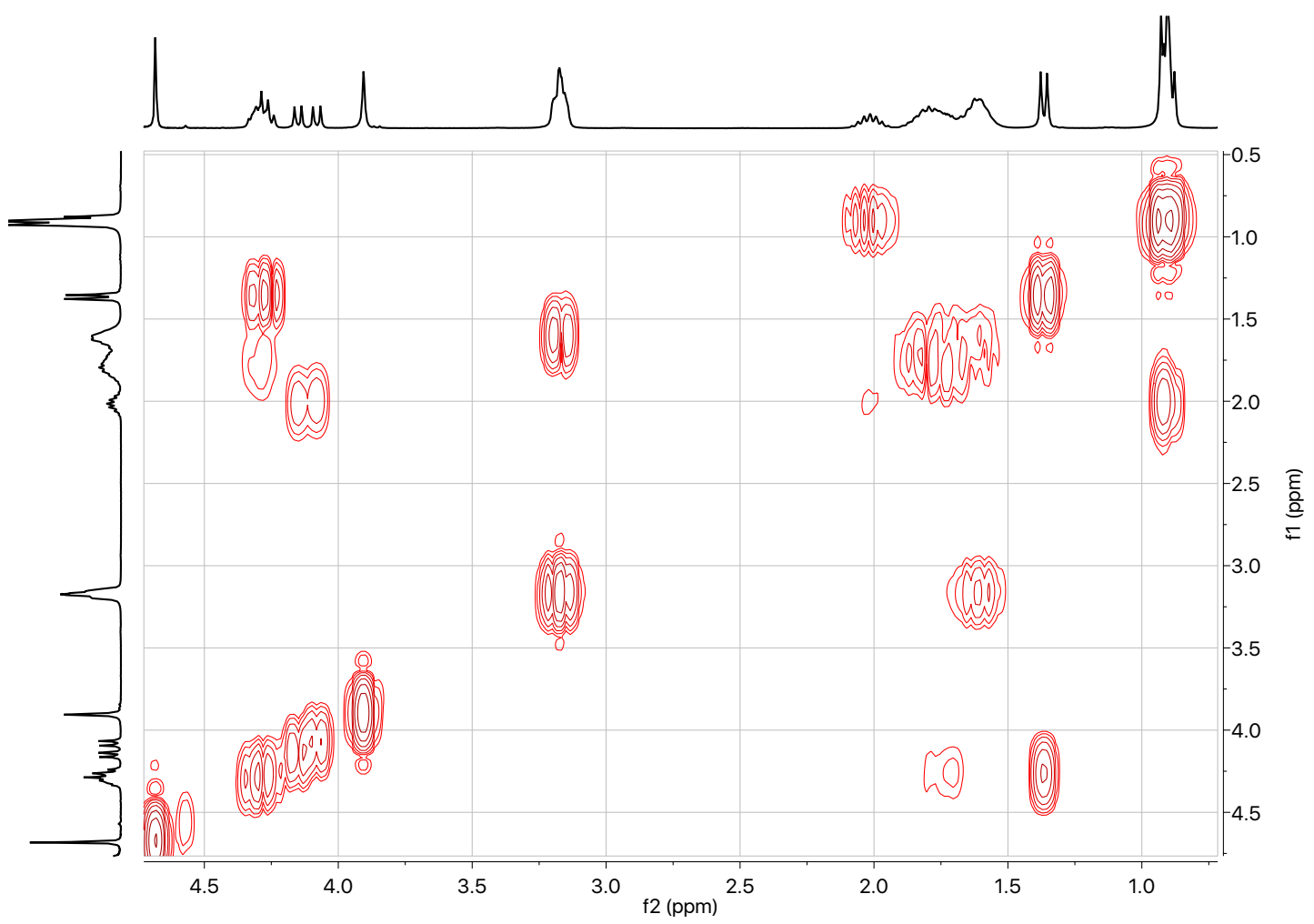

Figure $\mathrm{S} 2{ }^{1} \mathrm{H}$-COSY NMR $\left(300 \mathrm{MHz}, \mathrm{D}_{2} \mathrm{O}\right)$ of P1 (RRRGAVV-ONH $\left.\mathrm{H}_{2}\right)$. 


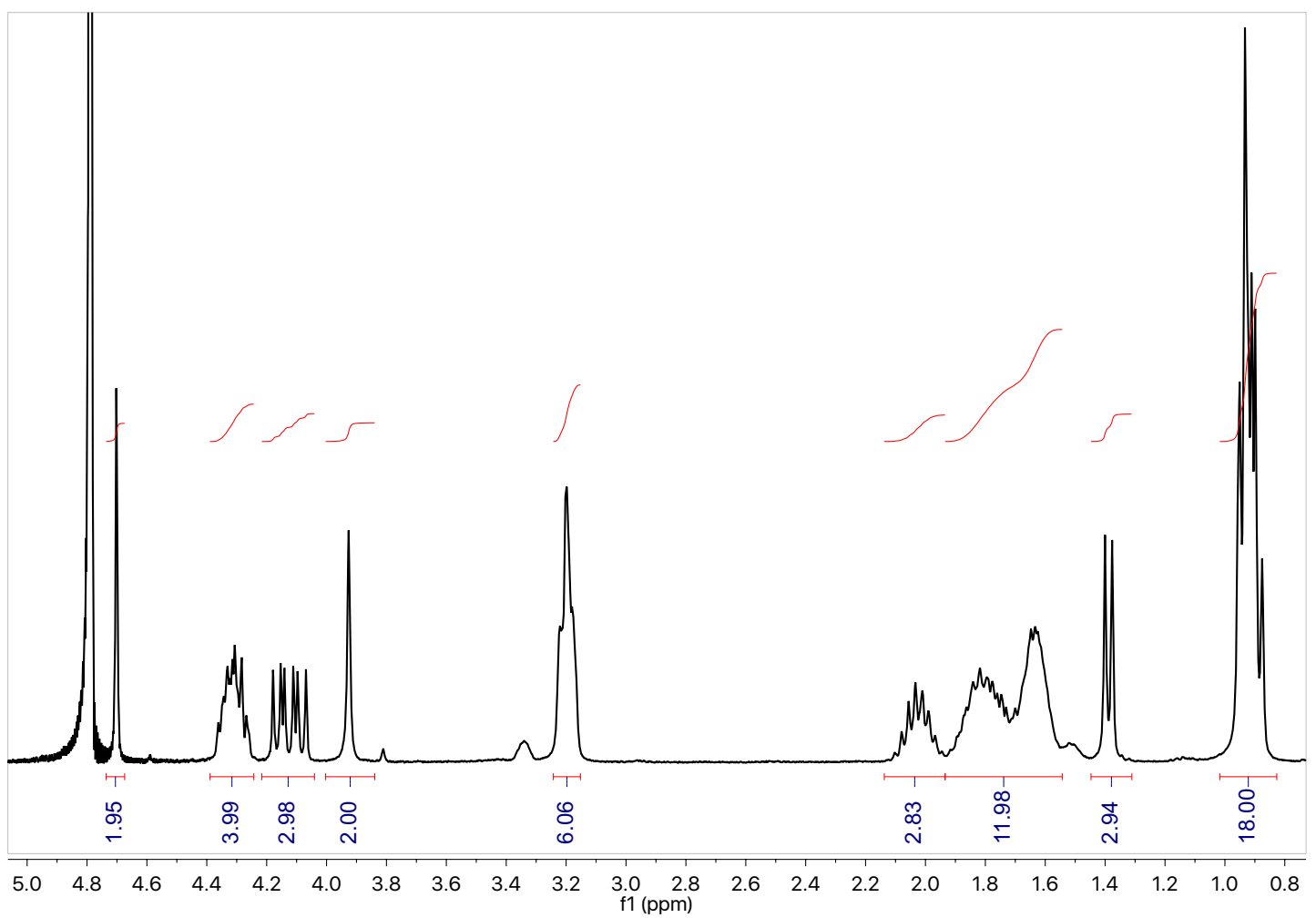

Figure $S 3{ }^{1} \mathrm{H}-\mathrm{NMR}\left(300 \mathrm{MHz}, \mathrm{D}_{2} \mathrm{O}\right)$ of $\mathbf{P 2}$ (RRRGAVVV-ONH $\left.\mathrm{H}_{2}\right)$.

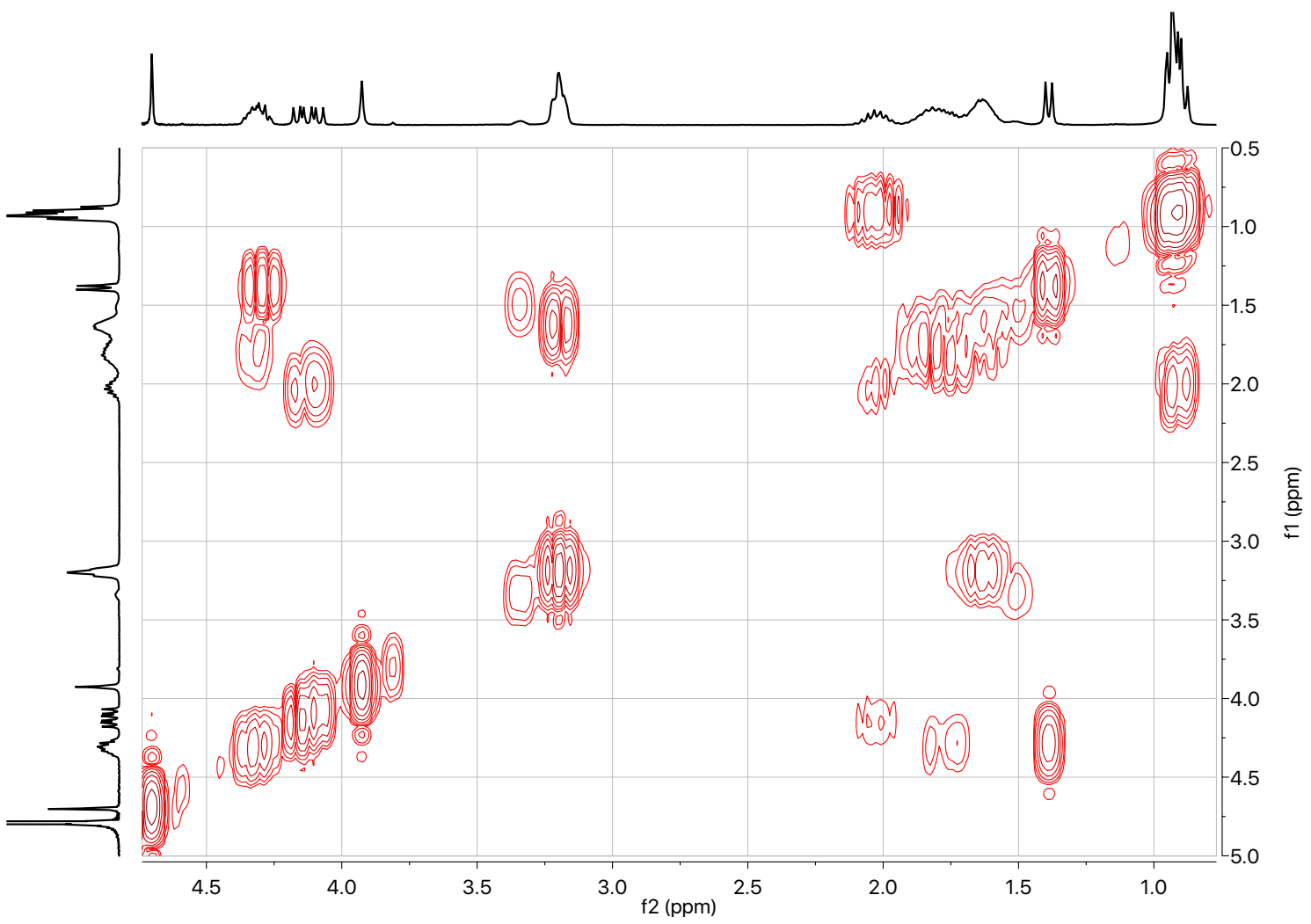

Figure $\mathrm{S}^{1}{ }^{1} \mathrm{H}$-COSY NMR $\left(300 \mathrm{MHz}, \mathrm{D}_{2} \mathrm{O}\right)$ of $\mathbf{P 2}$ (RRRGAVVV-ONH $\left.\mathrm{H}_{2}\right)$. 


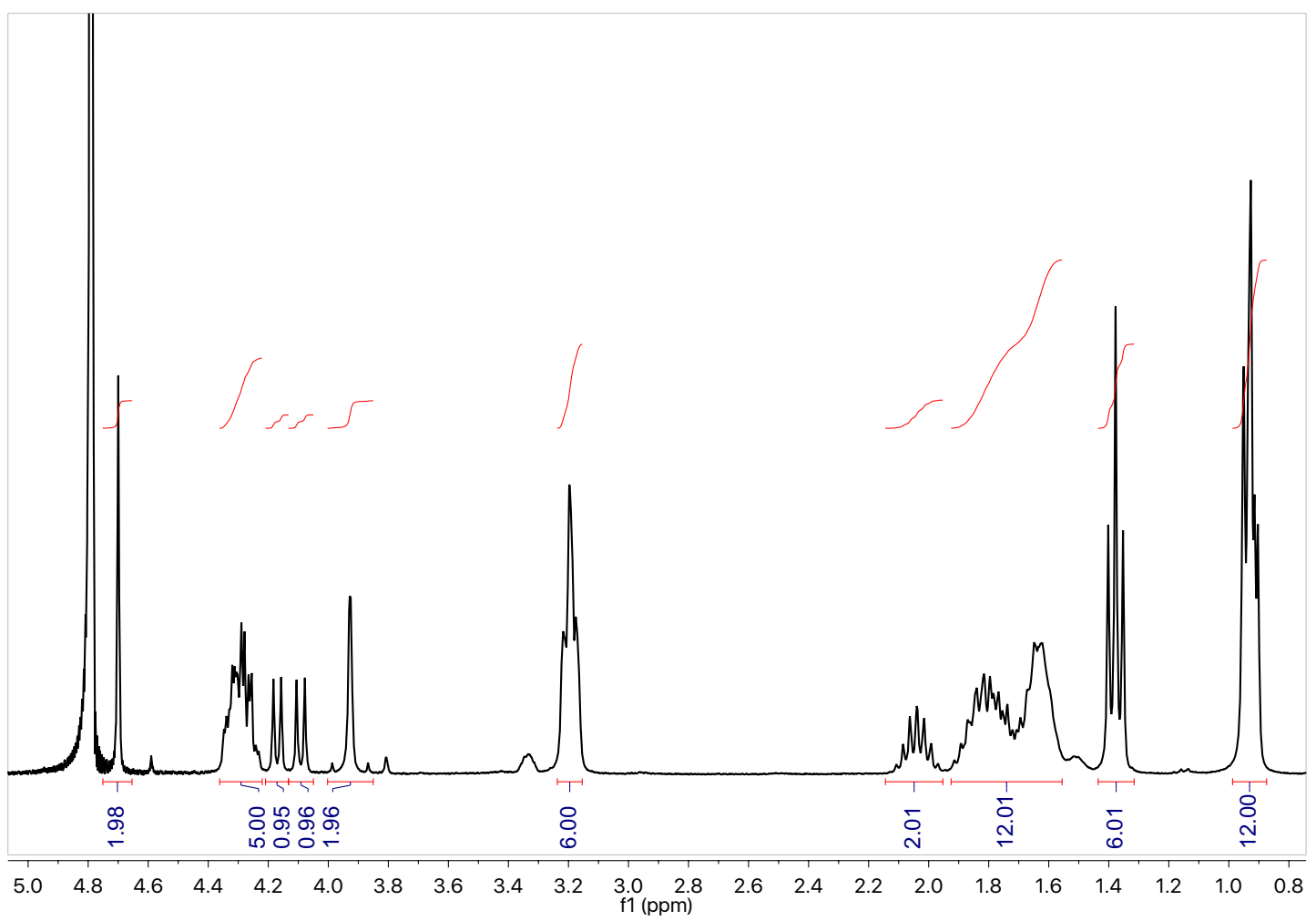

Figure $\mathrm{S}^{1}{ }^{1} \mathrm{H}-\mathrm{NMR}\left(300 \mathrm{MHz}, \mathrm{D}_{2} \mathrm{O}\right)$ of $\mathrm{P3}\left(\mathrm{RRRGAAVV}-\mathrm{ONH}_{2}\right)$.

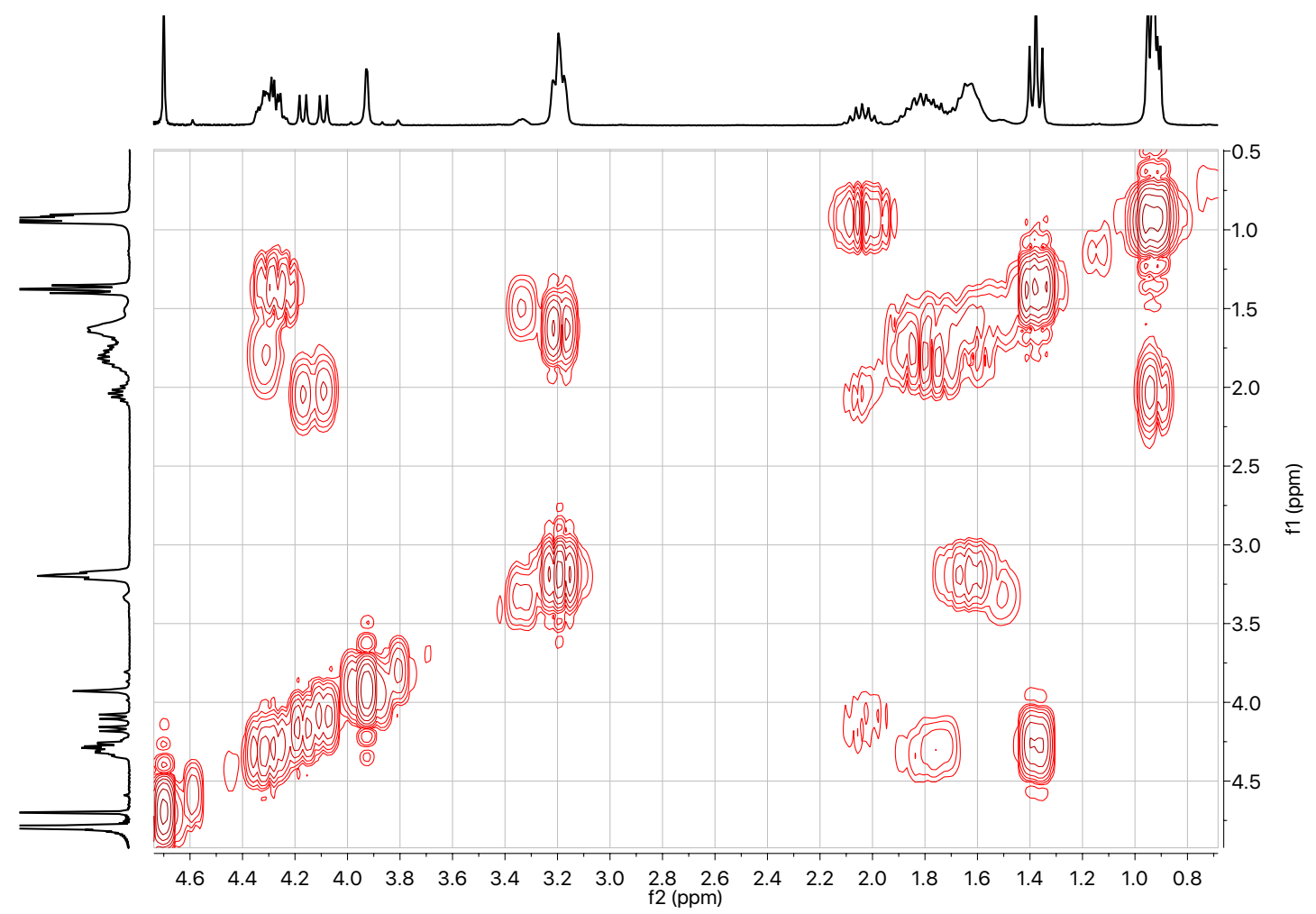

Figure S6 ${ }^{1} \mathrm{H}$-COSY NMR $\left(300 \mathrm{MHz}, \mathrm{D}_{2} \mathrm{O}\right)$ of $\mathbf{P} 3$ (RRRGAAVV-ONH 


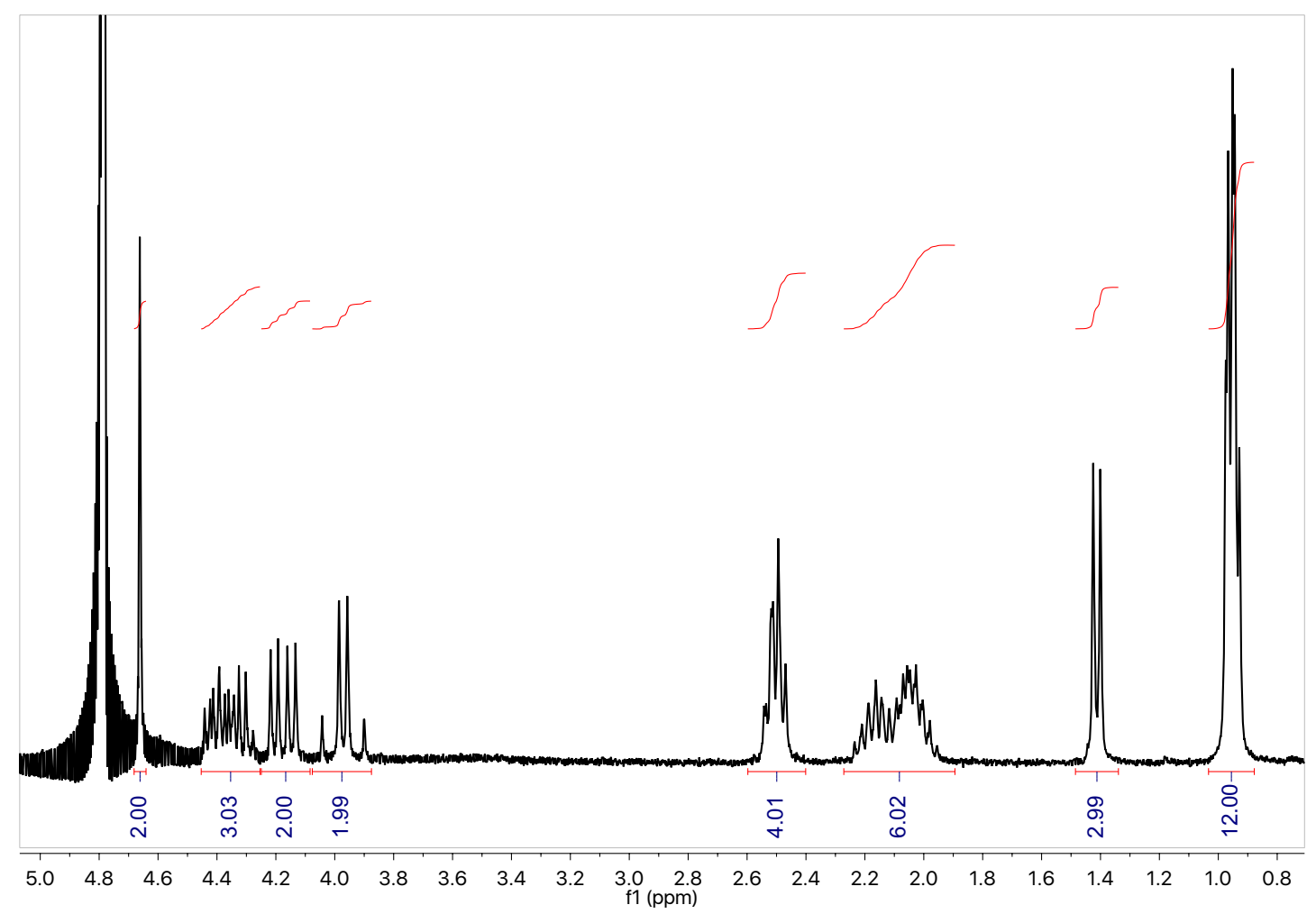

Figure $S 7{ }^{1} \mathrm{H}-\mathrm{NMR}\left(300 \mathrm{MHz}, \mathrm{D}_{2} \mathrm{O}\right)$ of $\mathbf{P 4}\left(\mathrm{EEGAVV}-\mathrm{ONH}_{2}\right)$.

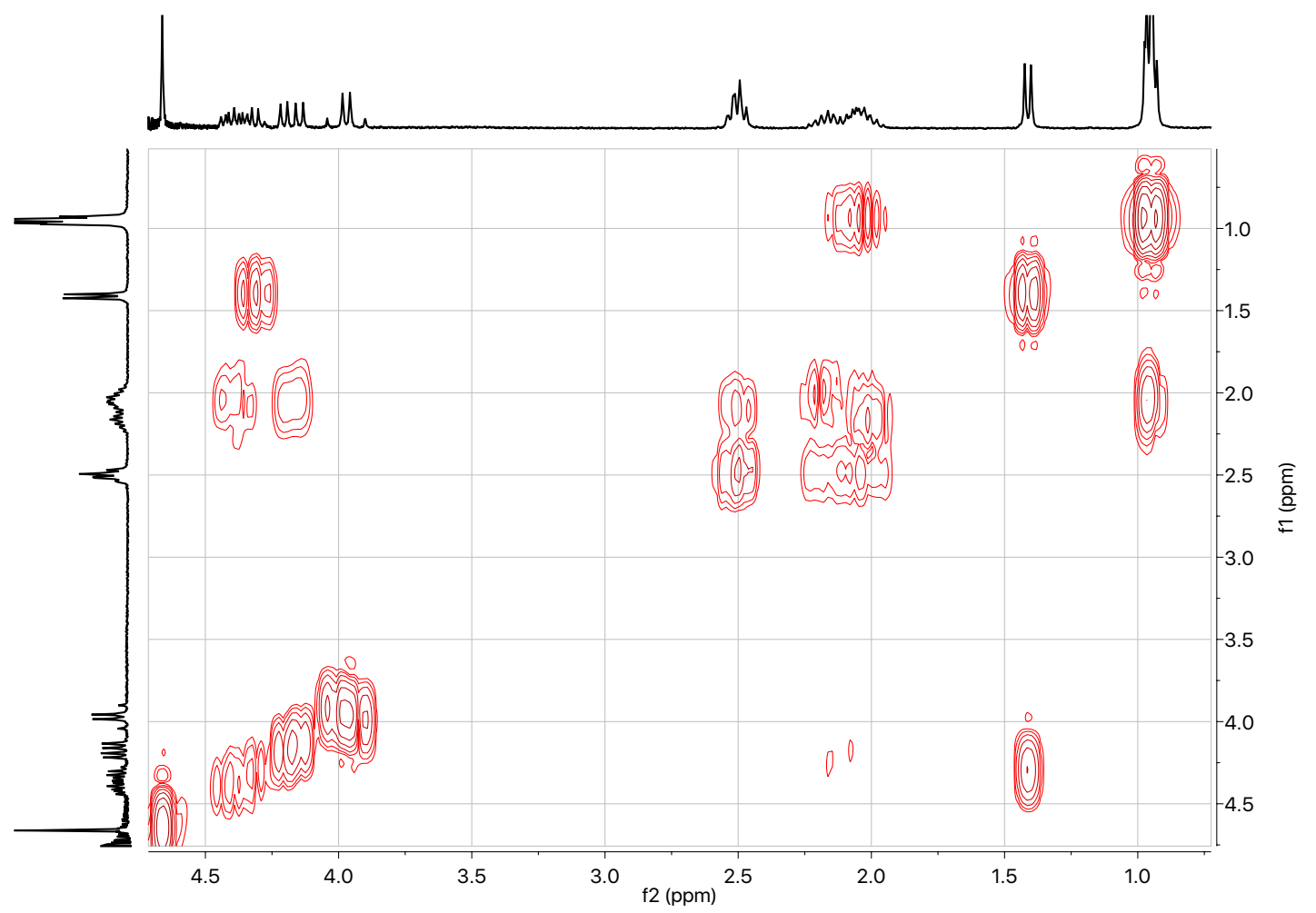

Figure $S 8^{1} \mathrm{H}$-COSY NMR $\left(300 \mathrm{MHz}, \mathrm{D}_{2} \mathrm{O}\right)$ of $\mathbf{P 4}\left(\right.$ EEGAVV-ONH $\left.\mathrm{H}_{2}\right)$. 


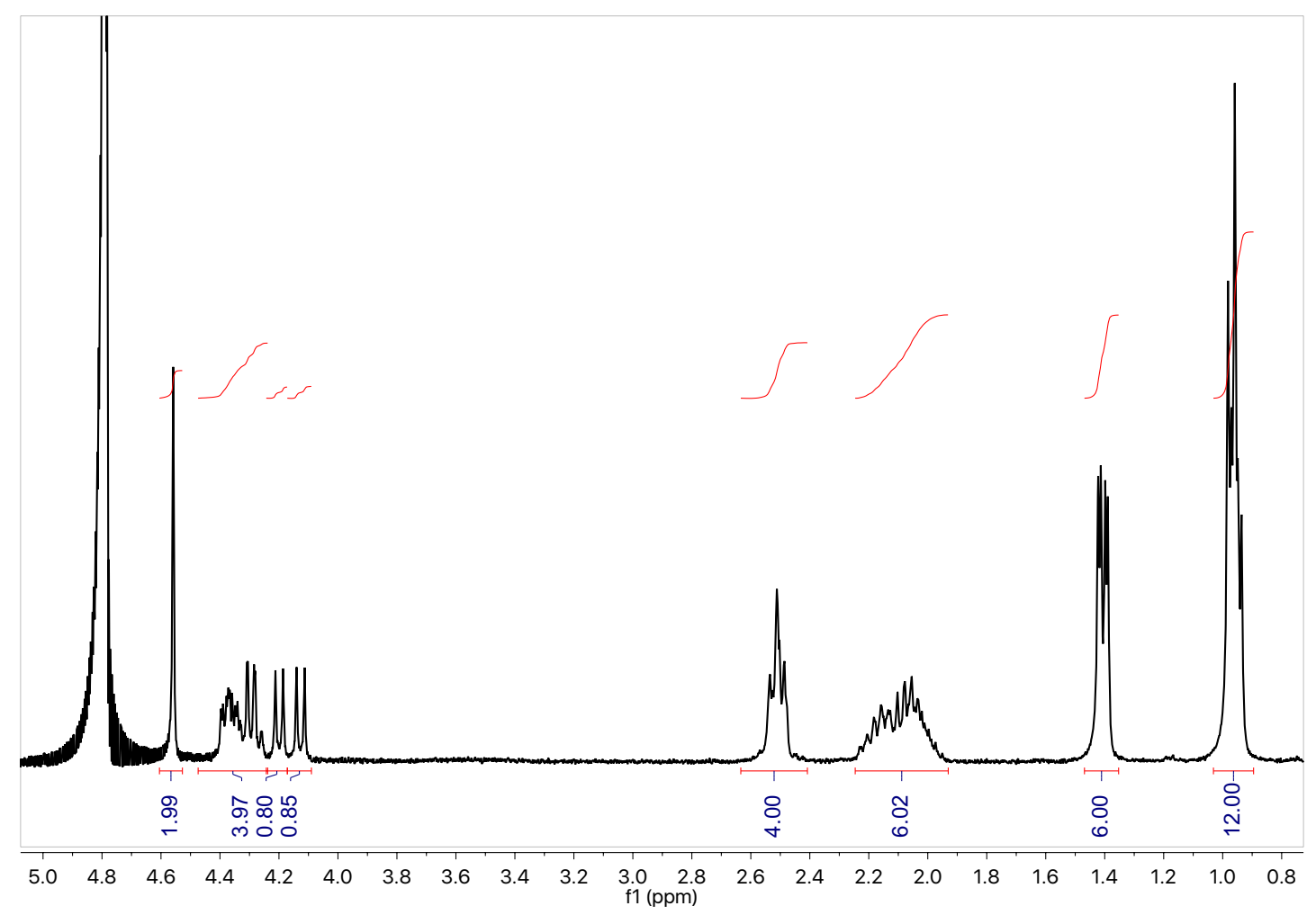

Figure $S 9{ }^{1} \mathrm{H}-\mathrm{NMR}\left(300 \mathrm{MHz}, \mathrm{D}_{2} \mathrm{O}\right)$ of P5 (EEAAVV-ONH $\left.\mathrm{H}_{2}\right)$.

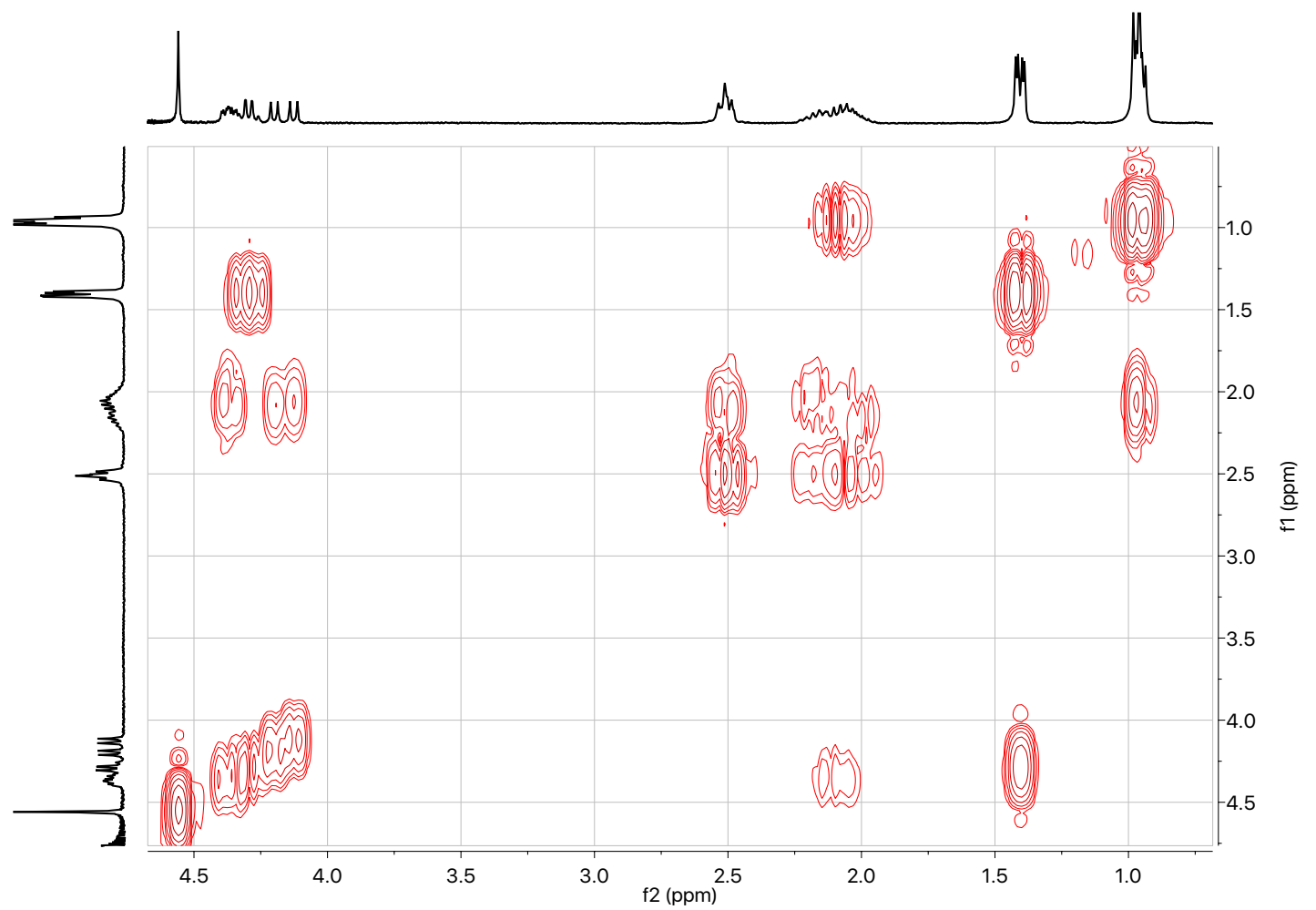

Figure $\mathrm{S}{ }^{1} \mathrm{H}$-COSY NMR $\left(300 \mathrm{MHz}, \mathrm{D}_{2} \mathrm{O}\right)$ of P5 (EEAAVV-ONH $\left.\mathrm{H}_{2}\right)$. 


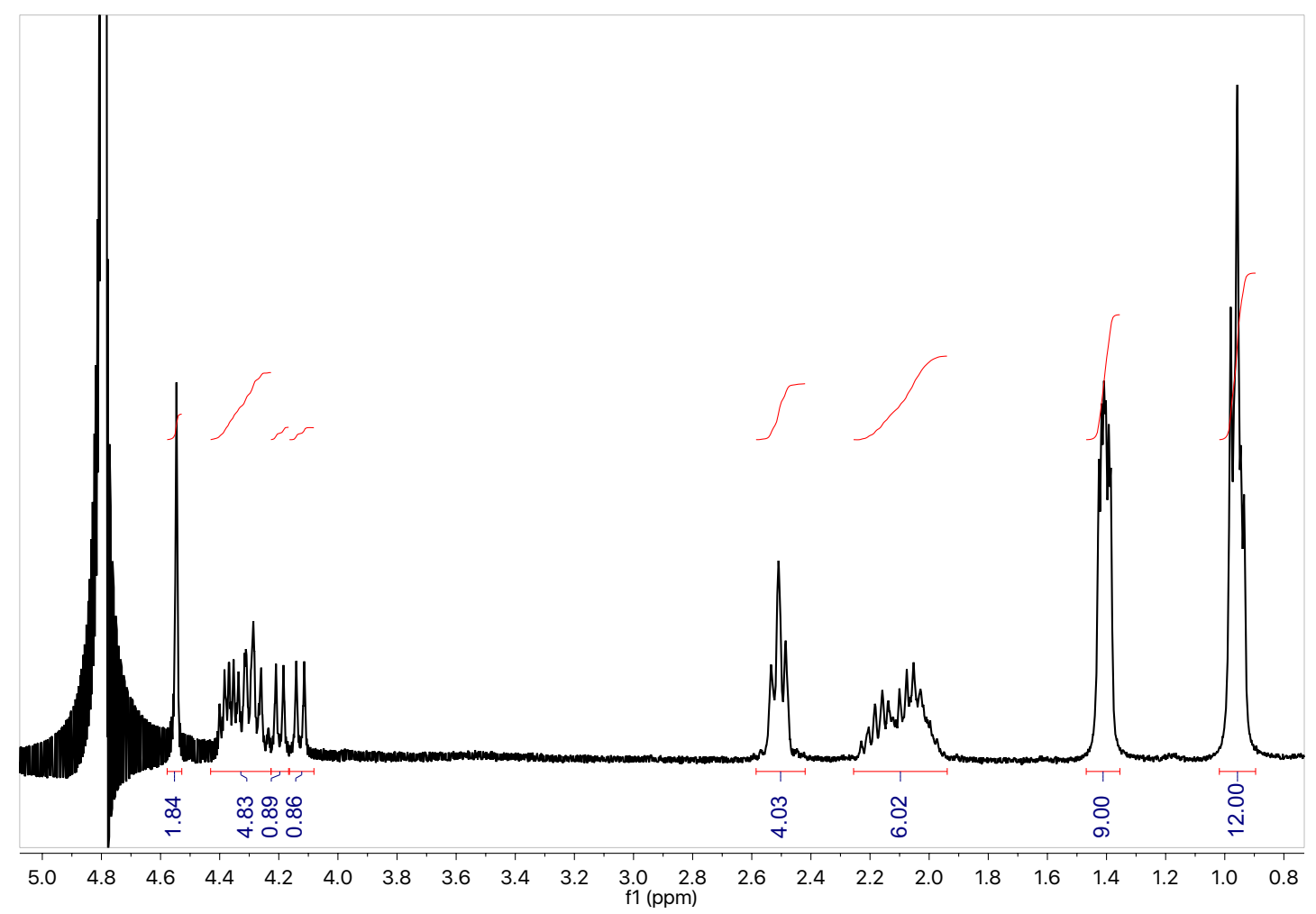

Figure $\mathrm{S}_{11}{ }^{1} \mathrm{H}-\mathrm{NMR}\left(300 \mathrm{MHz}, \mathrm{D}_{2} \mathrm{O}\right)$ of P6 (EEAAAVV-ONH $\left.\mathrm{H}_{2}\right)$.

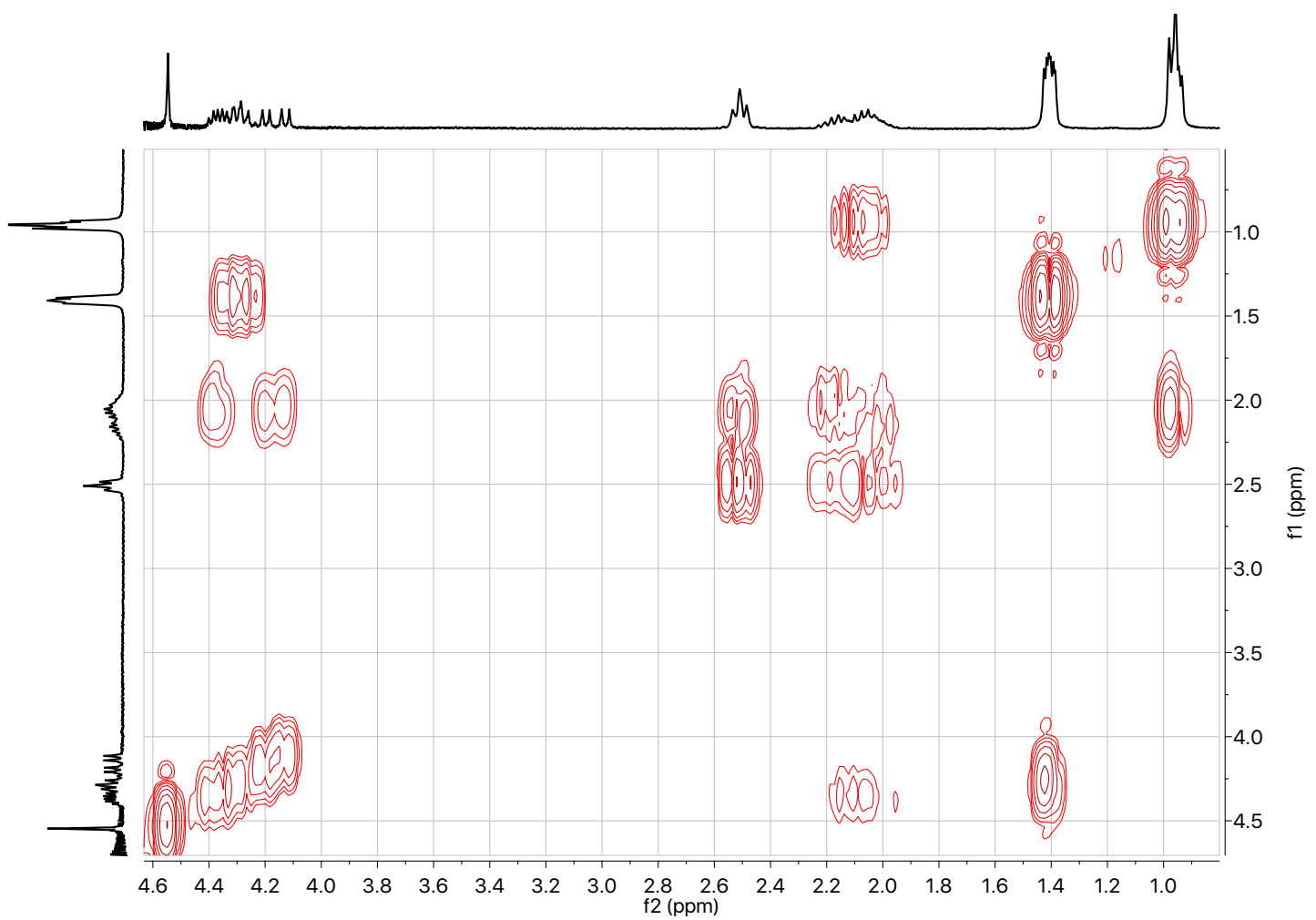

Figure $\mathrm{S}_{12}{ }^{1} \mathrm{H}$-COSY NMR $\left(300 \mathrm{MHz}, \mathrm{D}_{2} \mathrm{O}\right)$ of P6 (EEAAAVV-ONH 


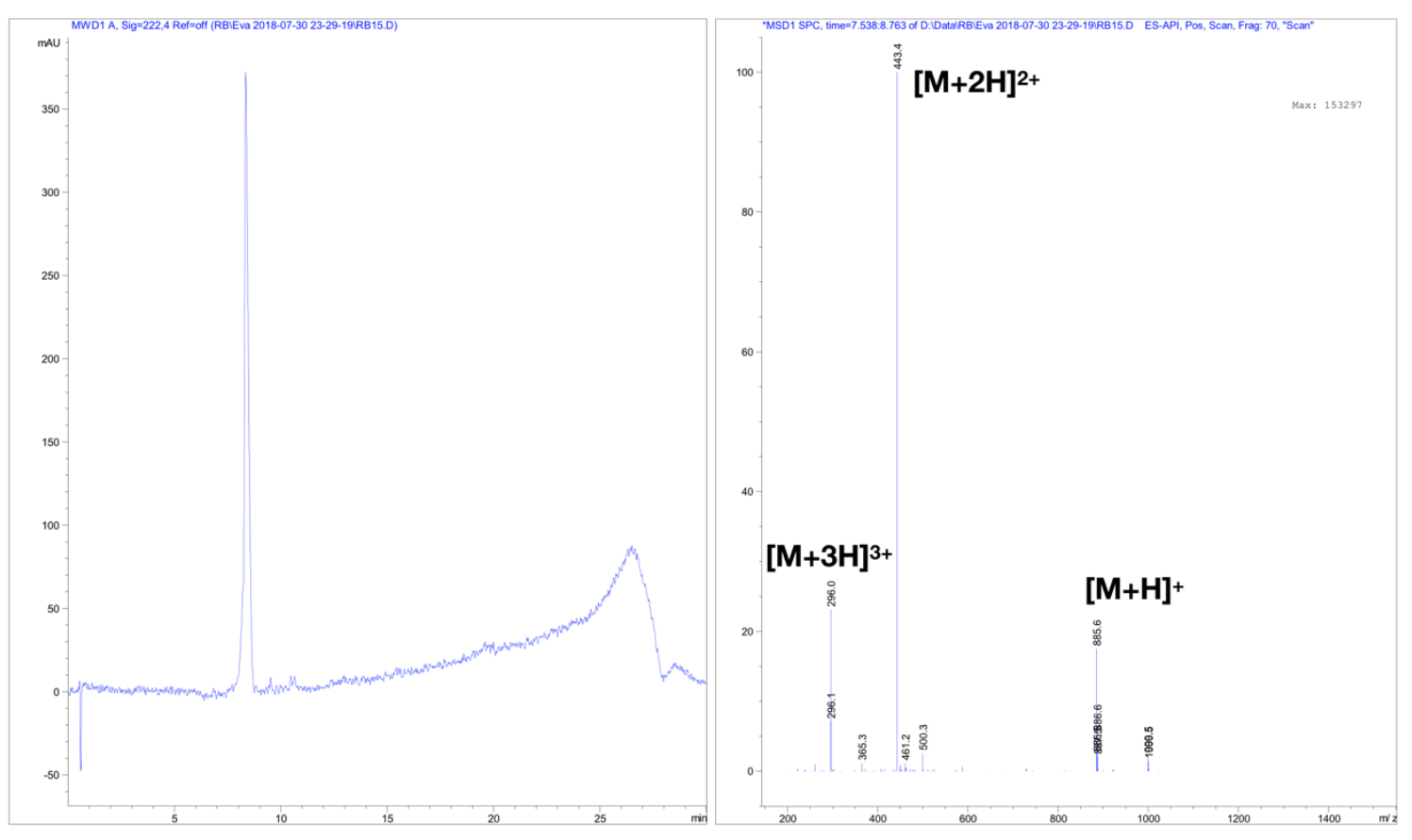

Figure S13 HPLC (UV-Vis detection at $222 \mathrm{~nm}$; left) and MS (ESI +eV; right) of P1 (RRRGAVV-ONH $\mathrm{H}_{2}$ ).

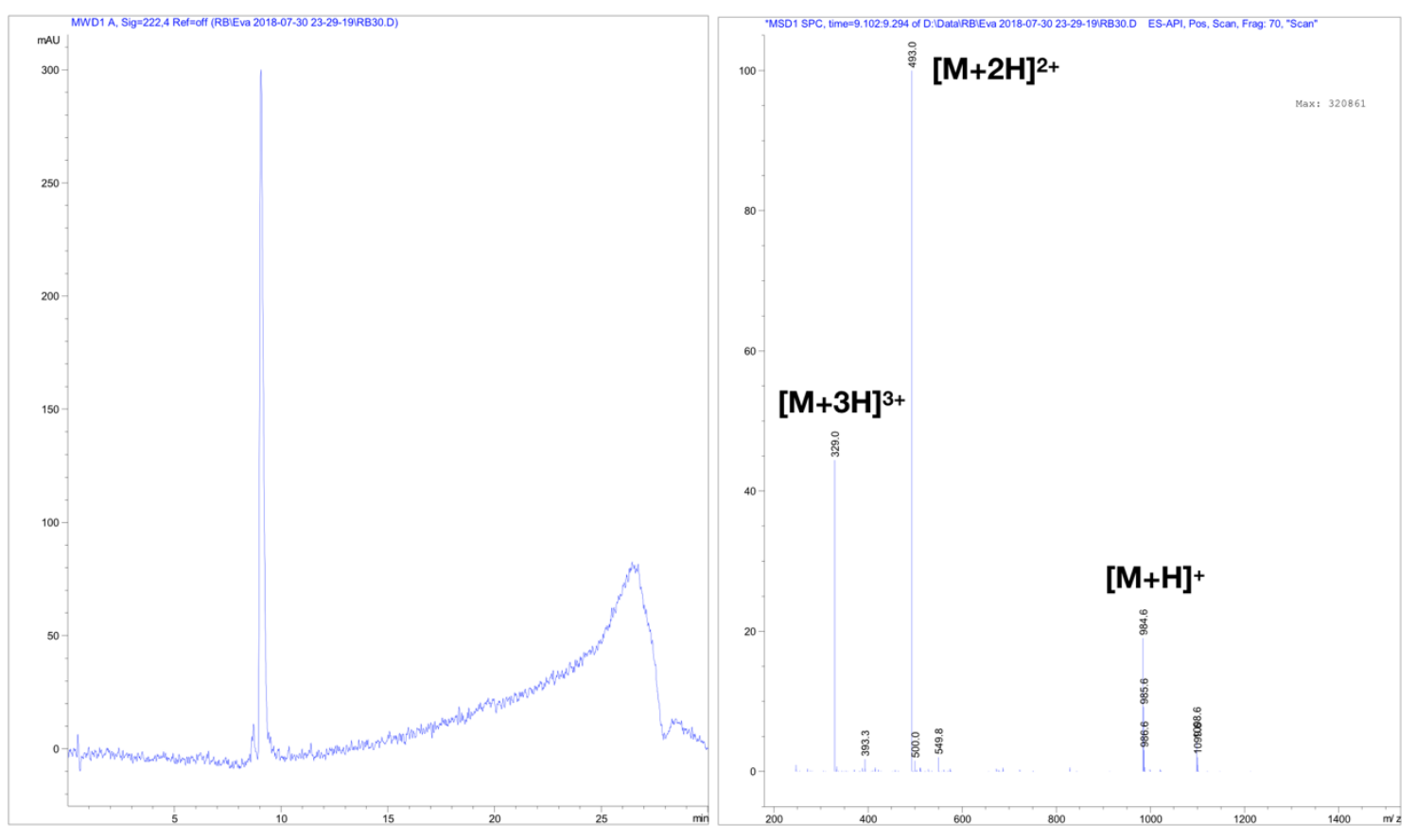

Figure S14 HPLC (UV-Vis detection at $222 \mathrm{~nm}$; left) and MS (ESI +eV; right) of P2 (RRRGAVVV-ONH ${ }_{2}$ ). 


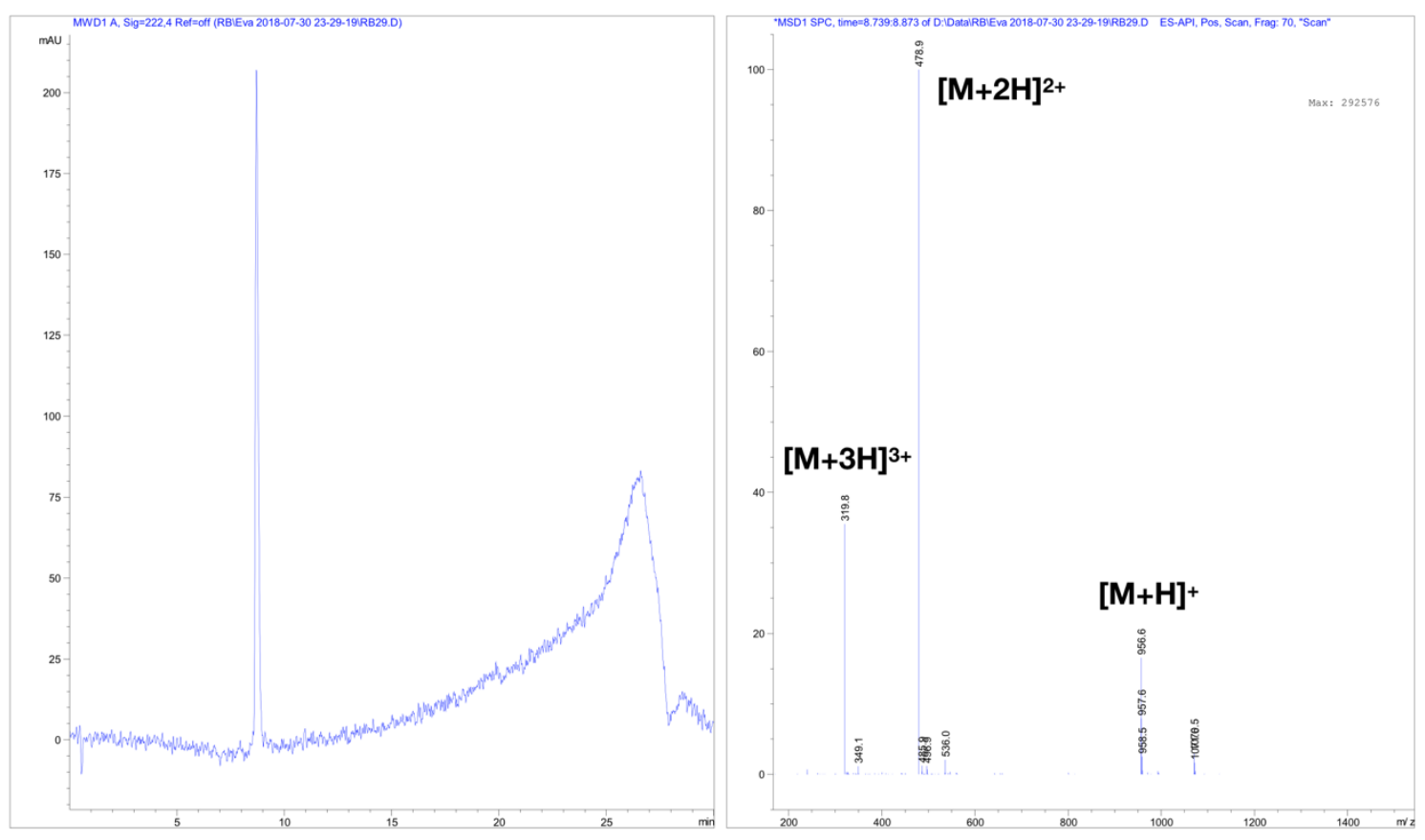

Figure S15 HPLC (UV-Vis detection at $222 \mathrm{~nm}$; left) and MS (ESI +eV; right) of $\mathbf{P} 3$ (RRRGAAVV-ONH $\mathrm{N}_{2}$.
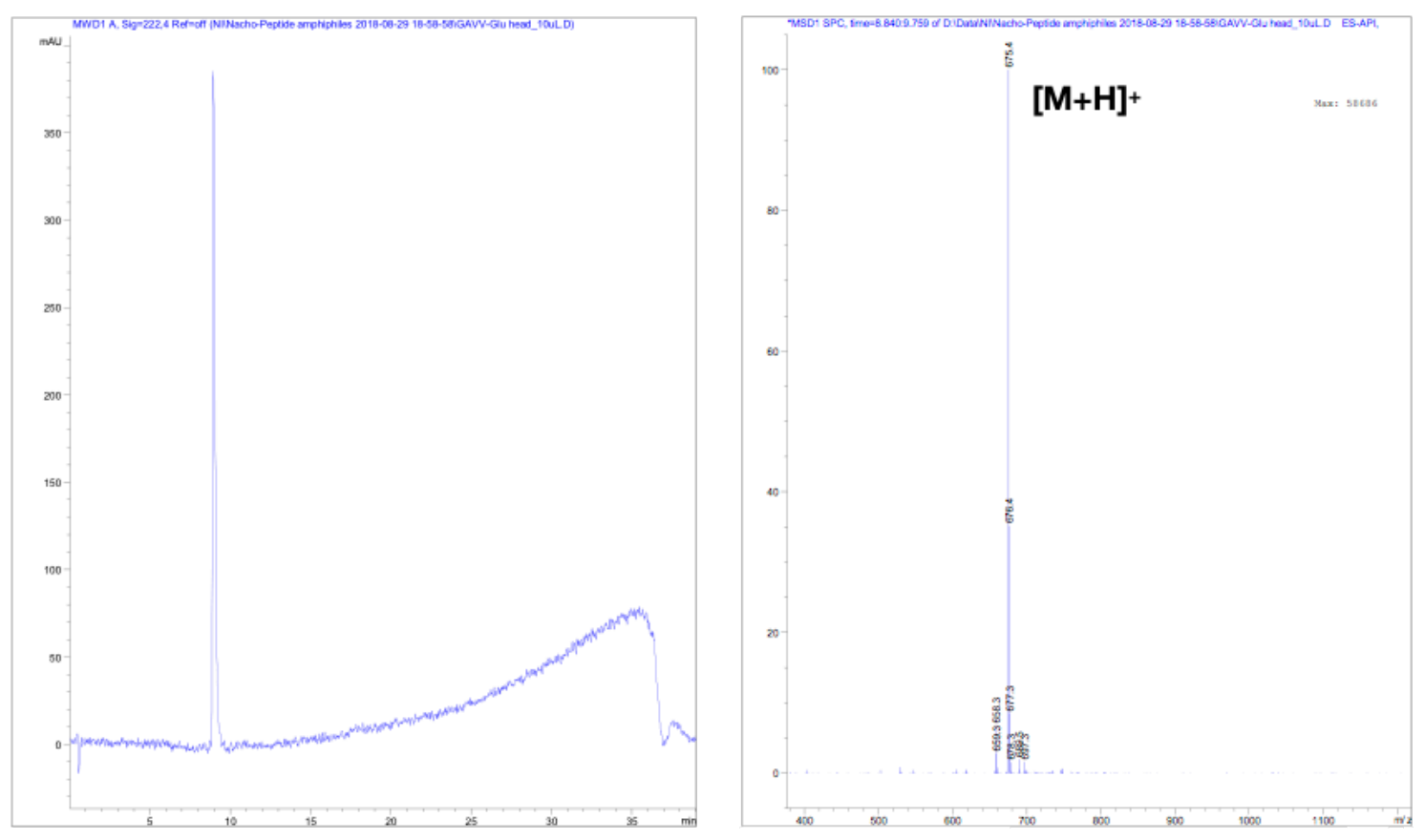

Figure S16 HPLC (UV-Vis detection at $222 \mathrm{~nm}$; left) and MS (ESI +eV; right) of P4 (EEGAVV$\mathrm{ONH}_{2}$ ). 

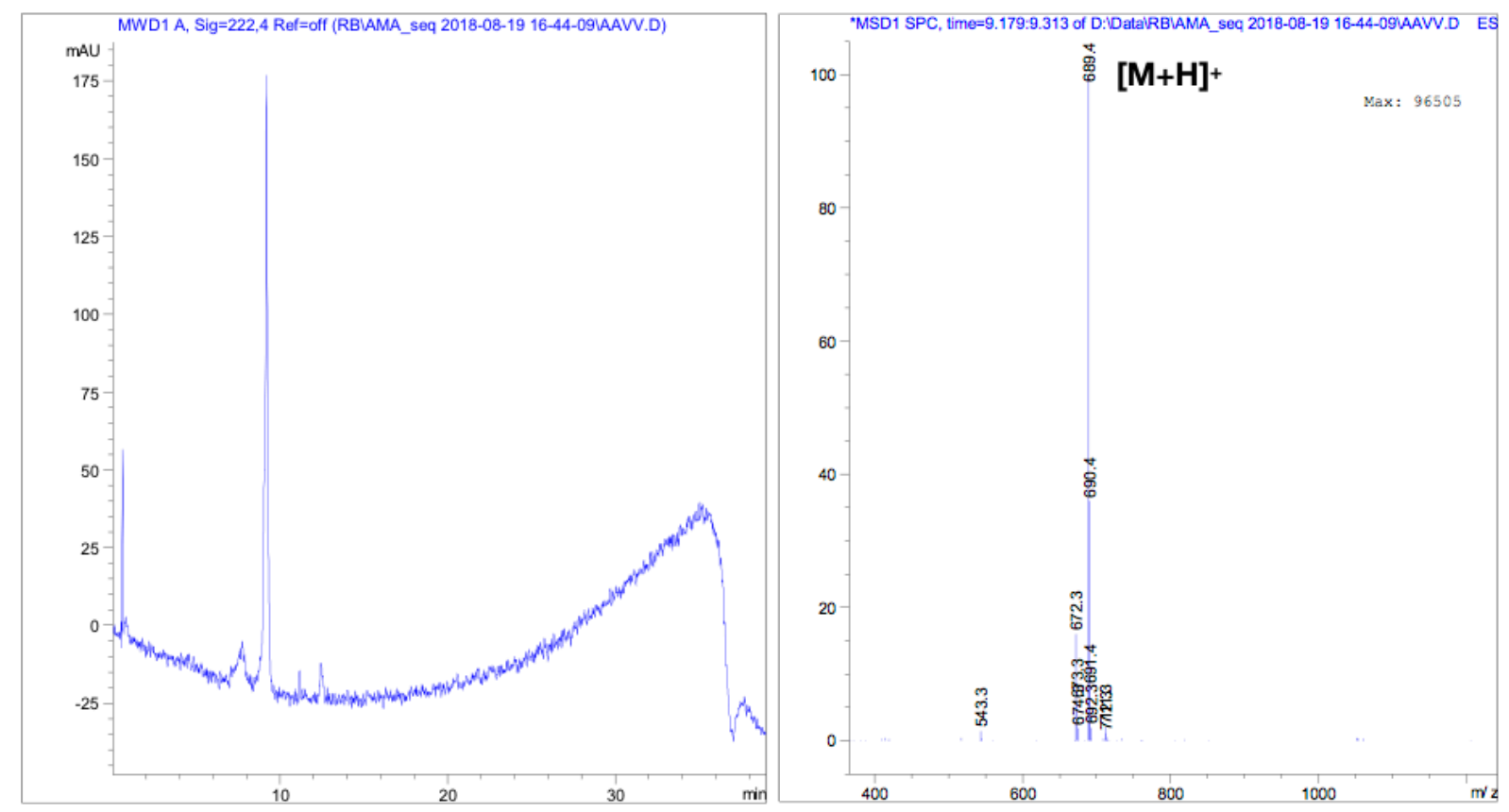

Figure S17 HPLC (UV-Vis detection at $222 \mathrm{~nm}$; left) and MS (ESI +eV; right) of P5 (EEAAVV$\mathrm{ONH}_{2}$ ).
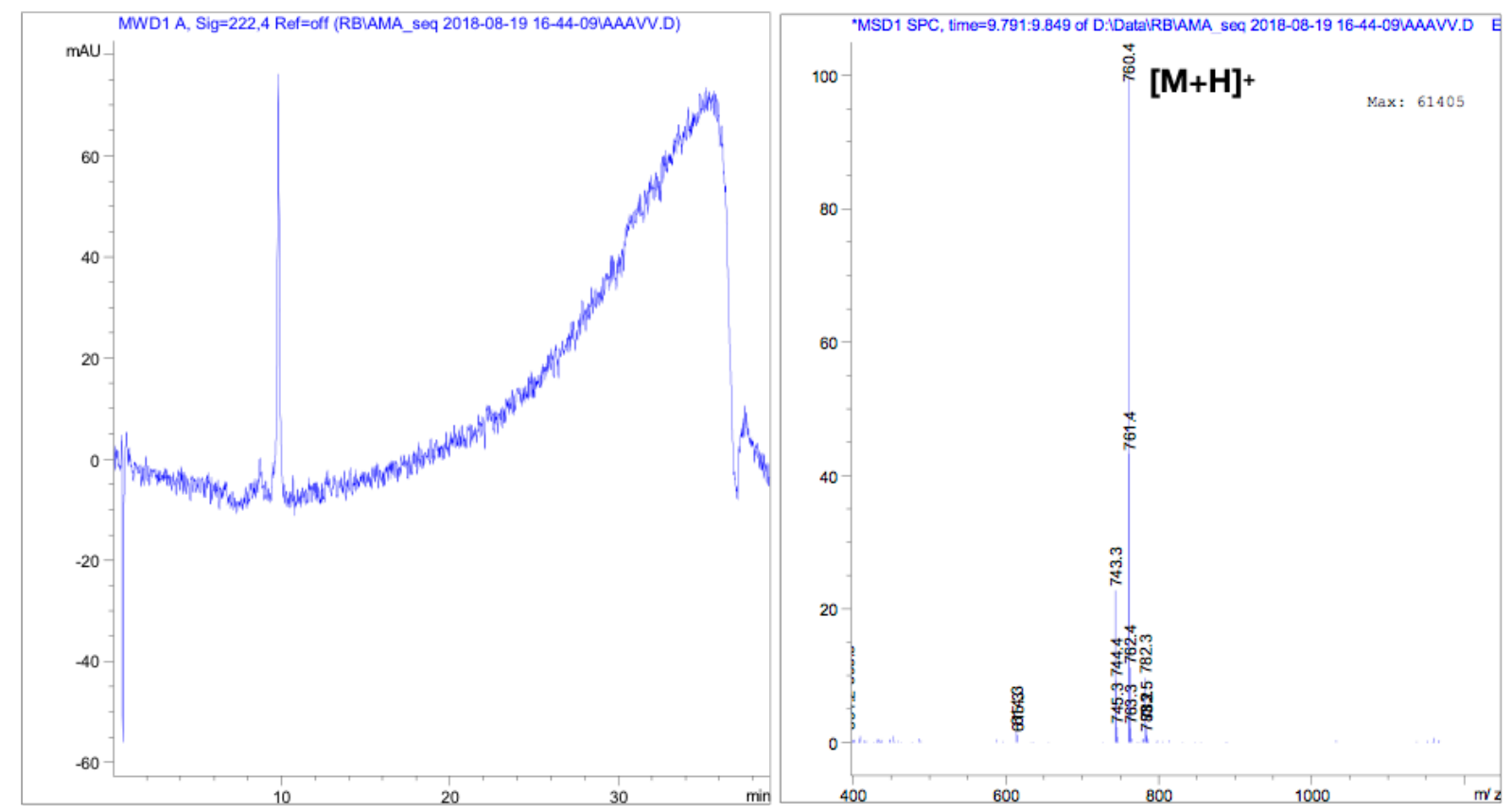

Figure S18 HPLC (UV-Vis detection at $222 \mathrm{~nm}$; left) and MS (ESI +eV; right) of P6 (EEAAAVV$\mathrm{ONH}_{2}$ ). 
3. Characterisation of peptide amphiphiles: HR-MS, HPLC-MS

P1T8 (RRRGAVV-ON= $\mathrm{C}_{8} \mathrm{H}_{15}$ ): $\boldsymbol{R}_{\boldsymbol{t}} \mathbf{1 4 . 5} \mathrm{min}$ (Fig. S19) RP-HPLC [Agilent SB-C18, $\mathrm{H}_{2} \mathrm{O}(0.1 \%$ TFA)/MeCN (0.1\% TFA) 100:0 (0 $\rightarrow 2 \mathrm{~min}$ ), 100:0 $\rightarrow 5: 95$ ( $2 \rightarrow 22 \mathrm{~min}$ ), 0:100 (>22 $\mathrm{min}$ )].

HR-MS $(E S I,+e V) m / z$ calculated for $\left[\mathrm{C}_{43} \mathrm{H}_{83} \mathrm{~N}_{18} \mathrm{O}_{9}\right]^{+}=995.6585 ; \mathrm{m} / \mathrm{z}$ found $=995.6583$.
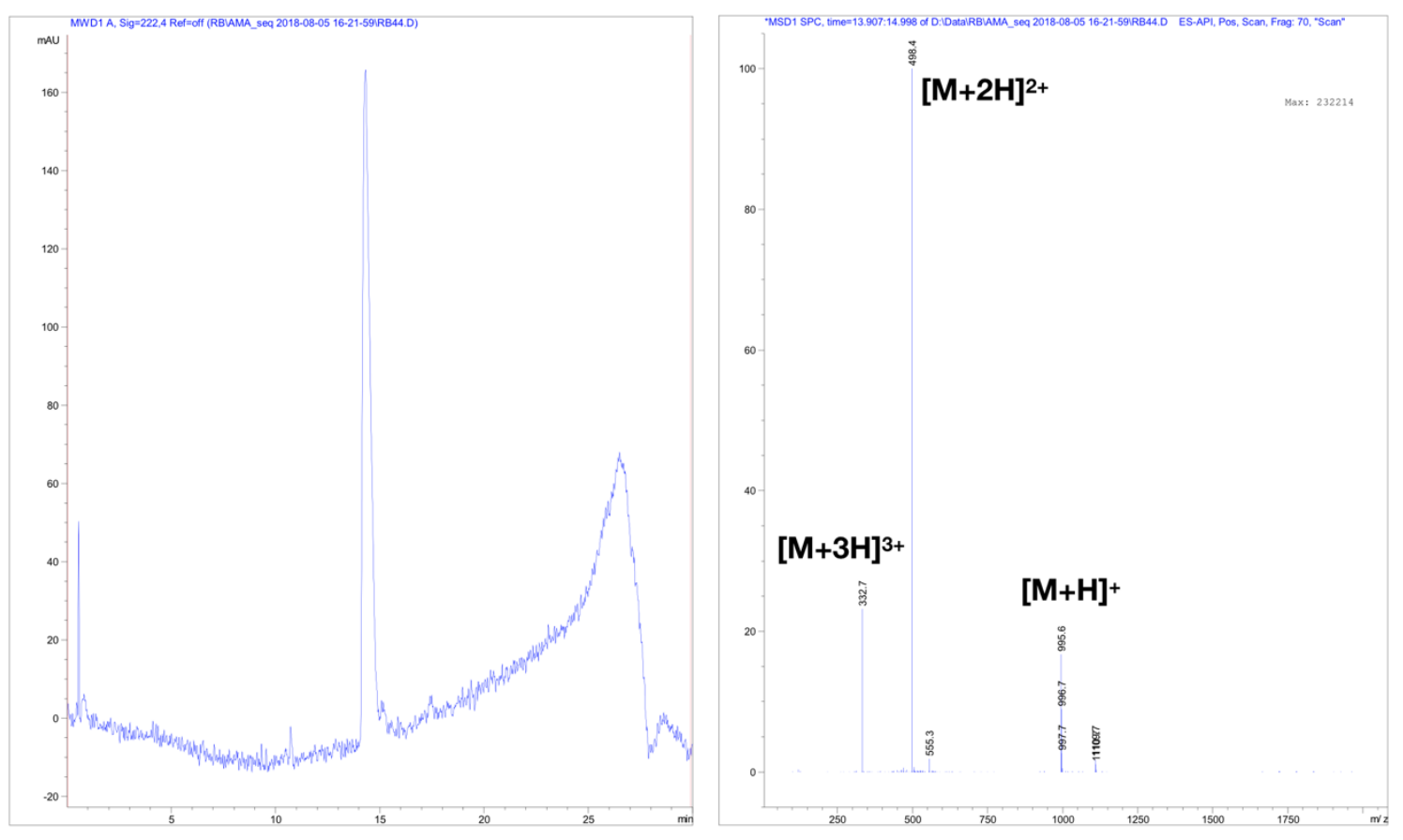

Figure S19 HPLC (UV-Vis detection at $222 \mathrm{~nm}$; left) and MS (ESI +eV; right) of amphiphile P1T8. 
P1T10 (RRRGAVV-ON= $\mathrm{C}_{10} \mathrm{H}_{19}$ ): $\boldsymbol{R}_{\boldsymbol{t}} \mathbf{1 6 . 5}$ min (Fig. S20) RP-HPLC [Agilent SB-C18, $\mathrm{H}_{2} \mathrm{O}(0.1 \%$ TFA)/MeCN (0.1\% TFA) 100:0 (0 $\rightarrow 2 \mathrm{~min}$ ), 100:0 $\rightarrow 5: 95$ ( $2 \rightarrow 22 \mathrm{~min}$ ), 0:100 (>22 $\mathrm{min})]$. HR-MS $(E S I,+e V) m / z$ calculated for $\left[\mathrm{C}_{45} \mathrm{H}_{87} \mathrm{~N}_{18} \mathrm{O}_{9}\right]^{+}=1023.6898 ; \mathrm{m} / \mathrm{z}$ found $=1023.6891$.
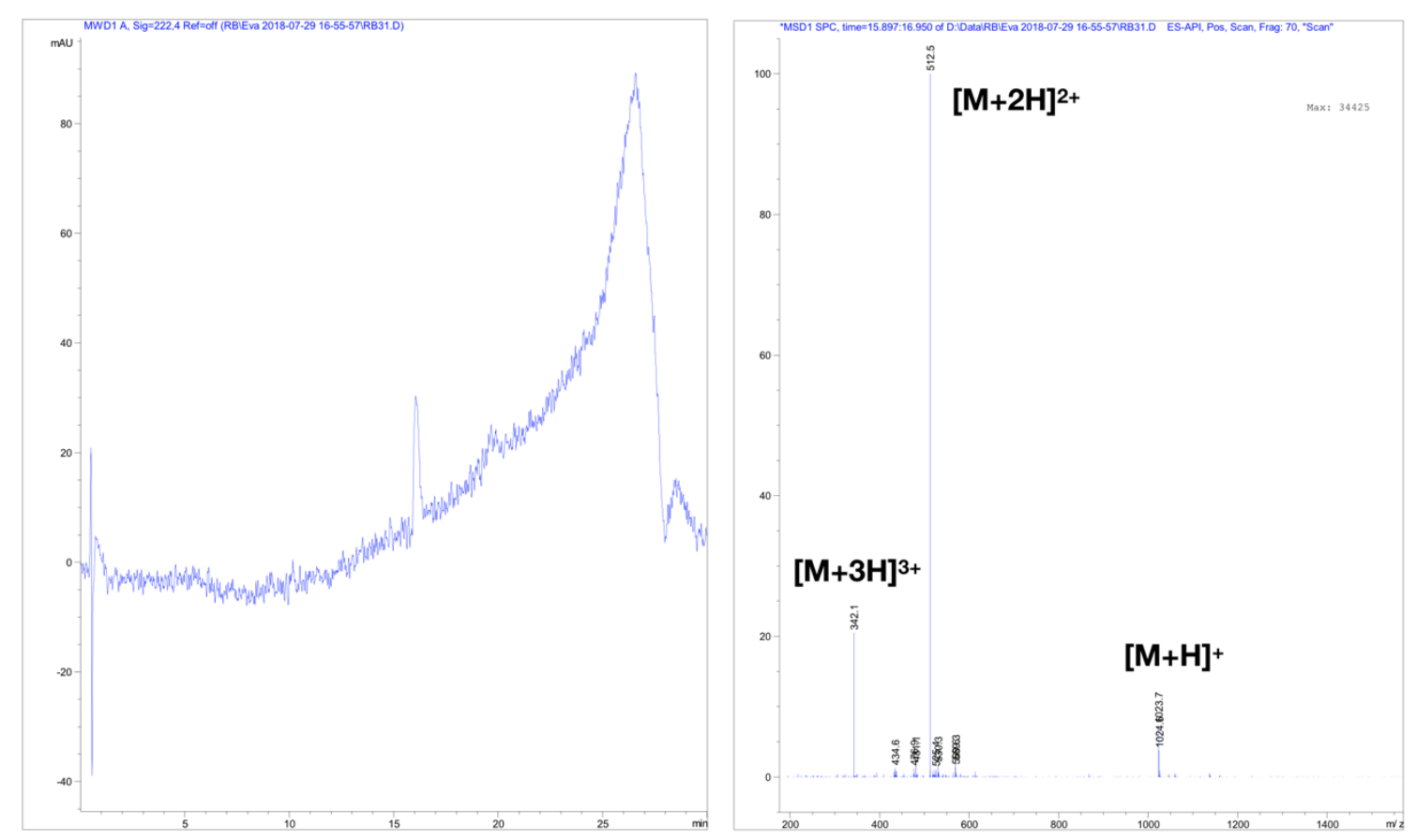

Figure S20 HPLC (UV-Vis detection at $222 \mathrm{~nm}$; left) and MS (ESI +eV; right) of amphiphile P1T10. 
P1T12 (RRRGAVV-ON=C ${ }_{12} \mathrm{H}_{23}$ ): $\boldsymbol{R}_{\boldsymbol{t}} \mathbf{1 7 . 5}$ min (Fig. S21) RP-HPLC [Agilent SB-C18, $\mathrm{H}_{2} \mathrm{O}(0.1 \%$ TFA)/MeCN (0.1\% TFA) 100:0 (0 $\rightarrow 2 \mathrm{~min}), 100: 0 \rightarrow 5: 95$ ( $2 \rightarrow 22 \mathrm{~min}$ ), 0:100 (>22 $\mathrm{min})]$. HR-MS $(E S I,+e V) \mathrm{m} / \mathrm{z}$ calculated for $\left[\mathrm{C}_{47} \mathrm{H}_{91} \mathrm{~N}_{18} \mathrm{O}_{9}\right]^{+}=1051.7211 ; \mathrm{m} / \mathrm{z}$ found $=1051.7204$.
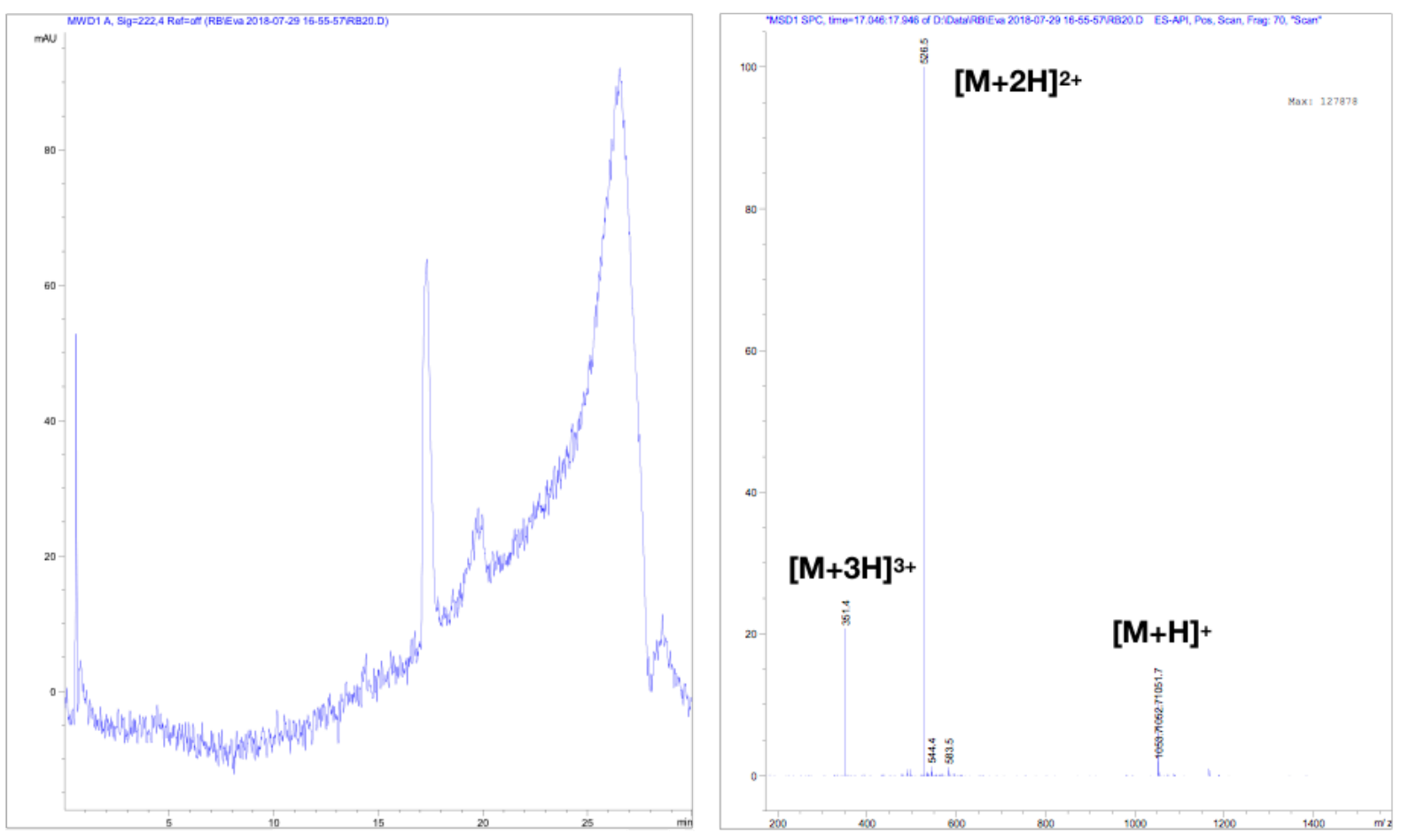

Figure S21 HPLC (UV-Vis detection at $222 \mathrm{~nm}$; left) and MS (ESI +eV; right) of amphiphile P1T12. 
P2T8 (RRRAVVV-ON=C $\mathrm{C}_{8} \mathrm{H}_{15}$ ): $\boldsymbol{R}_{\boldsymbol{t}} 15 \mathrm{~min}$ (Fig. S22) RP-HPLC [Agilent SB-C18, $\mathrm{H}_{2} \mathrm{O}(0.1 \%$ TFA)/MeCN (0.1\% TFA) 100:0 (0 $\rightarrow 2 \mathrm{~min}$ ), 100:0 $\rightarrow 5: 95$ (2 $\rightarrow 22 \mathrm{~min}$ ), 0:100 (>22 min)]. HR-MS $(E S I,+e V) \mathrm{m} / \mathrm{z}$ calculated for $\left[\mathrm{C}_{48} \mathrm{H}_{92} \mathrm{~N}_{19} \mathrm{O}_{10}\right]^{+}=1094.7269 ; \mathrm{m} / \mathrm{z}$ found $=1094.7266$.

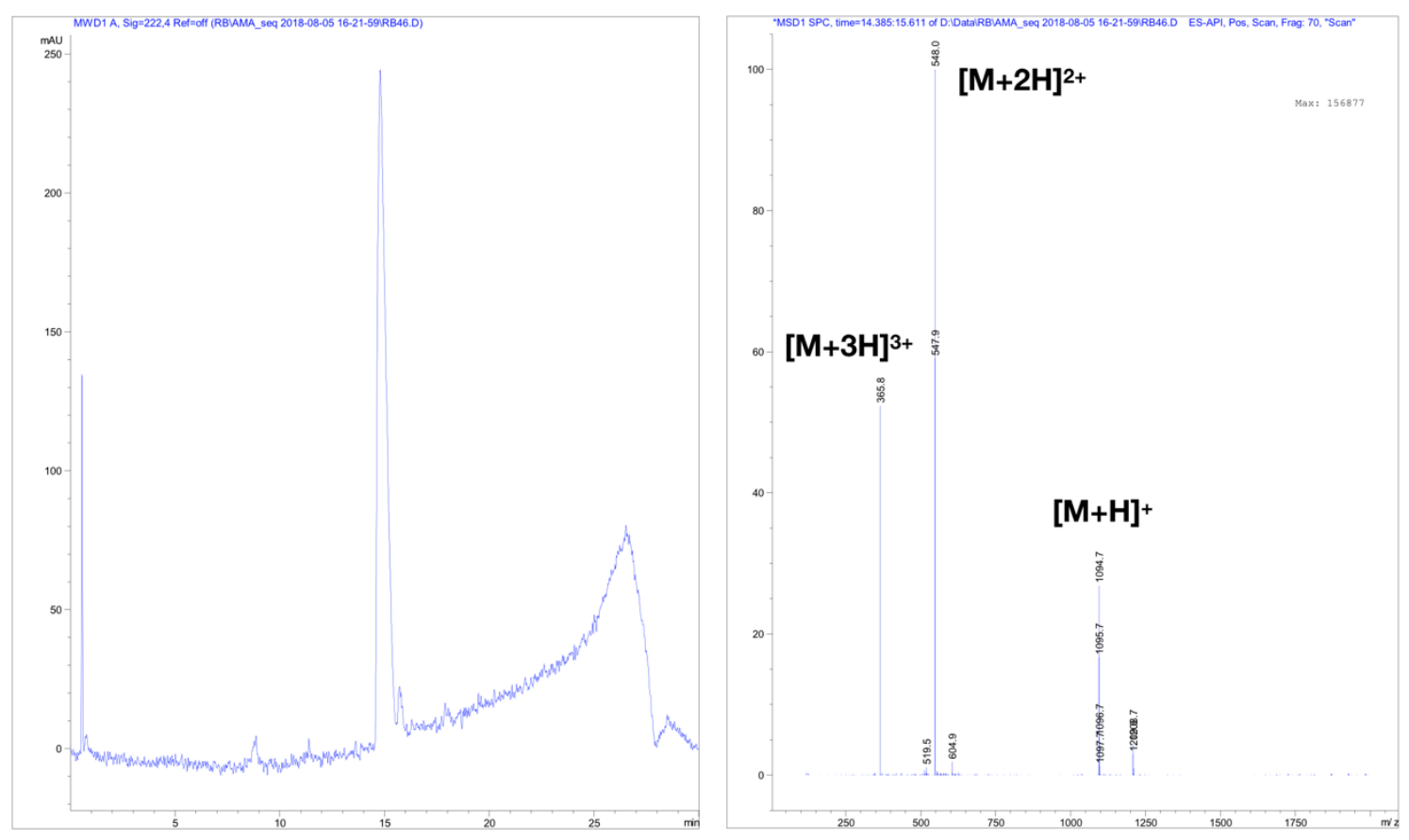

Figure S22 HPLC (UV-Vis detection at $222 \mathrm{~nm}$; left) and MS (ESI +eV; right) of amphiphile P2T8. 
P2T10 (RRRAVVV-ON= $\mathrm{C}_{10} \mathrm{H}_{19}$ ): $\boldsymbol{R}_{\boldsymbol{t}} \mathbf{1 6 . 5}$ min (Fig. S23) RP-HPLC [Agilent SB-C18, $\mathrm{H}_{2} \mathrm{O}(0.1 \%$ TFA)/MeCN (0.1\% TFA) 100:0 (0 $\rightarrow 2 \mathrm{~min}$ ), 100:0 $\rightarrow 5: 95$ (2 $\rightarrow 22 \mathrm{~min}$ ), 0:100 (>22 $\mathrm{min}$ )]. HR-MS $(E S I,+e V) m / z$ calculated for $\left[\mathrm{C}_{50} \mathrm{H}_{96} \mathrm{~N}_{19} \mathrm{O}_{10}\right]^{+}=1122.7582 ; \mathrm{m} / \mathrm{z}$ found $=1122.7580$.

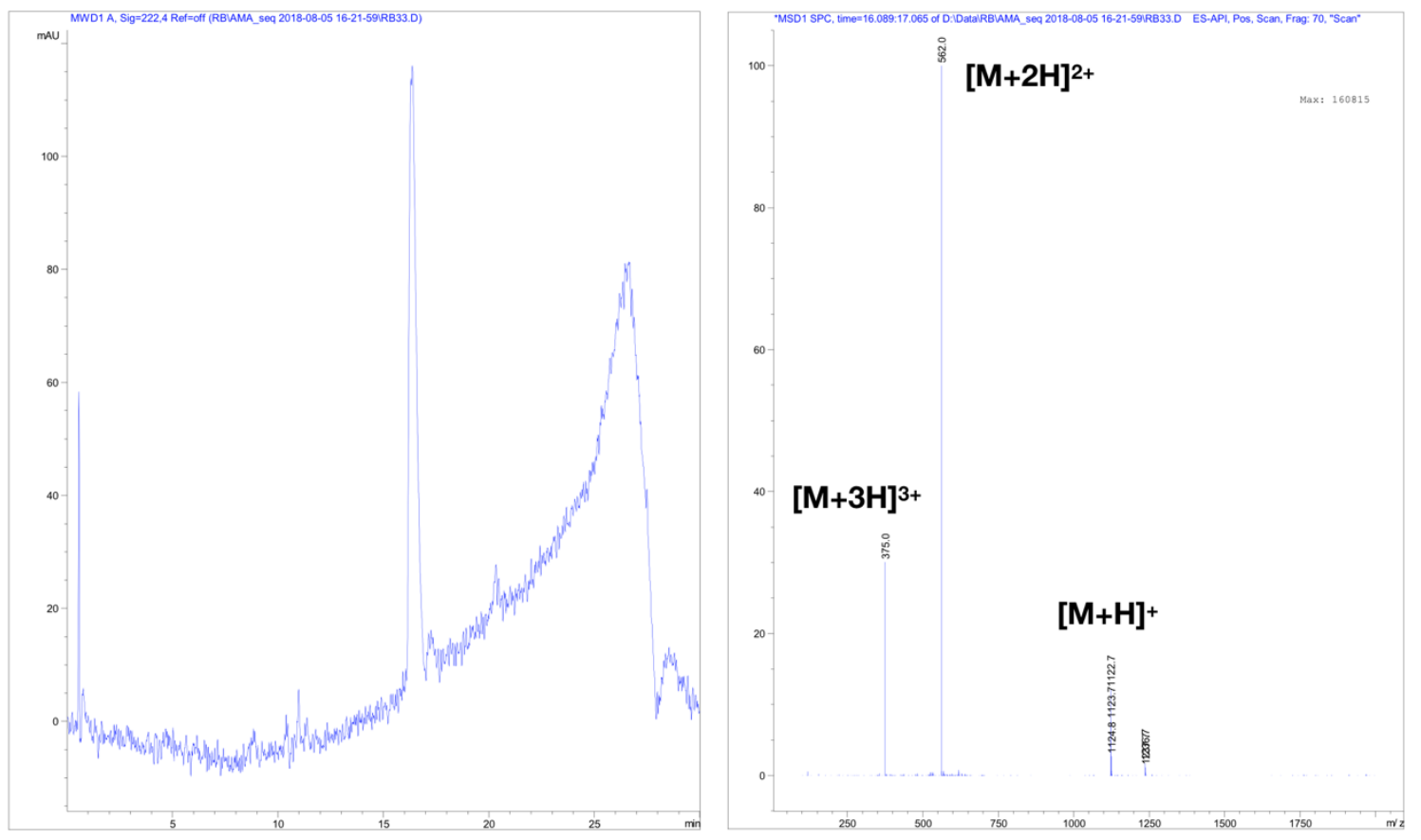

Figure S23 HPLC (UV-Vis detection at $222 \mathrm{~nm}$; left) and MS (ESI +eV; right) of amphiphile P2T10. 
P2T12 (RRRAVVV-ON= $\mathrm{C}_{12} \mathrm{H}_{23}$ ): $\boldsymbol{R}_{\boldsymbol{t}} 18 \mathrm{~min}$ (Fig. S24) RP-HPLC [Agilent SB-C18, $\mathrm{H}_{2} \mathrm{O}(0.1 \%$ TFA)/MeCN (0.1\% TFA) 100:0 (0 $\rightarrow 2 \mathrm{~min}$ ), 100:0 $\rightarrow 5: 95$ (2 $\rightarrow 22 \mathrm{~min}$ ), 0:100 (>22 min)]. HR-MS $(E S I,+e V) m / z$ calculated for $\left[\mathrm{C}_{52} \mathrm{H}_{100} \mathrm{~N}_{19} \mathrm{O}_{10}\right]^{+}=1150.7895 ; \mathrm{m} / \mathrm{z}$ found $=1150.7890$.

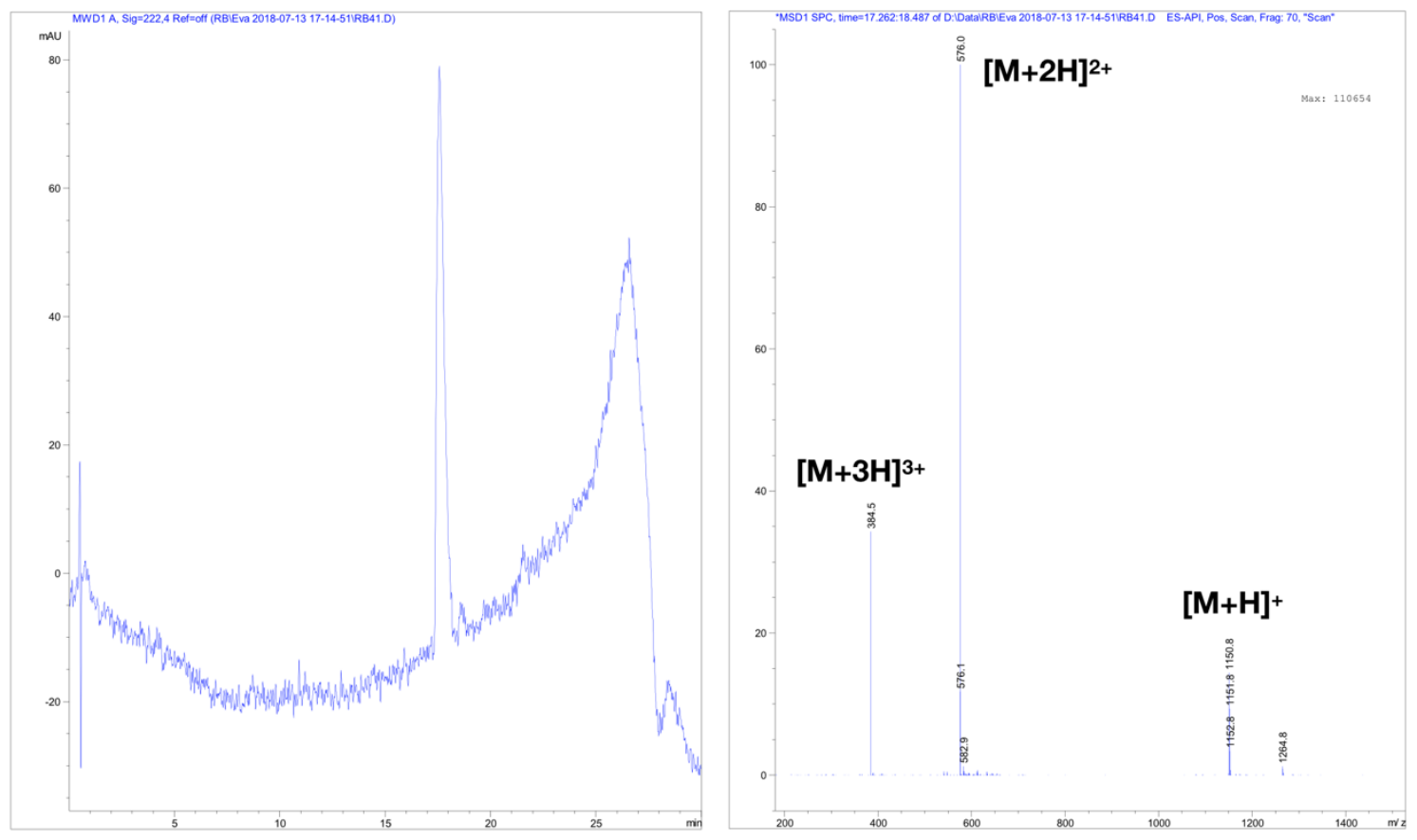

Figure S24 HPLC (UV-Vis detection at $222 \mathrm{~nm}$; left) and MS (ESI +eV; right) of amphiphile P2T12. 
P3T8 (RRRAAVV-ON=C $\mathrm{C}_{8} \mathrm{H}_{15}$ ): $\boldsymbol{R}_{\boldsymbol{t}} 15 \mathrm{~min}$ (Fig. S25) RP-HPLC [Agilent SB-C18, $\mathrm{H}_{2} \mathrm{O}(0.1 \%$ TFA)/MeCN (0.1\% TFA) 100:0 (0 $\rightarrow 2 \mathrm{~min}$ ), 100:0 $\rightarrow 5: 95$ (2 $\rightarrow 22 \mathrm{~min}$ ), 0:100 (>22 $\mathrm{min}$ )].

HR-MS $(E S I,+e V) m / z$ calculated for $\left[\mathrm{C}_{46} \mathrm{H}_{88} \mathrm{~N}_{19} \mathrm{O}_{10}\right]^{+}=1066.6956 ; \mathrm{m} / \mathrm{z}$ found $=1066.6958$.

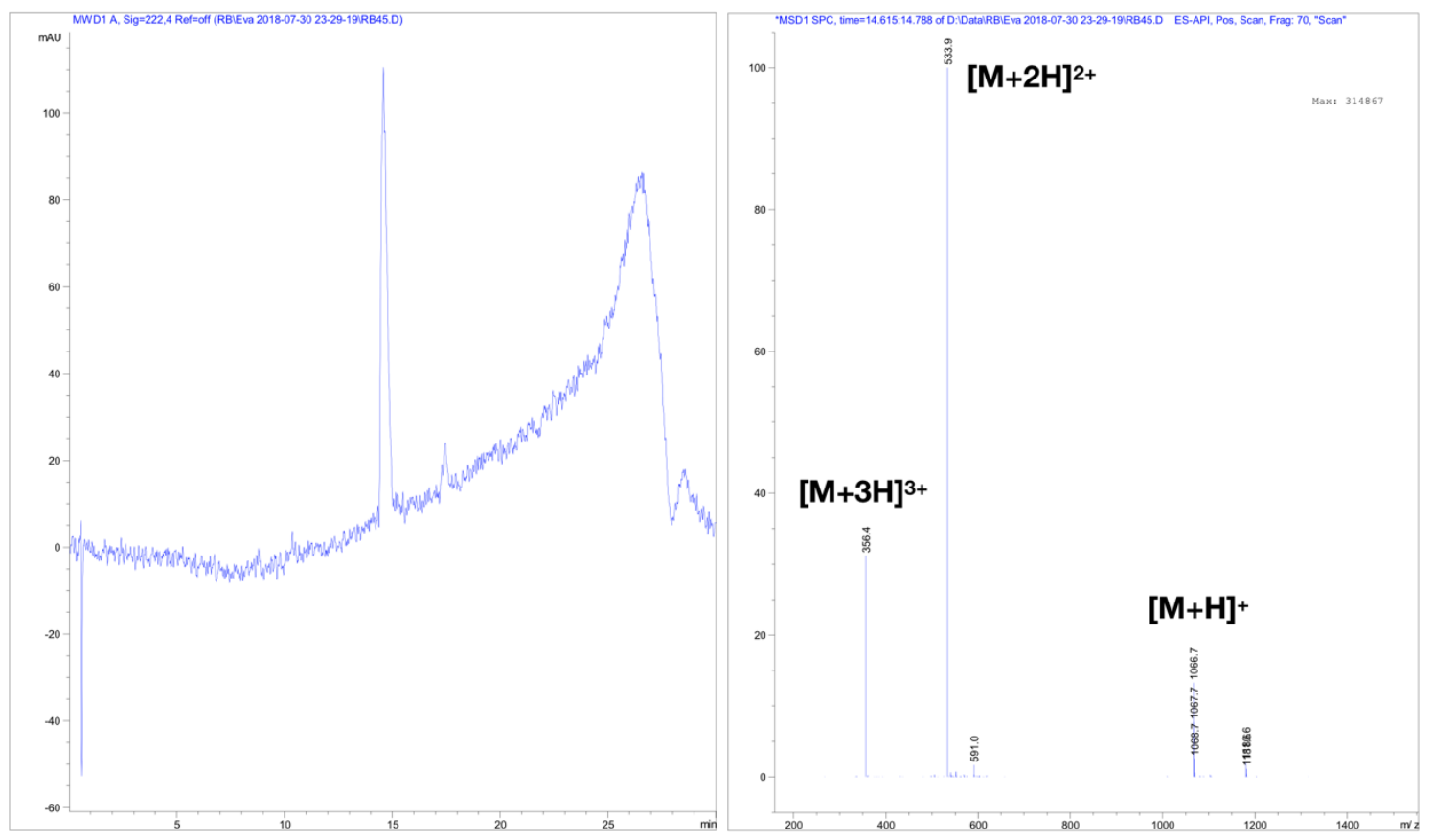

Figure S25 HPLC (UV-Vis detection at $222 \mathrm{~nm}$; left) and MS (ESI +eV; right) of amphiphile P3T8. 
P3T10 (RRRAAVV-ON=C $\mathrm{C}_{10} \mathrm{H}_{19}$ ): $\boldsymbol{R}_{\boldsymbol{t}} 16 \mathrm{~min}$ (Fig. S26) RP-HPLC [Agilent SB-C18, $\mathrm{H}_{2} \mathrm{O}(0.1 \%$ TFA)/MeCN (0.1\% TFA) 100:0 (0 $\rightarrow 2 \mathrm{~min}$ ), 100:0 $\rightarrow 5: 95$ (2 $\rightarrow 22 \mathrm{~min}), 0: 100$ (>22 $\mathrm{min}$ )]. HR-MS $(E S I,+e V) m / z$ calculated for $\left[\mathrm{C}_{48} \mathrm{H}_{92} \mathrm{~N}_{19} \mathrm{O}_{10}\right]^{+}=1094.7269 ; \mathrm{m} / \mathrm{z}$ found $=1094.7271$.

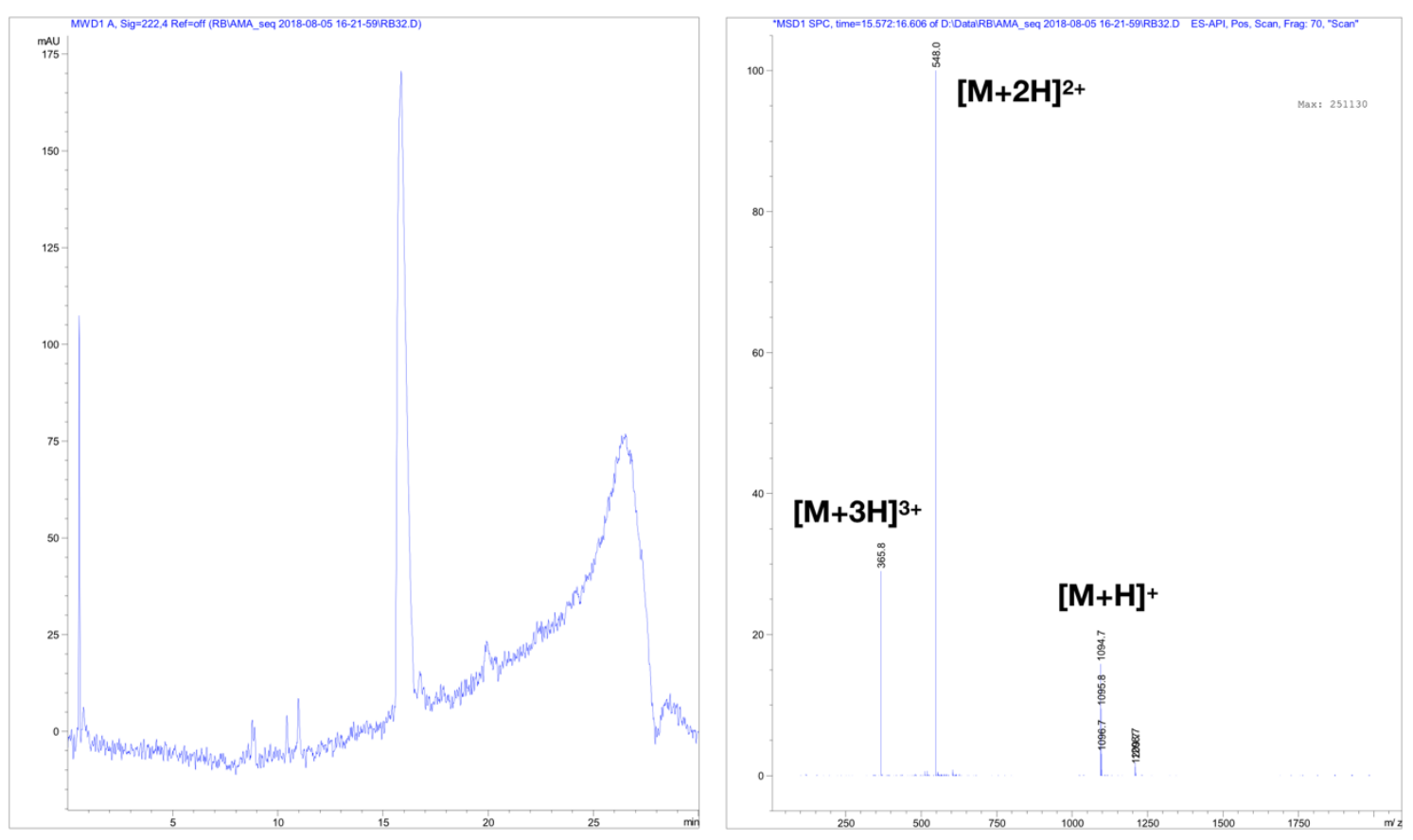

Figure S26 HPLC (UV-Vis detection at $222 \mathrm{~nm}$; left) and MS (ESI +eV; right) of amphiphile P3T10. 
P3T12 (RRRAAVV-ON= $\mathrm{C}_{12} \mathrm{H}_{23}$ ): $\boldsymbol{R}_{\boldsymbol{t}} \mathbf{1 7 . 5}$ min (Fig. S27) RP-HPLC [Agilent SB-C18, $\mathrm{H}_{2} \mathrm{O}(0.1 \%$ TFA)/MeCN (0.1\% TFA) 100:0 (0 $\rightarrow 2 \mathrm{~min}$ ), 100:0 $\rightarrow 5: 95$ (2 $\rightarrow 22 \mathrm{~min}$ ), 0:100 (>22 min)]. HR-MS $(E S I,+e V) m / z$ calculated for $\left[\mathrm{C}_{50} \mathrm{H}_{96} \mathrm{~N}_{19} \mathrm{O}_{10}\right]^{+}=1122.7582 ; \mathrm{m} / \mathrm{z}$ found $=1122.7586$.

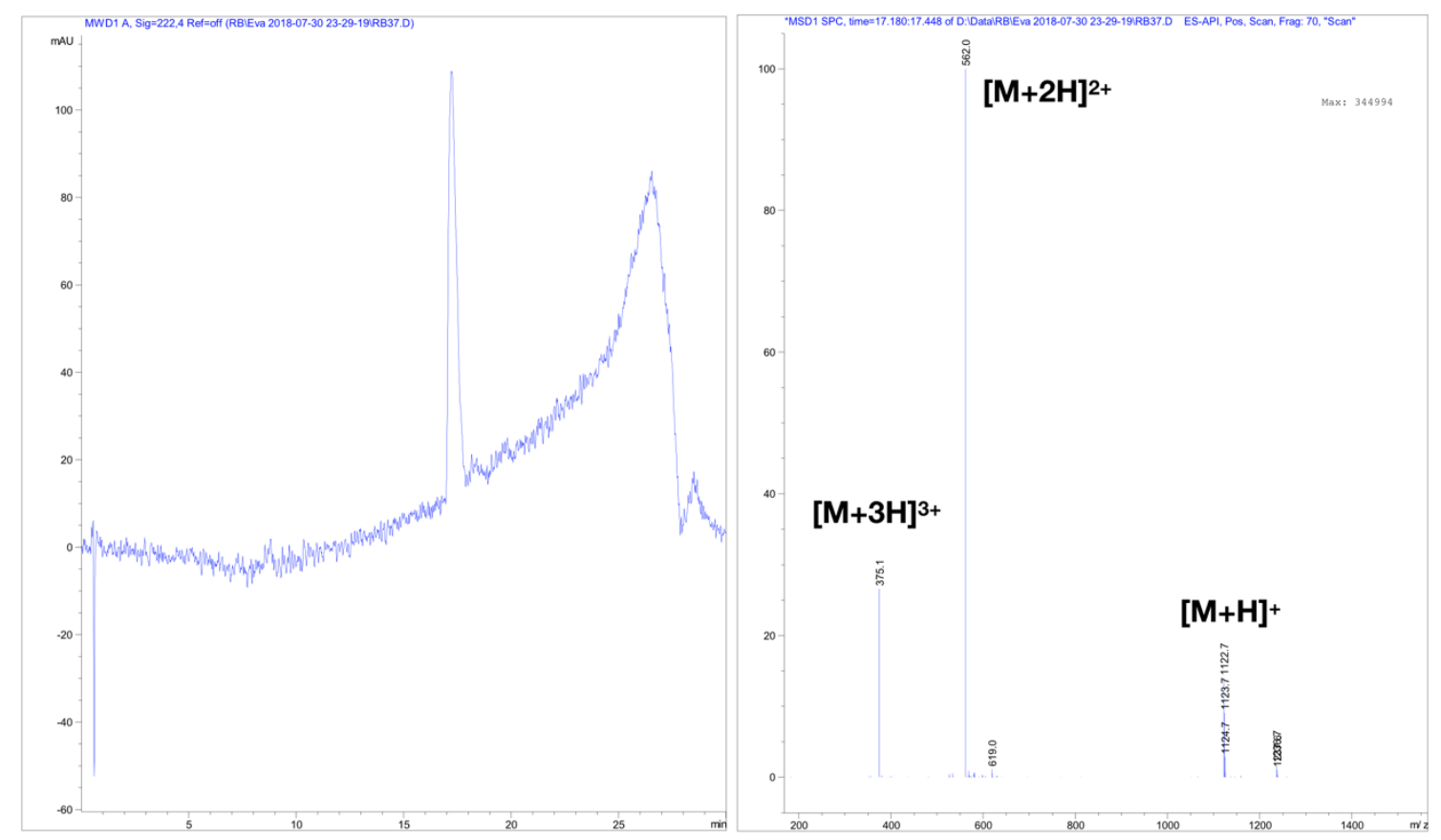

Figure S27 HPLC (UV-Vis detection at $222 \mathrm{~nm}$; left) and MS (ESI +eV; right) of amphiphile P3T12. 
P4T8 (EEGAVV-ON= $\mathrm{C}_{8} \mathrm{H}_{15}$ ): $\boldsymbol{R}_{\boldsymbol{t}} \mathbf{1 8 . 5}$ min (Fig. S28) RP-HPLC [Agilent SB-C18, $\mathrm{H}_{2} \mathrm{O}(0.1 \%$ TFA)/MeCN (0.1\% TFA) 100:0 (0 $\rightarrow 2 \mathrm{~min}$ ), 100:0 $\rightarrow 5: 95$ ( $2 \rightarrow 32 \mathrm{~min}$ ), 0:100 (>32 $\mathrm{min}$ )]. HR-MS $(E S I,+e V) m / z$ calculated for $\left[\mathrm{C}_{35} \mathrm{H}_{60} \mathrm{~N}_{8} \mathrm{NaO}_{12}\right]^{+}=807.4223 ; \mathrm{m} / \mathrm{z}$ found $=807.4226$.

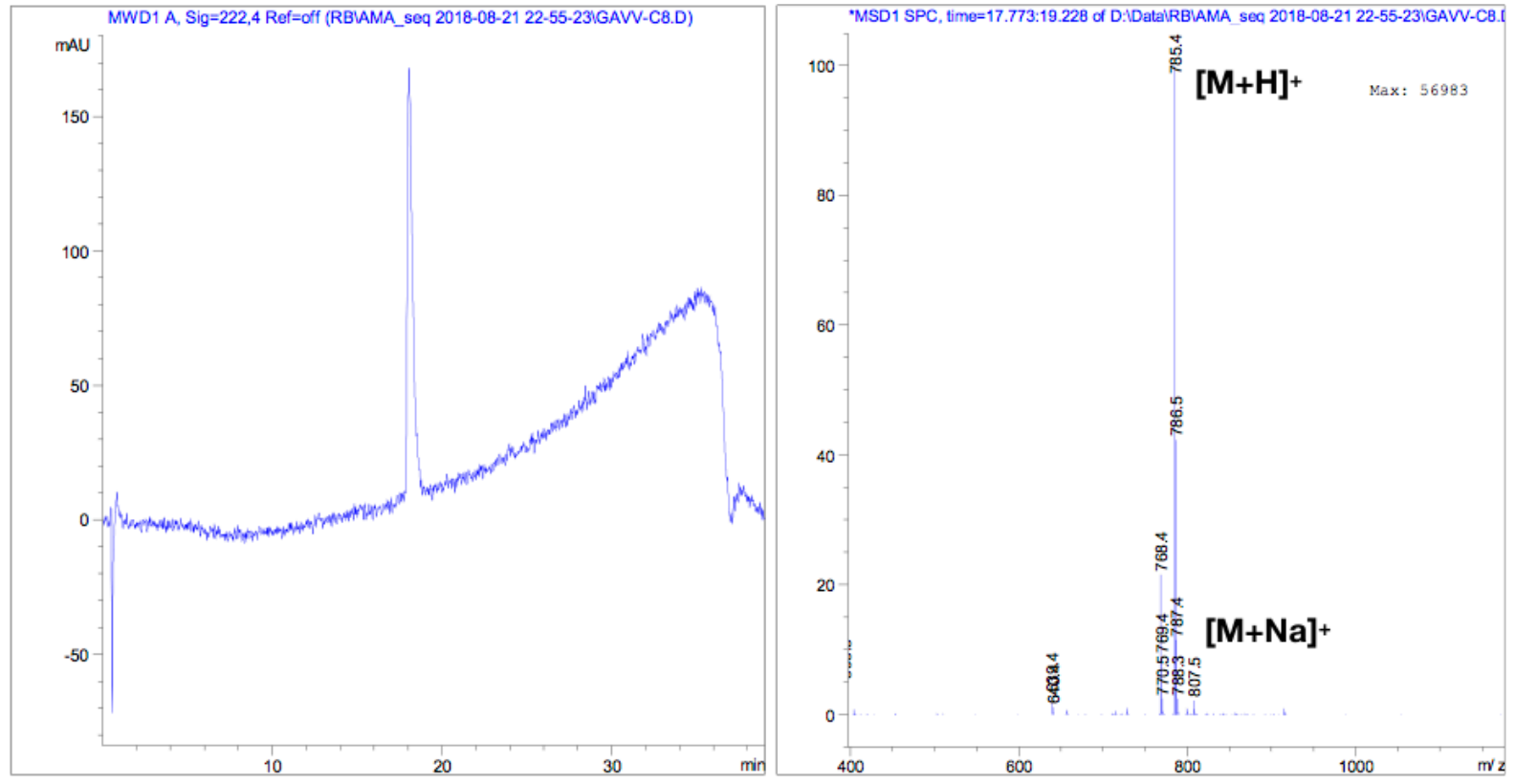

Figure S28 HPLC (UV-Vis detection at $222 \mathrm{~nm}$; left) and MS (ESI +eV; right) of amphiphile P4T8. 
P4T10 (EEGAVV-ON= $\mathrm{C}_{10} \mathrm{H}_{19}$ ): $\boldsymbol{R}_{\boldsymbol{t}} 21 \mathrm{~min}$ (Fig. S29) RP-HPLC [Agilent SB-C18, $\mathrm{H}_{2} \mathrm{O}(0.1 \%$ TFA)/MeCN (0.1\% TFA) 100:0 (0 $\rightarrow 2 \mathrm{~min}$ ), 100:0 $\rightarrow 5: 95$ ( $2 \rightarrow 32 \mathrm{~min}$ ), 0:100 (>32 $\mathrm{min}$ )]. HR-MS $(E S I,+e V) m / z$ calculated for $\left[\mathrm{C}_{37} \mathrm{H}_{65} \mathrm{~N}_{8} \mathrm{O}_{12}\right]^{+}=813.4716 ; \mathrm{m} / \mathrm{z}$ found $=813.4718$.
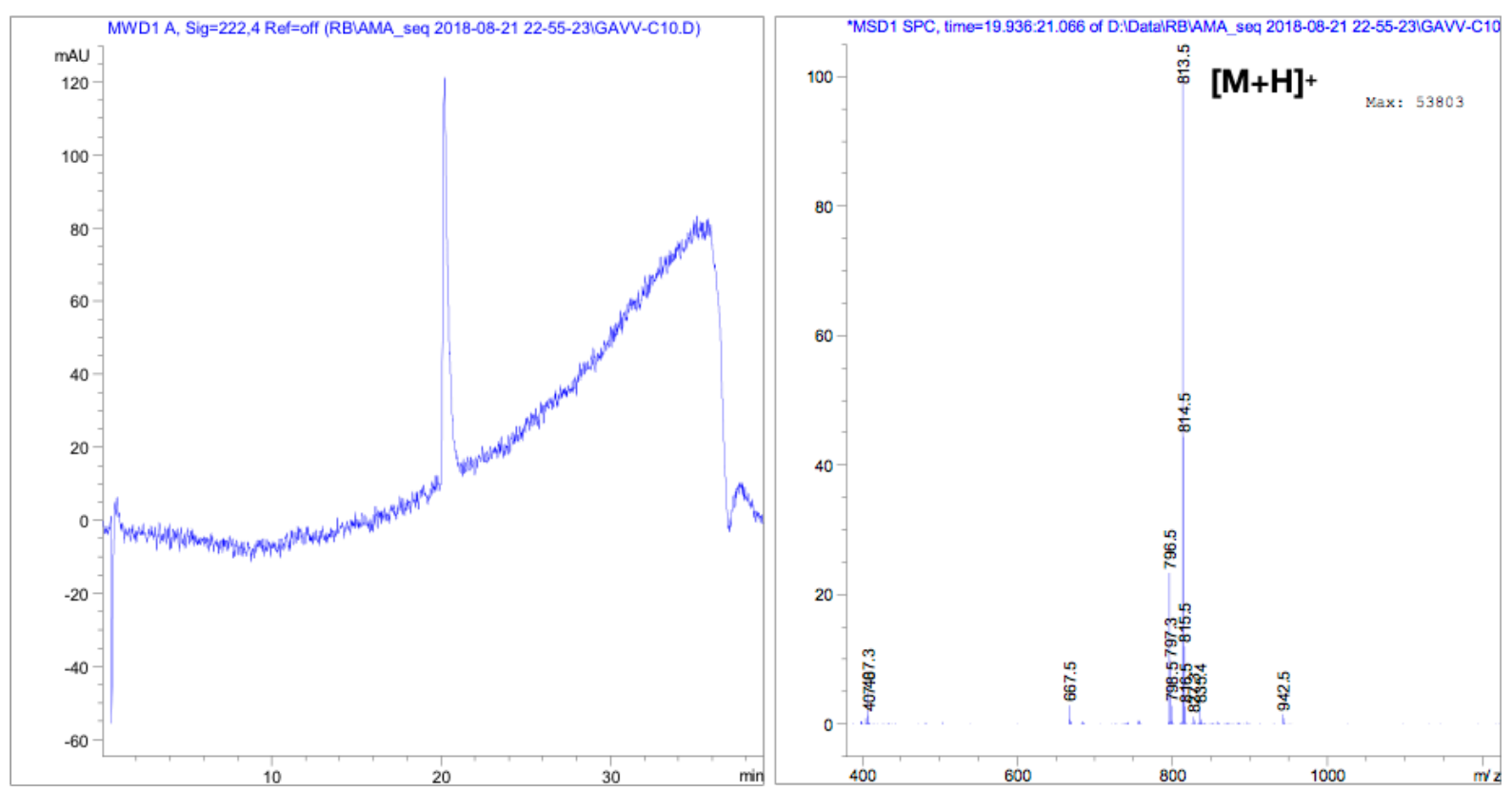

Figure S29 HPLC (UV-Vis detection at $222 \mathrm{~nm}$; left) and MS (ESI +eV; right) of amphiphile P4T10. 
P4T12 (EEGAVV-ON= $\mathrm{C}_{12} \mathrm{H}_{23}$ ): $\boldsymbol{R}_{\boldsymbol{t}} 23 \mathrm{~min}$ (Fig. S30) RP-HPLC [Agilent SB-C18, $\mathrm{H}_{2} \mathrm{O}(0.1 \%$ TFA)/MeCN (0.1\% TFA) 100:0 (0 $\rightarrow 2 \mathrm{~min}$ ), 100:0 $\rightarrow 5: 95$ (2 $\rightarrow 32 \mathrm{~min}$ ), 0:100 (>32 min)]. HR-MS $(E S I,+e V) \mathrm{m} / \mathrm{z}$ calculated for $\left[\mathrm{C}_{39} \mathrm{H}_{68} \mathrm{~N}_{8} \mathrm{NaO}_{12}\right]^{+}=863.4849 ; \mathrm{m} / \mathrm{z}$ found $=863.4850$.

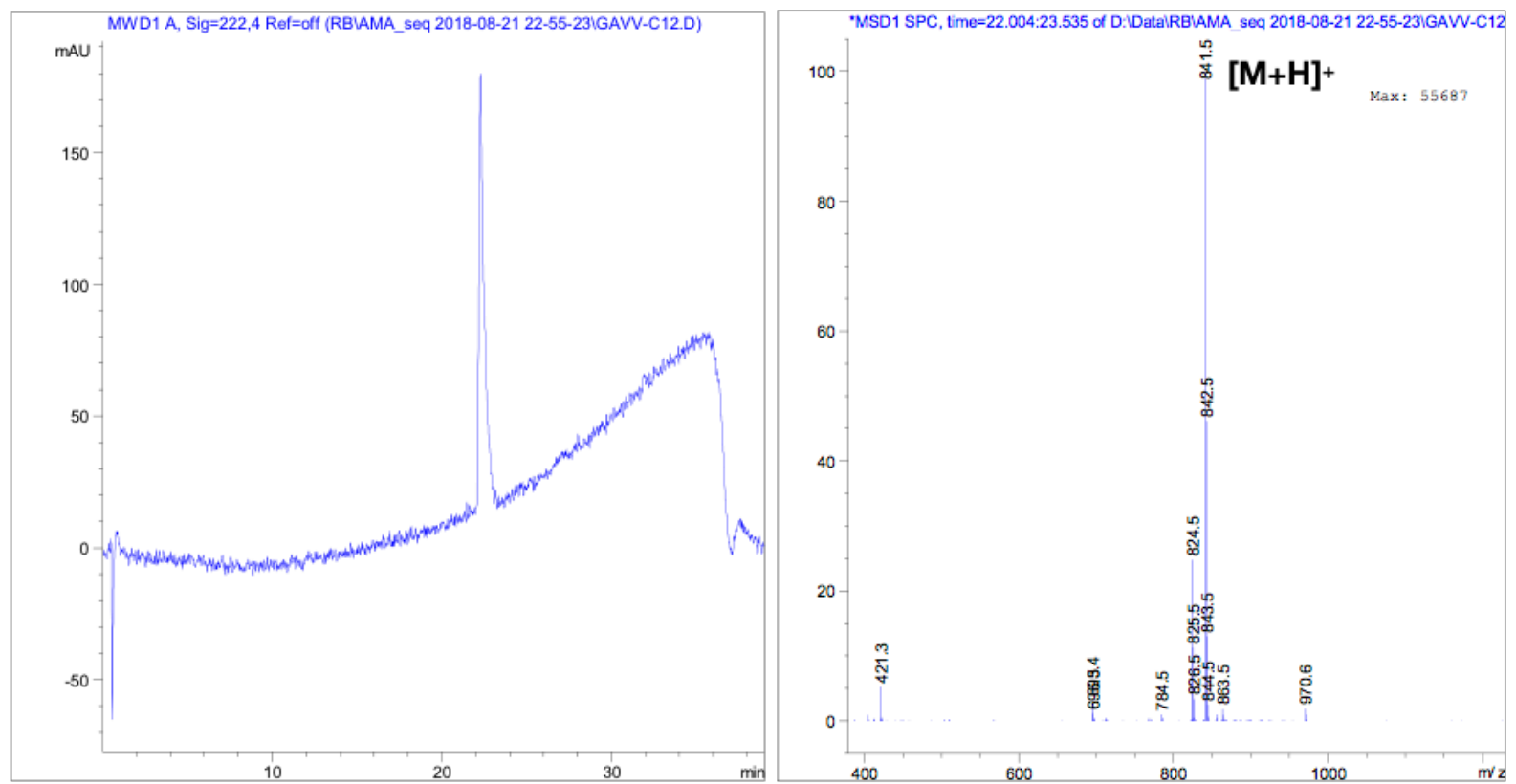

Figure S30 HPLC (UV-Vis detection at $222 \mathrm{~nm}$; left) and MS (ESI +eV; right) of amphiphile P4T12. 
P4T14 (EEGAVV-ON=C ${ }_{14} \mathrm{H}_{27}$ ): $\boldsymbol{R}_{\boldsymbol{t}} \mathbf{2 5 . 5}$ min (Fig. S31) RP-HPLC [Agilent SB-C18, $\mathrm{H}_{2} \mathrm{O}(0.1 \%$ TFA)/MeCN (0.1\% TFA) 100:0 (0 $\rightarrow 2 \mathrm{~min}$ ), 100:0 $\rightarrow 5: 95$ ( $2 \rightarrow 32 \mathrm{~min}$ ), 0:100 (>32 $\mathrm{min}$ )]. HR-MS $(E S I,+e V) m / z$ calculated for $\left[\mathrm{C}_{41} \mathrm{H}_{72} \mathrm{~N}_{8} \mathrm{NaO}_{12}\right]^{+}=891.5162 ; \mathrm{m} / \mathrm{z}$ found $=891.5164$.

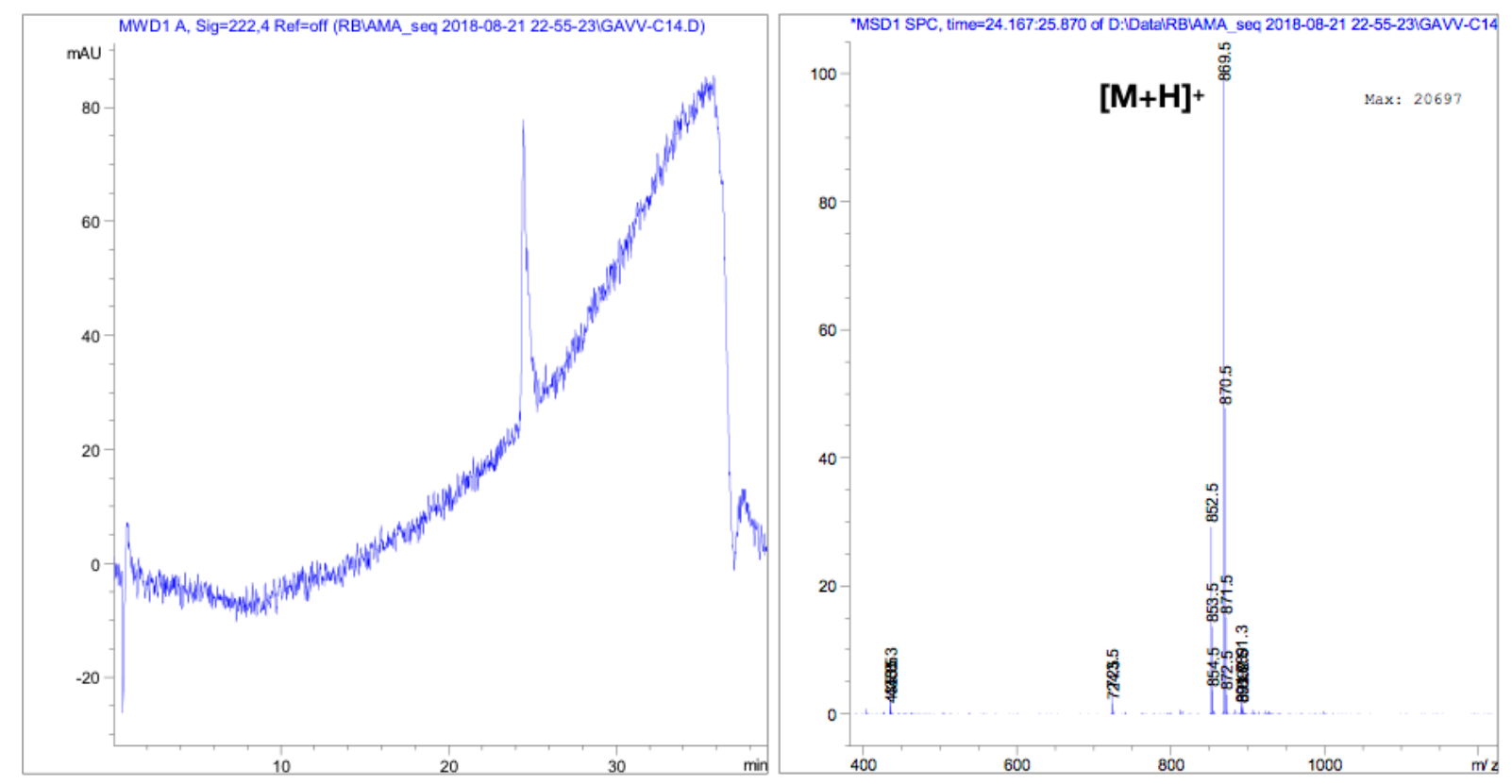

Figure S31 HPLC (UV-Vis detection at $222 \mathrm{~nm}$; left) and MS (ESI +eV; right) of amphiphile P4T14. 
P5T8 (EEAAVV-ON= $\mathrm{C}_{8} \mathrm{H}_{15}$ ): $\boldsymbol{R}_{\boldsymbol{t}} 19 \mathrm{~min}$ (Fig. S32) RP-HPLC [Agilent SB-C18, $\mathrm{H}_{2} \mathrm{O}(0.1 \%$ TFA)/MeCN (0.1\% TFA) 100:0 (0 $\rightarrow 2 \mathrm{~min}$ ), 100:0 $\rightarrow 5: 95$ ( $2 \rightarrow 32 \mathrm{~min}$ ), 0:100 (>32 $\mathrm{min}$ )].

HR-MS $(E S I,+e V) m / z$ calculated for $\left[\mathrm{C}_{36} \mathrm{H}_{63} \mathrm{~N}_{8} \mathrm{O}_{12}\right]^{+}=799.4560 ; \mathrm{m} / \mathrm{z}$ found $=799.4558$.
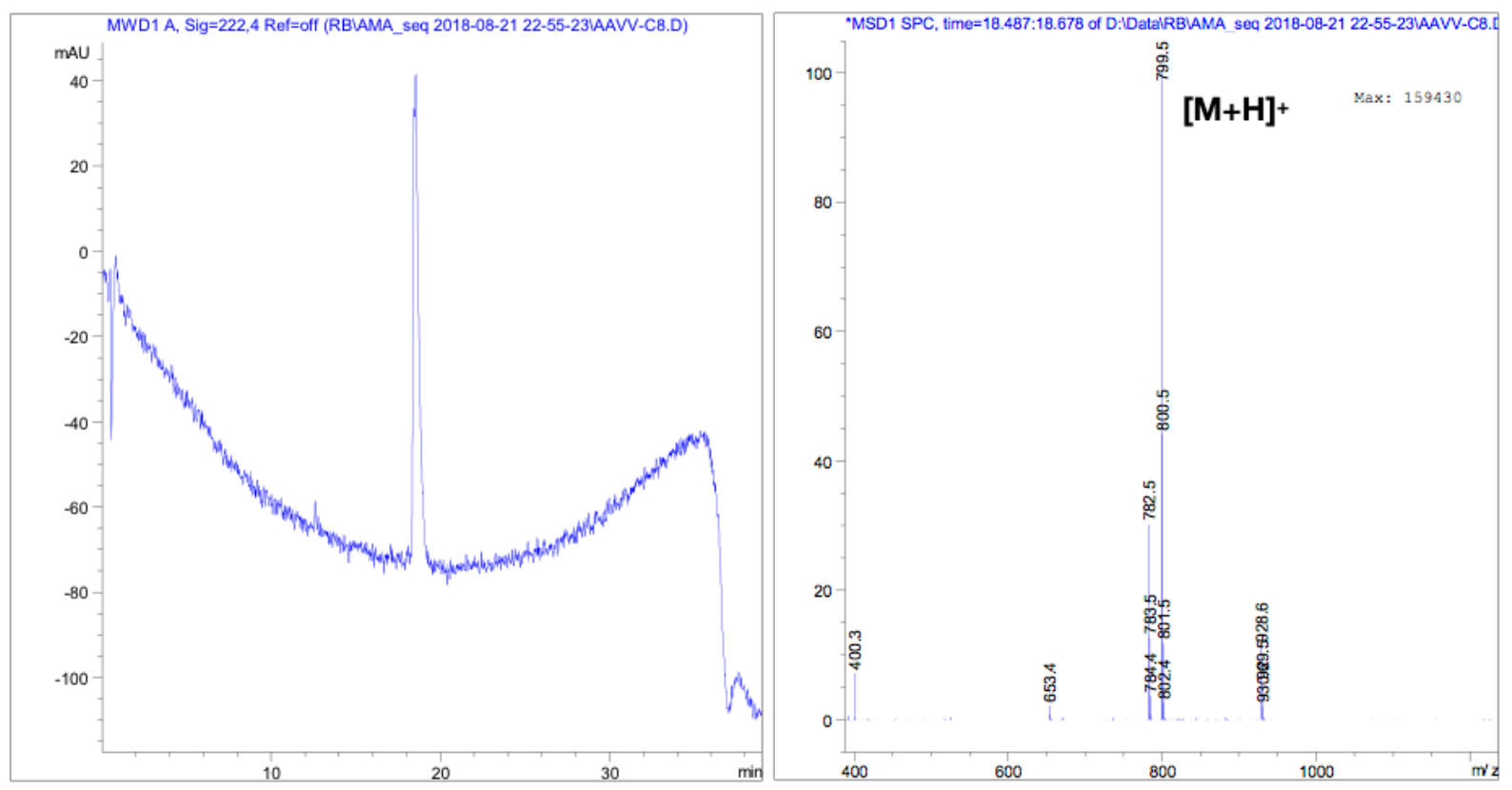

Figure S32 HPLC (UV-Vis detection at $222 \mathrm{~nm}$; left) and MS (ESI +eV; right) of amphiphile P5T8. 
P5T10 (EEAAVV-ON= $\mathrm{C}_{12} \mathrm{H}_{23}$ ): $\boldsymbol{R}_{\boldsymbol{t}} 23 \mathrm{~min}$ (Fig. S33) RP-HPLC [Agilent SB-C18, $\mathrm{H}_{2} \mathrm{O}(0.1 \%$ TFA)/MeCN (0.1\% TFA) 100:0 (0 $\rightarrow 2 \mathrm{~min}$ ), 100:0 $\rightarrow 5: 95$ (2 $\rightarrow 32 \mathrm{~min}$ ), 0:100 (>32 $\mathrm{min}$ )].

HR-MS $(E S I,+e V) m / z$ calculated for $\left[\mathrm{C}_{38} \mathrm{H}_{67} \mathrm{~N}_{8} \mathrm{O}_{12}\right]^{+}=827.4873 ; \mathrm{m} / \mathrm{z}$ found $=827.4878$.

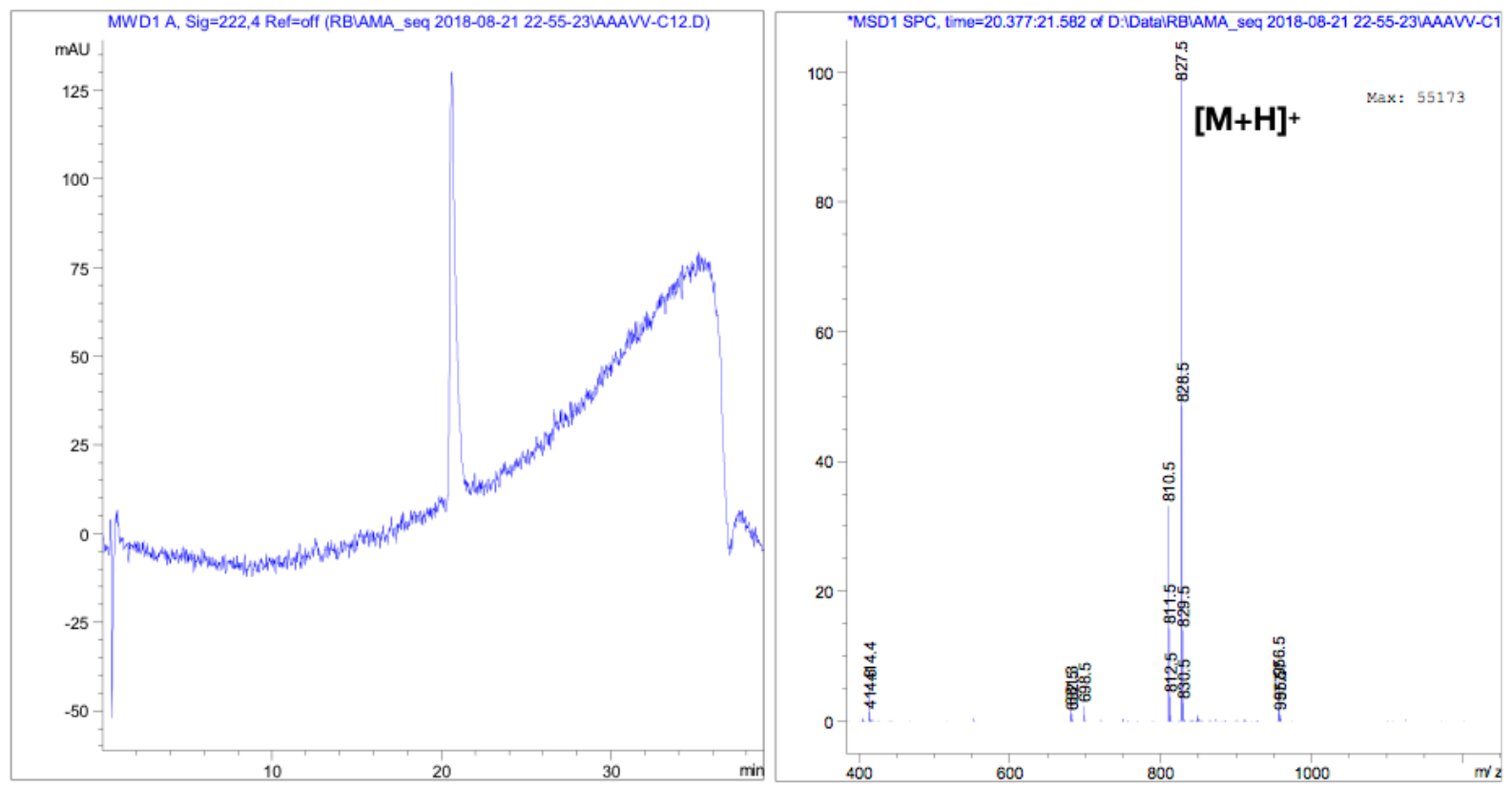

Figure S33 HPLC (UV-Vis detection at $222 \mathrm{~nm}$; left) and MS (ESI +eV; right) of amphiphile P5T10. 
P5T12 (EEAAVV-ON=C ${ }_{12} \mathrm{H}_{23}$ ): $\boldsymbol{R}_{\boldsymbol{t}} \mathbf{2 3 . 5}$ min (Fig. S34) RP-HPLC [Agilent SB-C18, $\mathrm{H}_{2} \mathrm{O}(0.1 \%$ TFA)/MeCN (0.1\% TFA) 100:0 (0 $\rightarrow 2 \mathrm{~min}$ ), 100:0 $\rightarrow 5: 95$ (2 $\rightarrow 32 \mathrm{~min}$ ), 0:100 (>32 min)]. HR-MS $(E S I,+e V) m / z$ calculated for $\left[\mathrm{C}_{40} \mathrm{H}_{71} \mathrm{~N}_{8} \mathrm{O}_{12}\right]^{+}=855.5186 ; \mathrm{m} / \mathrm{z}$ found $=855.5187$.

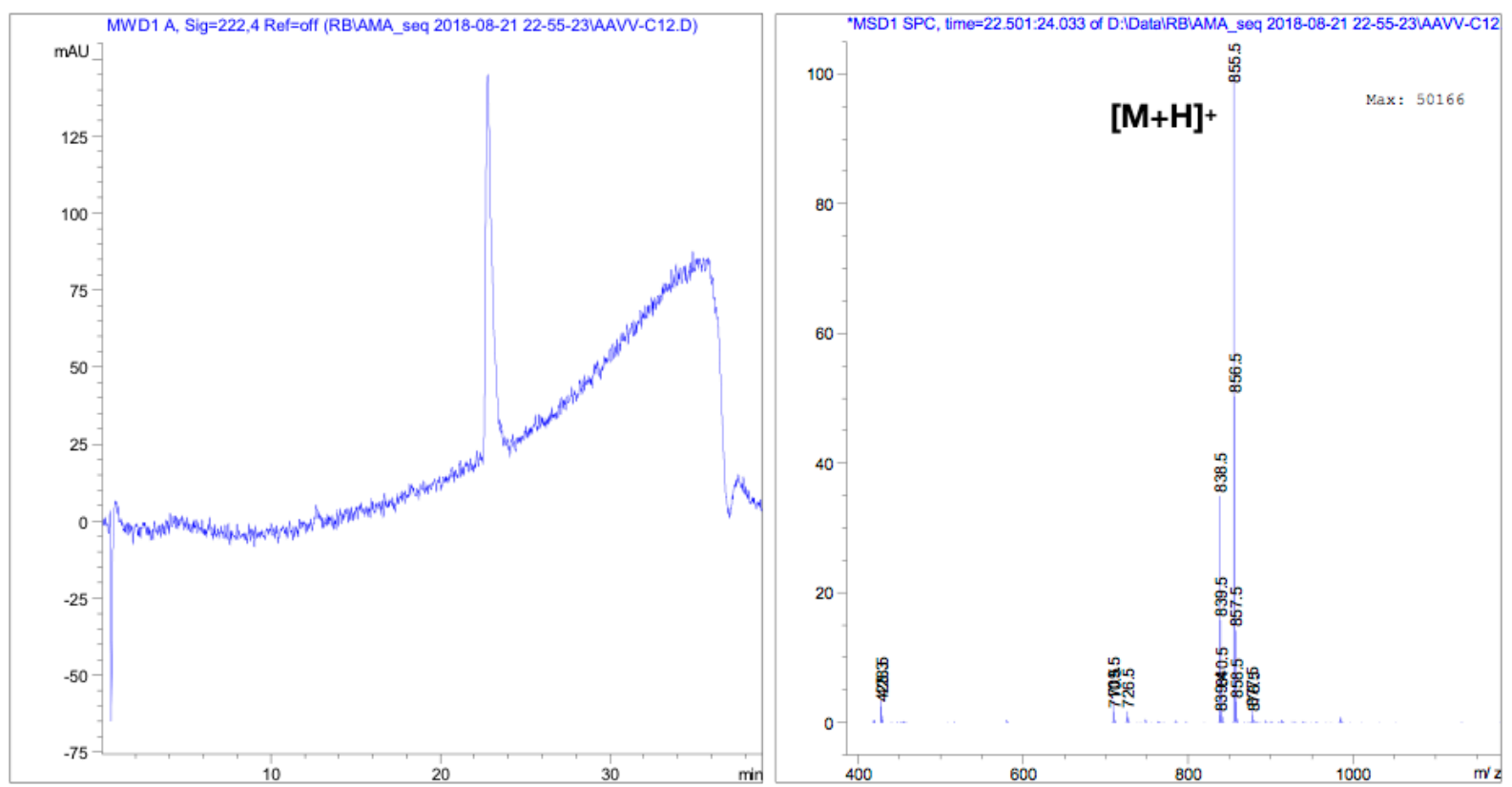

Figure S34 HPLC (UV-Vis detection at $222 \mathrm{~nm}$; left) and MS (ESI +eV; right) of amphiphile P5T12. 
P5T14 (EEAAVV-ON=C ${ }_{14} \mathrm{H}_{27}$ ): $\boldsymbol{R}_{\boldsymbol{t}} \mathbf{2 5 . 5}$ min (Fig. S35) RP-HPLC [Agilent SB-C18, $\mathrm{H}_{2} \mathrm{O}(0.1 \%$ TFA)/MeCN (0.1\% TFA) 100:0 (0 $\rightarrow 2 \mathrm{~min}), 100: 0 \rightarrow 5: 95$ ( $2 \rightarrow 32 \mathrm{~min}$ ), 0:100 (>32 $\mathrm{min})]$. HR-MS $(E S I,+e V) m / z$ calculated for $\left[\mathrm{C}_{42} \mathrm{H}_{75} \mathrm{~N}_{8} \mathrm{O}_{12}\right]^{+}=883.5499 ; \mathrm{m} / \mathrm{z}$ found $=883.5497$.

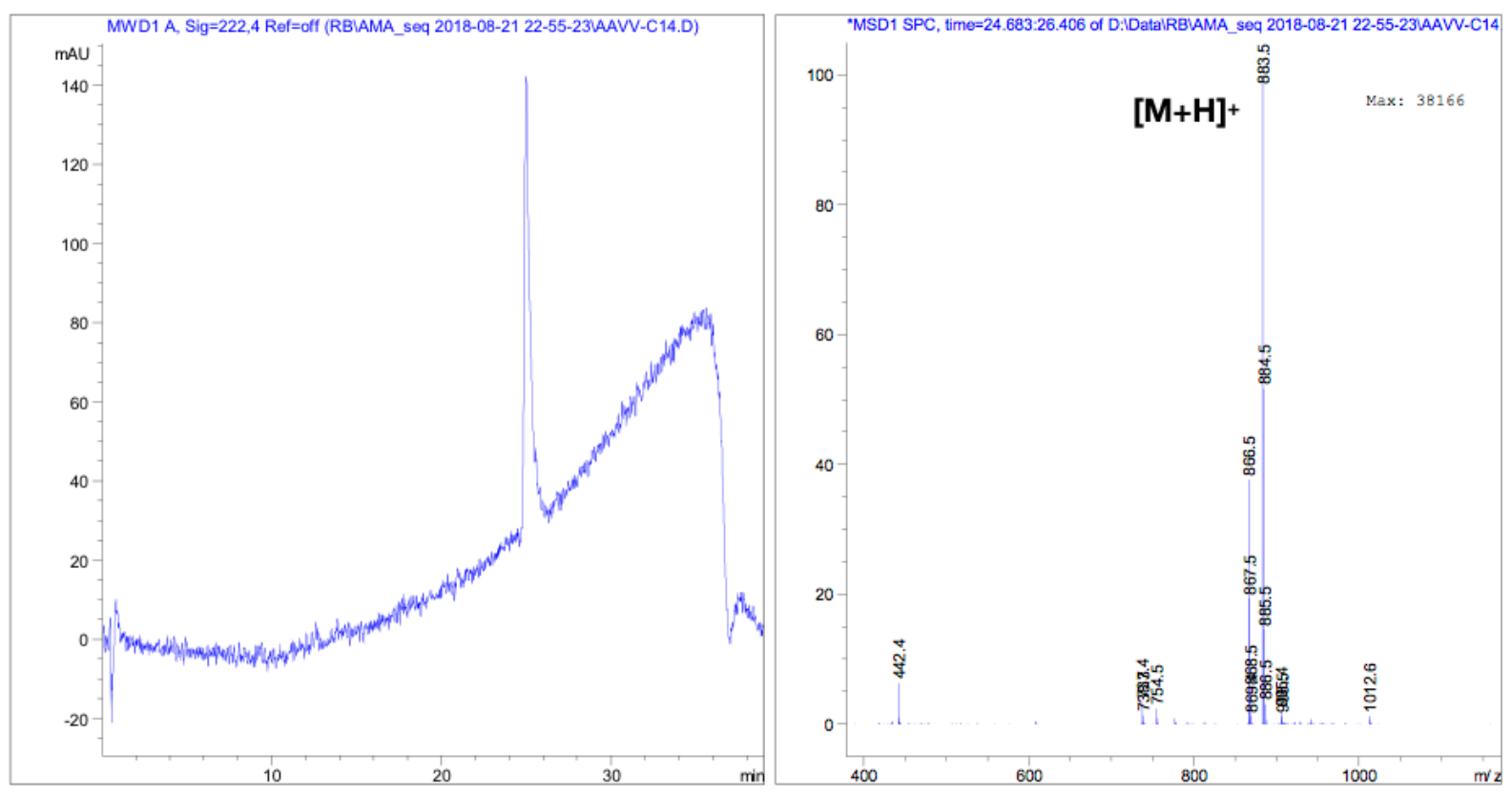

Figure S35 HPLC (UV-Vis detection at $222 \mathrm{~nm}$; left) and MS (ESI +eV; right) of amphiphile P5T14. 
P6T8 (EEAAAVV-ON= $\mathrm{C}_{8} \mathrm{H}_{15}$ ): $\boldsymbol{R}_{\boldsymbol{t}} 19.5 \mathrm{~min}$ (Fig. S36) RP-HPLC [Agilent SB-C18, $\mathrm{H}_{2} \mathrm{O}(0.1 \%$ TFA)/MeCN (0.1\% TFA) 100:0 (0 $\rightarrow 2 \mathrm{~min}$ ), 100:0 $\rightarrow 5: 95$ (2 $\rightarrow 32 \mathrm{~min}$ ), 0:100 (>32 min)]. HR-MS $(E S I,+e V) m / z$ calculated for $\left[\mathrm{C}_{39} \mathrm{H}_{68} \mathrm{~N}_{9} \mathrm{O}_{13}\right]^{+}=870.4931 ; \mathrm{m} / \mathrm{z}$ found $=870.4930$.

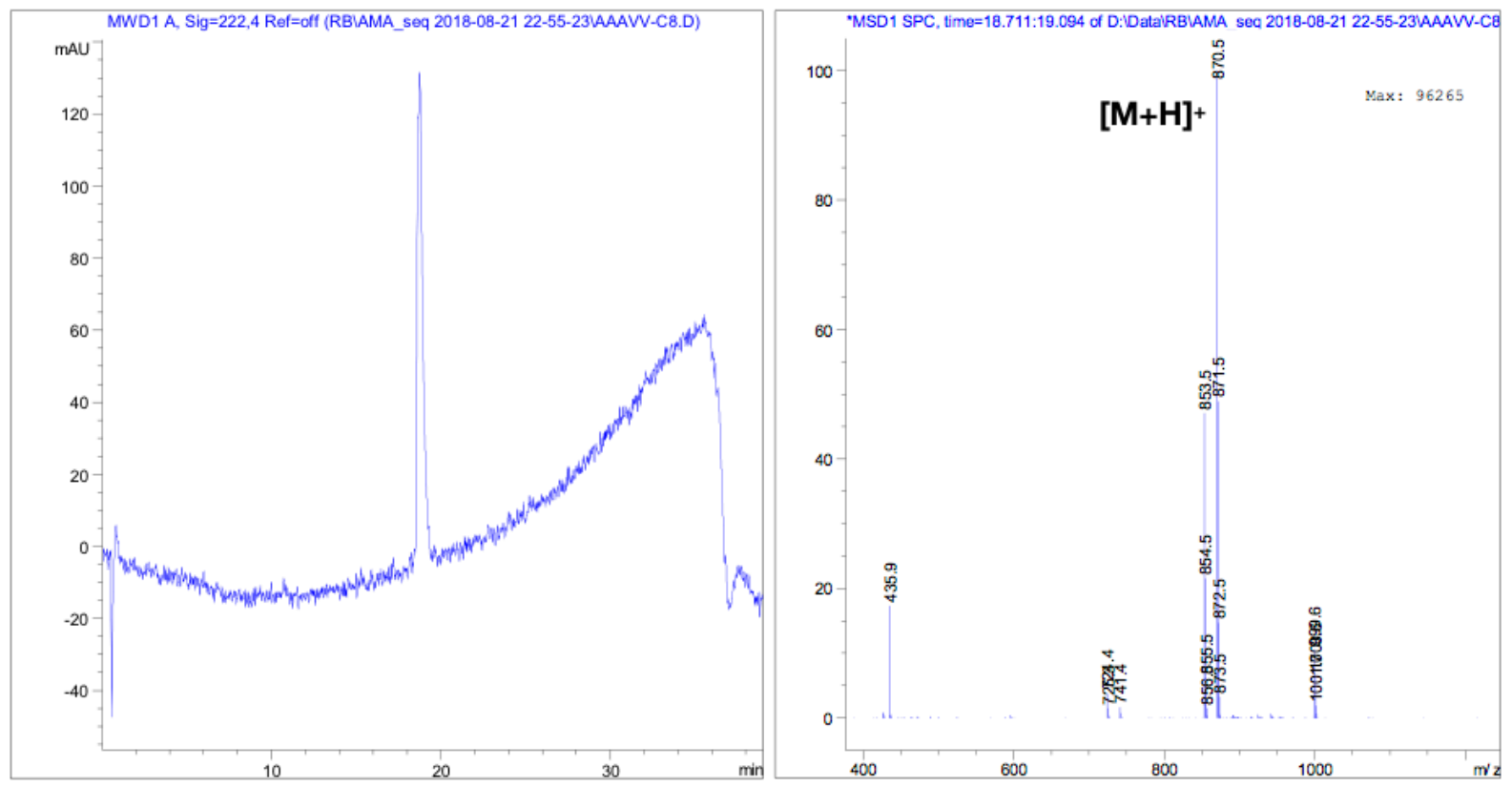

Figure S36 HPLC (UV-Vis detection at $222 \mathrm{~nm}$; left) and MS (ESI +eV; right) of amphiphile P6T8. 
P6T10 (EEAAAVV-ON= $\mathrm{C}_{10} \mathrm{H}_{19}$ ): $\boldsymbol{R}_{\boldsymbol{t}} \mathbf{2 1 . 5}$ min (Fig. S37) RP-HPLC [Agilent SB-C18, $\mathrm{H}_{2} \mathrm{O}(0.1 \%$ TFA)/MeCN (0.1\% TFA) 100:0 (0 $\rightarrow 2 \mathrm{~min}$ ), 100:0 $\rightarrow 5: 95$ (2 $\rightarrow 32 \mathrm{~min}$ ), 0:100 (>32 min)]. HR-MS $(E S I,+e V) m / z$ calculated for $\left[\mathrm{C}_{41} \mathrm{H}_{72} \mathrm{~N}_{9} \mathrm{O}_{13}\right]^{+}=898.5244 ; \mathrm{m} / \mathrm{z}$ found $=898.5244$.

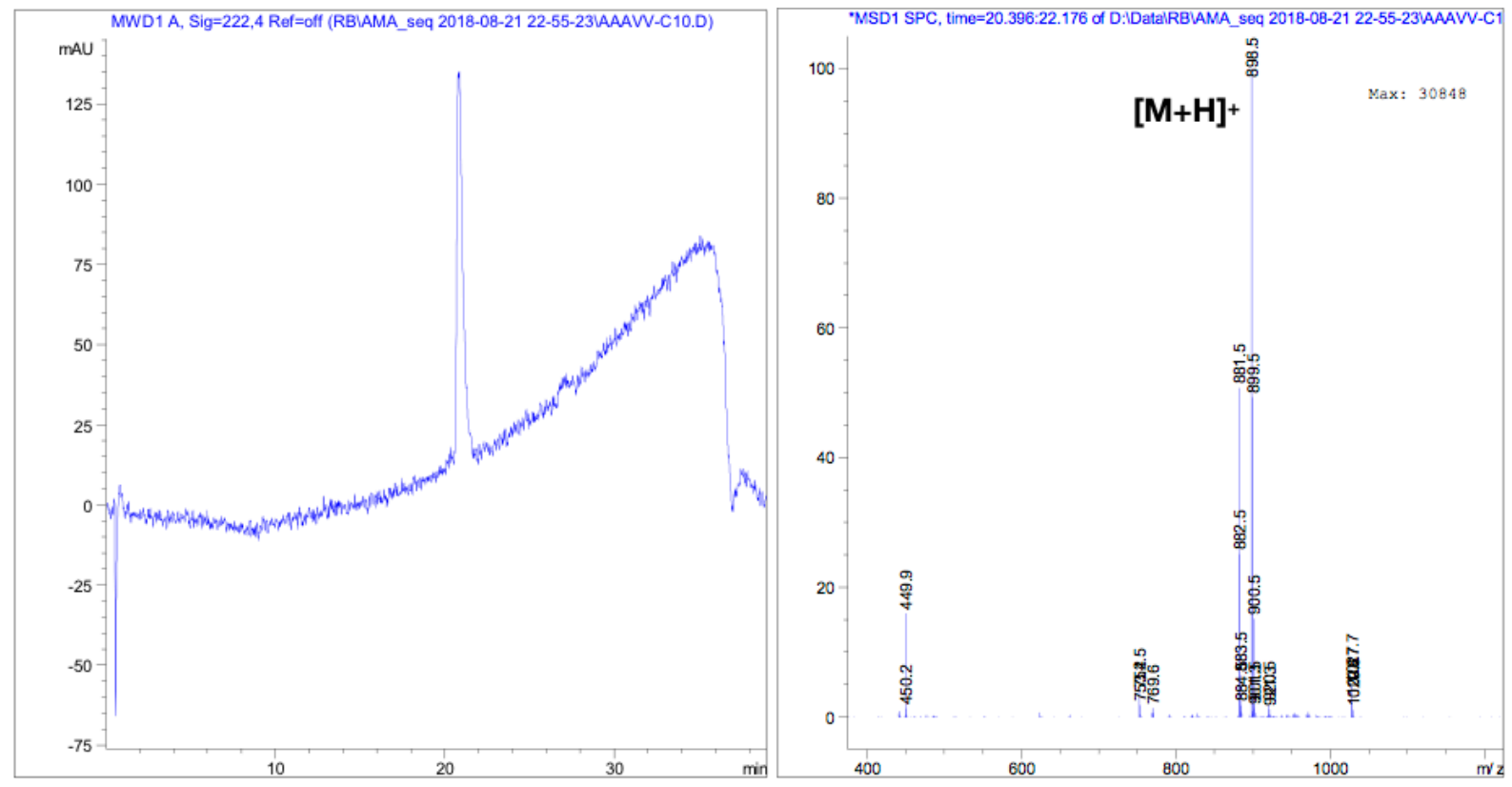

Figure S37 HPLC (UV-Vis detection at $222 \mathrm{~nm}$; left) and MS (ESI +eV; right) of amphiphile P6T10. 
P6T12 (EEAAAVV-ON= $\mathrm{C}_{12} \mathrm{H}_{23}$ ): $\boldsymbol{R}_{\boldsymbol{t}} 24 \mathrm{~min}$ (Fig. S38) RP-HPLC [Agilent SB-C18, $\mathrm{H}_{2} \mathrm{O}(0.1 \%$ TFA)/MeCN (0.1\% TFA) 100:0 (0 $\rightarrow 2 \mathrm{~min}$ ), 100:0 $\rightarrow 5: 95$ (2 $\rightarrow 32 \mathrm{~min}$ ), 0:100 (>32 min)].

HR-MS $(E S I,+e V) m / z$ calculated for $\left[\mathrm{C}_{43} \mathrm{H}_{76} \mathrm{~N}_{9} \mathrm{O}_{13}\right]^{+}=926.5557 ; \mathrm{m} / \mathrm{z}$ found $=926.5554$.

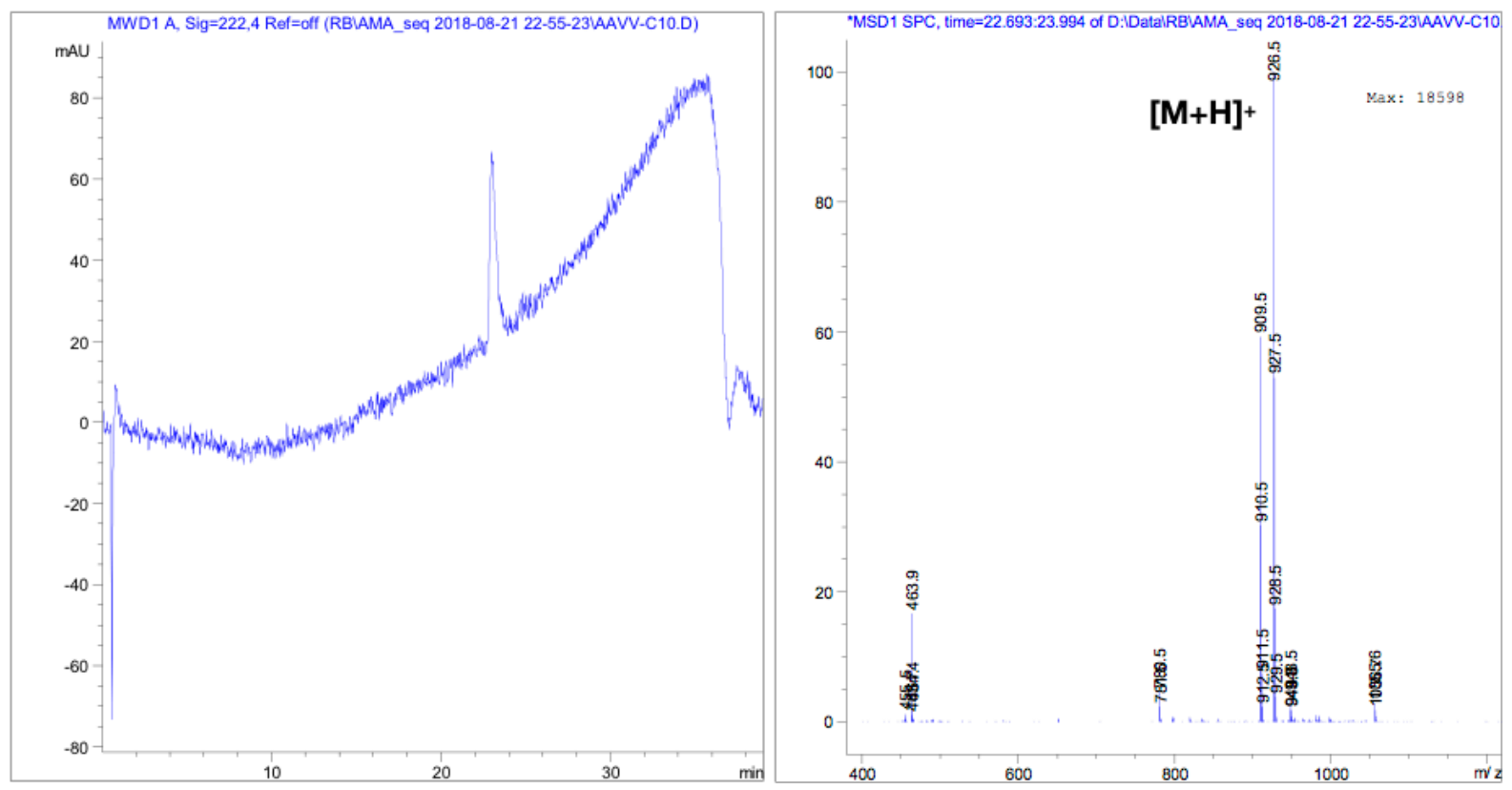

Figure S38 HPLC (UV-Vis detection at $222 \mathrm{~nm}$; left) and MS (ESI +eV; right) of amphiphile P6T12. 
P6T14 (EEAAAVV-ON= $\mathrm{C}_{14} \mathrm{H}_{27}$ ): $\boldsymbol{R}_{\boldsymbol{t}} 26 \mathrm{~min}$ (Fig. S39) RP-HPLC [Agilent SB-C18, $\mathrm{H}_{2} \mathrm{O}(0.1 \%$ TFA)/MeCN (0.1\% TFA) 100:0 (0 $\rightarrow 2 \mathrm{~min}$ ), 100:0 $\rightarrow 5: 95$ ( $2 \rightarrow 32 \mathrm{~min}), 0: 100$ (>32 $\mathrm{min})]$.

HR-MS $(E S I,+e V) m / z$ calculated for $\left[\mathrm{C}_{45} \mathrm{H}_{80} \mathrm{~N}_{9} \mathrm{O}_{13}\right]^{+}=954.5870 ; \mathrm{m} / \mathrm{z}$ found $=954.5874$.

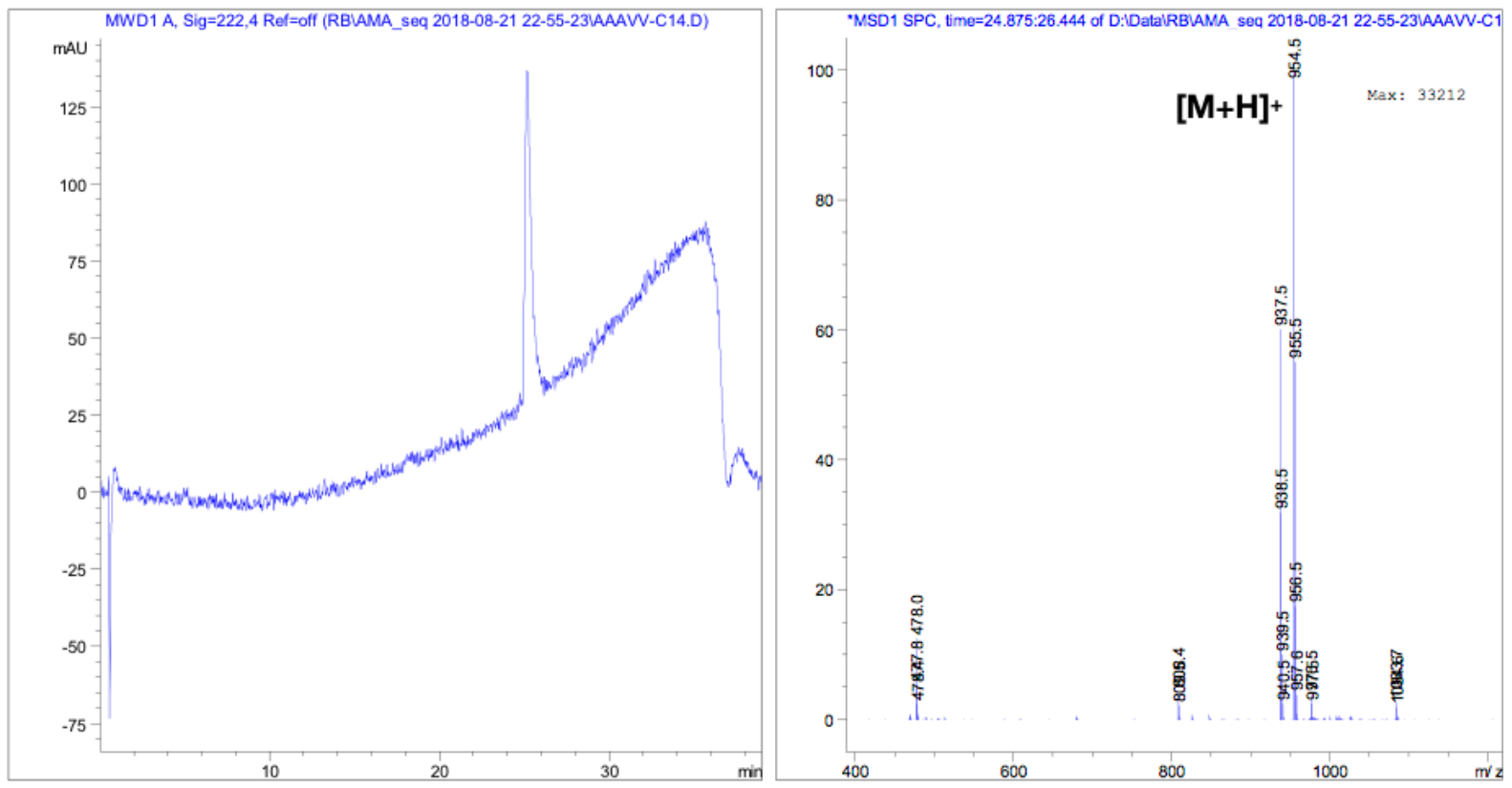

Figure S39 HPLC (UV-Vis detection at $222 \mathrm{~nm}$; left) and MS (ESI +eV; right) of amphiphile P6T14.

\section{Microscopy images (fluorescence/STEM)}
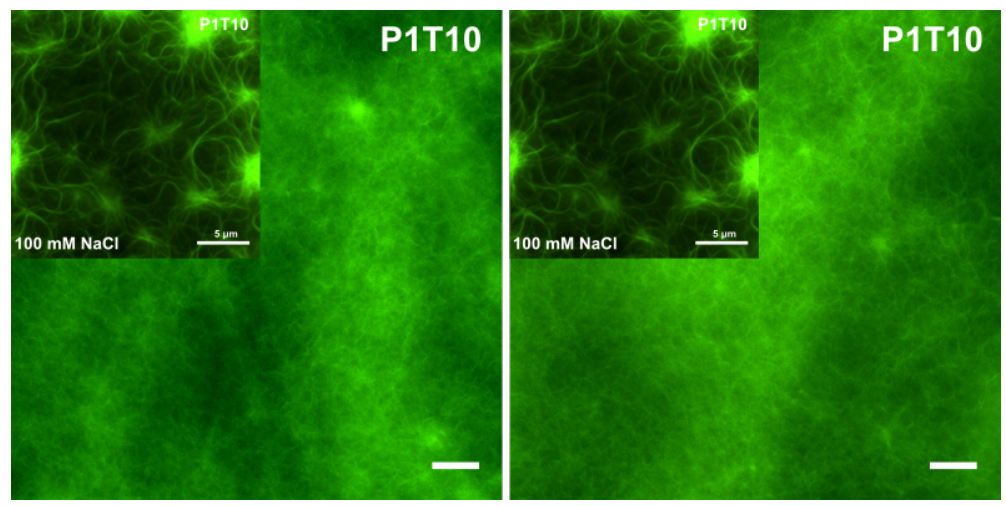

Figure S40 Fluorescence microscopy images of P1T10 peptide amphiphile $\left(10 \mathrm{mg} \cdot \mathrm{mL}^{-1}, 50\right.$ $\mathrm{mM}$ Tris-HCL, $\mathrm{pH}$ 7.5) after self-assembly overnight. For comparison, inset pictures represent P1T10 in the same buffer with $100 \mathrm{mM} \mathrm{NaCl}$ (Figure 2). All samples selfassembled on a glass slide, main image scale bars $=20 \mu \mathrm{m}$, inset scale bars $=5 \mu \mathrm{m}$. 

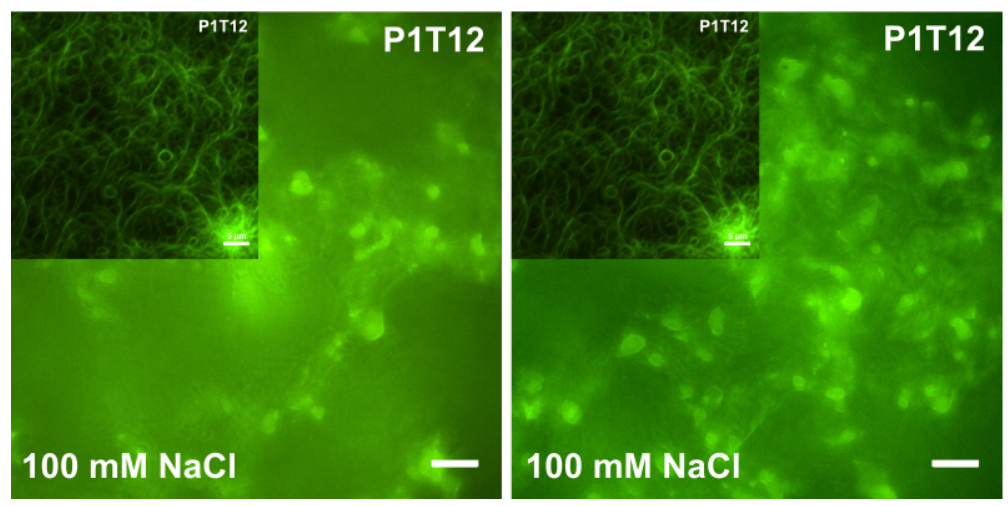

Figure S41 Fluorescence microscopy images of P1T12 peptide amphiphile $\left(10 \mathrm{mg} \cdot \mathrm{mL}^{-1}, 50\right.$ $\mathrm{mM}$ Tris-HCL, $\mathrm{pH} 7.5)$ after self-assembly overnight in the presence of $\mathrm{NaCl}(100 \mathrm{mM})$. For comparison, inset pictures represent P1T12 in the same buffer without $\mathrm{NaCl}$ (Figure 2). All samples self-assembled on a glass slide, main image scale bars $=20 \mu \mathrm{m}$, inset scale bars $=5$ $\mu \mathrm{m}$.
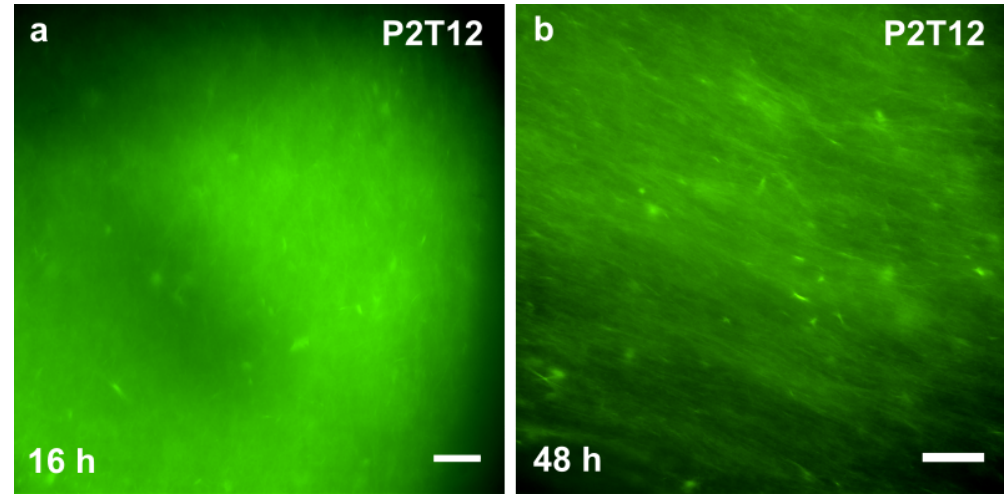

Figure S42 Fluorescence microscopy images of P2T12 peptide amphiphile $\left(10 \mathrm{mg} \cdot \mathrm{mL}^{-1}, 50\right.$ $\mathrm{mM}$ Tris- $\mathrm{HCl}, \mathrm{pH}$ 7.5) after self-assembly overnight (a) and after a period of $48 \mathrm{~h}$ (b), showing more defined fibres at longer times. All samples self-assembled on a glass slide, all scale bars $=20 \mu \mathrm{m}$. 


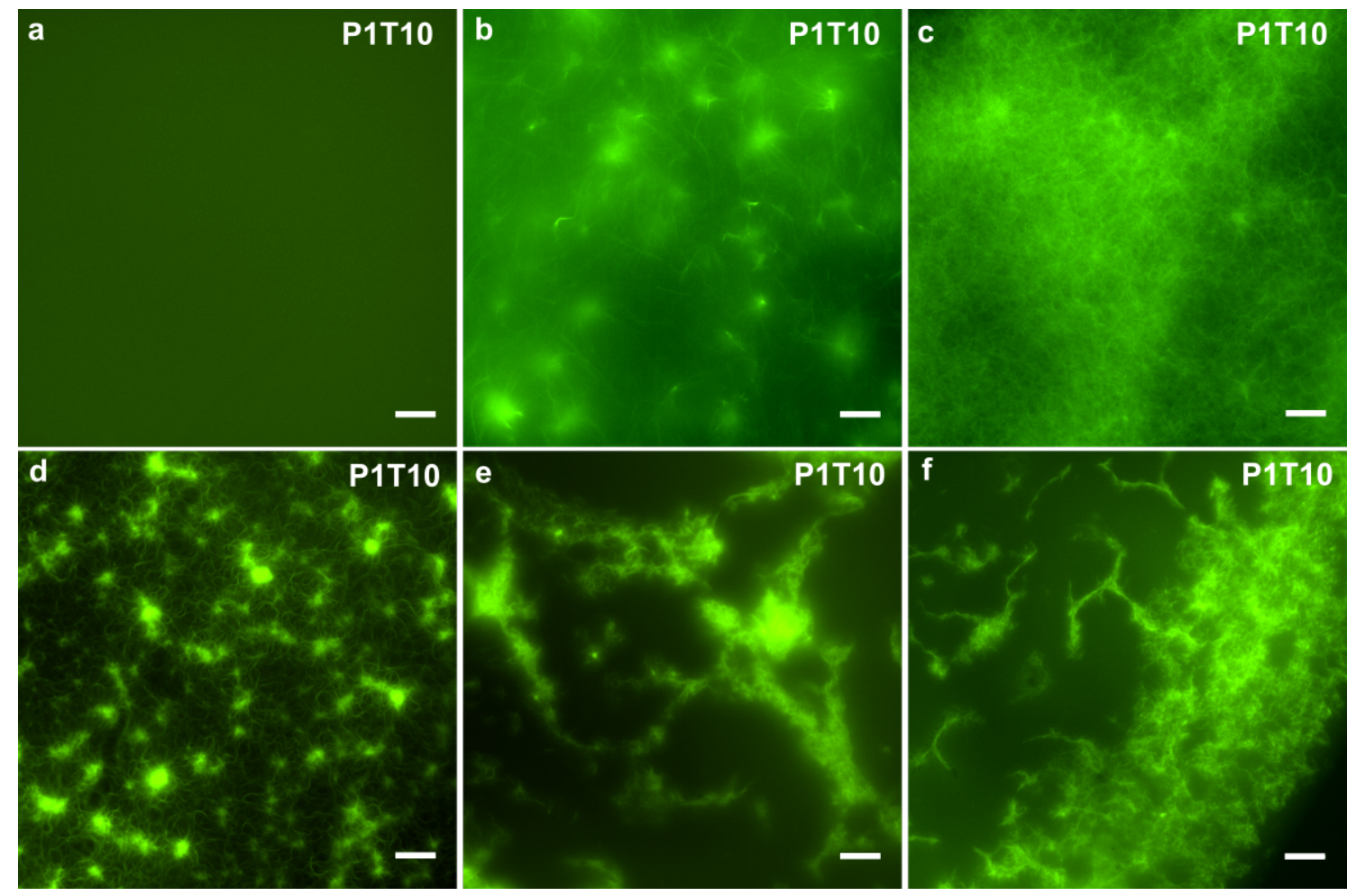

Figure S43 Fluorescence microscopy images of P1T10 self-assembled under different experimental conditions: (a) in an Eppendorf tube at a concentration of $10 \mathrm{mg} \cdot \mathrm{mL}^{-1}$ over a period of 2 weeks ( $50 \mathrm{mM}$ Tris- $\mathrm{HCl}, \mathrm{pH} 7.5,100 \mathrm{mM} \mathrm{NaCl})$, (b) in an Eppendorf tube at a concentration of $50 \mathrm{mg} \cdot \mathrm{mL}^{-1}$ over a period of 2 weeks $(50 \mathrm{mM}$ Tris- $\mathrm{HCl}, \mathrm{pH} 7.5,100 \mathrm{mM}$ $\mathrm{NaCl})$, (c) on a glass slide over a period of $16 \mathrm{~h},(50 \mathrm{mM}$ Tris- $\mathrm{HCl}, \mathrm{pH} 7.5)$ (d) on a glass slide over a period of $16 \mathrm{~h}$ after the addition of $100 \mathrm{mM} \mathrm{NaCl}(50 \mathrm{mM}$ Tris- $\mathrm{HCl}, \mathrm{pH} 7.5)$ and $(\mathbf{e}, \mathbf{f})$ on a hydrophobic glass slide (coated with $(1 \mathrm{H}, 1 \mathrm{H}, 2 \mathrm{H}, 2 \mathrm{H}$-perfluorooctyl)silane) at a concentration of $10 \mathrm{mg} \cdot \mathrm{mL}^{-1}(50 \mathrm{mM}$ Tris- $\mathrm{HCl}, \mathrm{pH} 7.5,100 \mathrm{mM} \mathrm{NaCl})$ : (e) centre of droplet and (f) left hand side of droplet. All scale bars $=20 \mu \mathrm{m}$. 


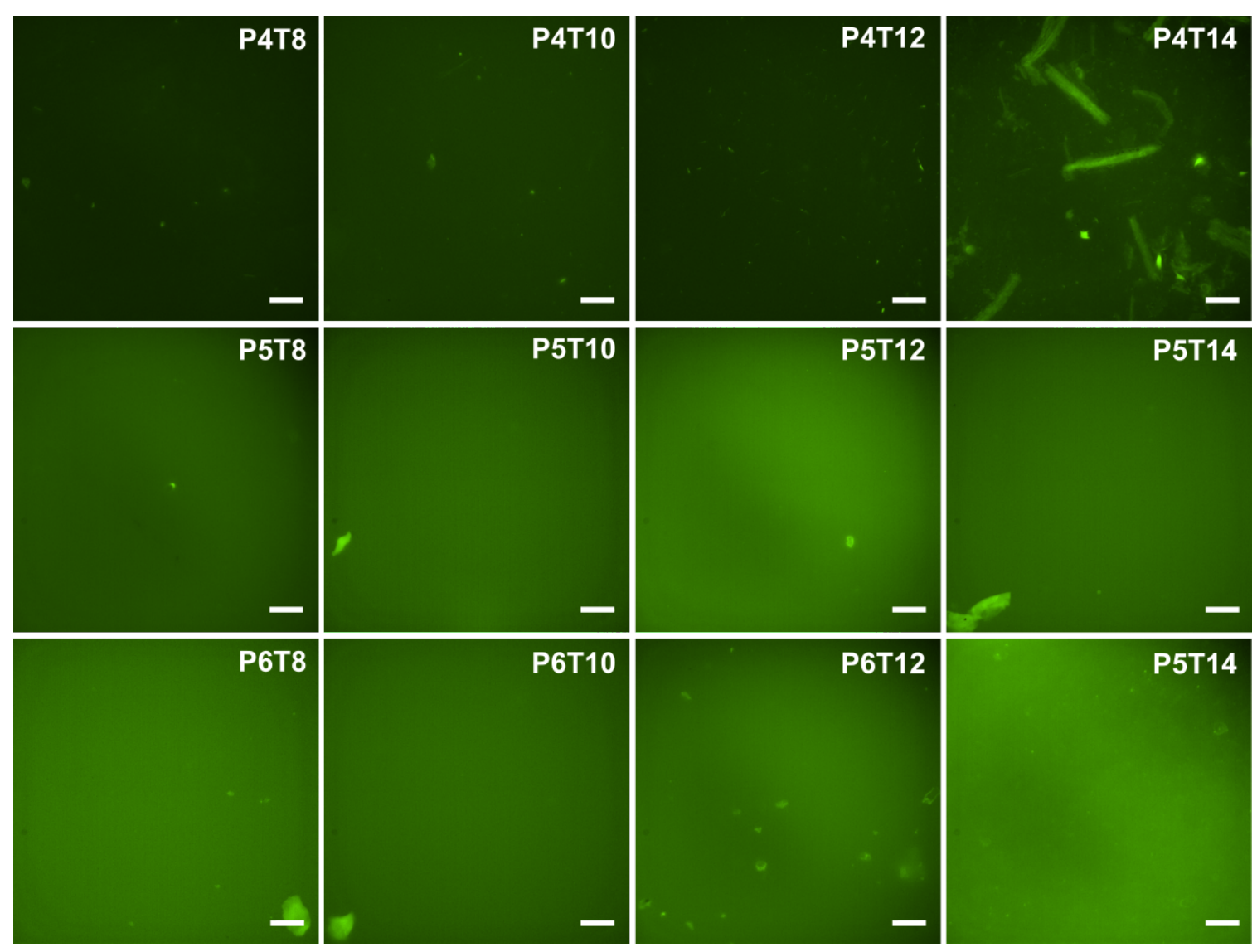

Figure S44 Fluorescence microscopy example images showing the lack of ordered selfassembly on the micron scale in anionic peptide amphiphiles at $10 \mathrm{mg} \cdot \mathrm{mL}^{-1}$ (100 $\mathrm{mM} \mathrm{HEPES}$, $\mathrm{pH} 7.5,100 \mathrm{mM} \mathrm{NaCl}$ ). All samples self-assembled on a glass slide, all scale bars $=20 \mu \mathrm{m}$.

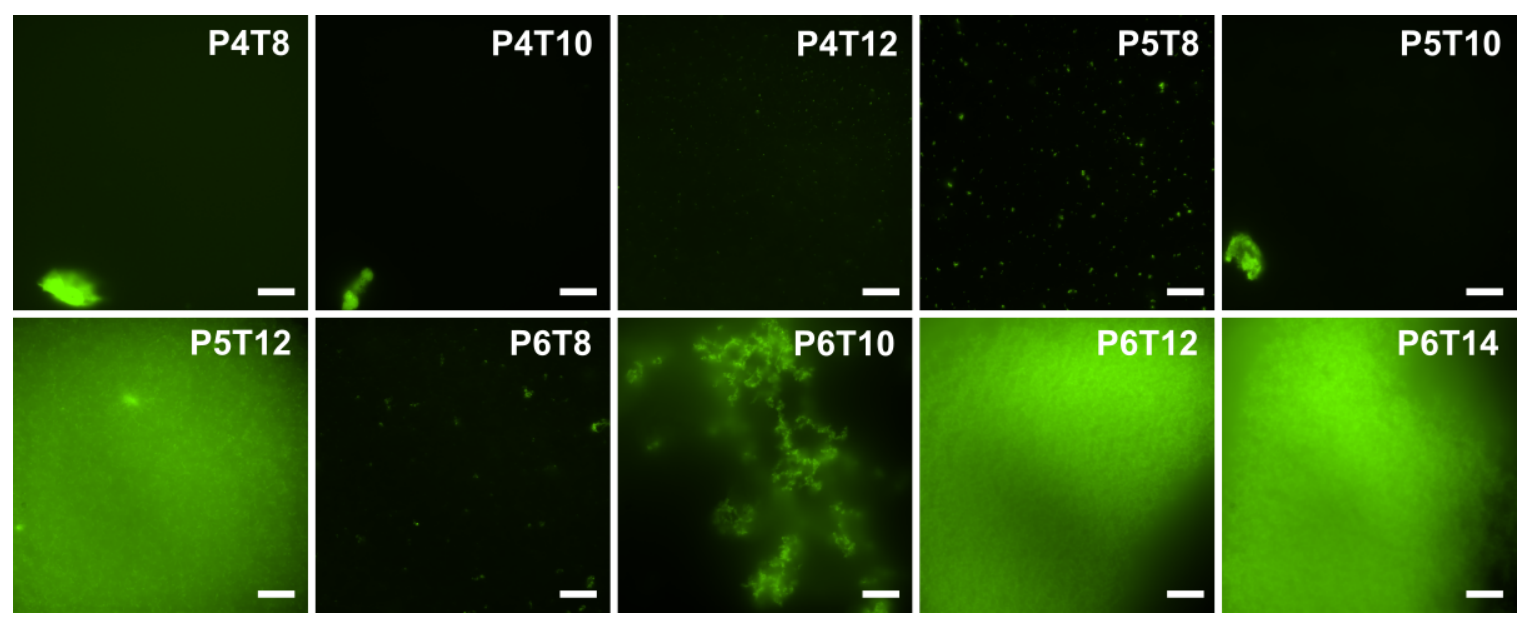

Figure S45 Fluorescence microscopy images of anionic peptide amphiphiles showing the lack of self-assembly or disordered aggregation at $0.5 \mathrm{mg} \cdot \mathrm{mL}^{-1}(100 \mathrm{mM} \mathrm{HEPES}, \mathrm{pH} 7.5,100$ $\mathrm{mM} \mathrm{NaCl}$ ). All samples self-assembled on a glass slide, all scale bars $=20 \mu \mathrm{m}$. 


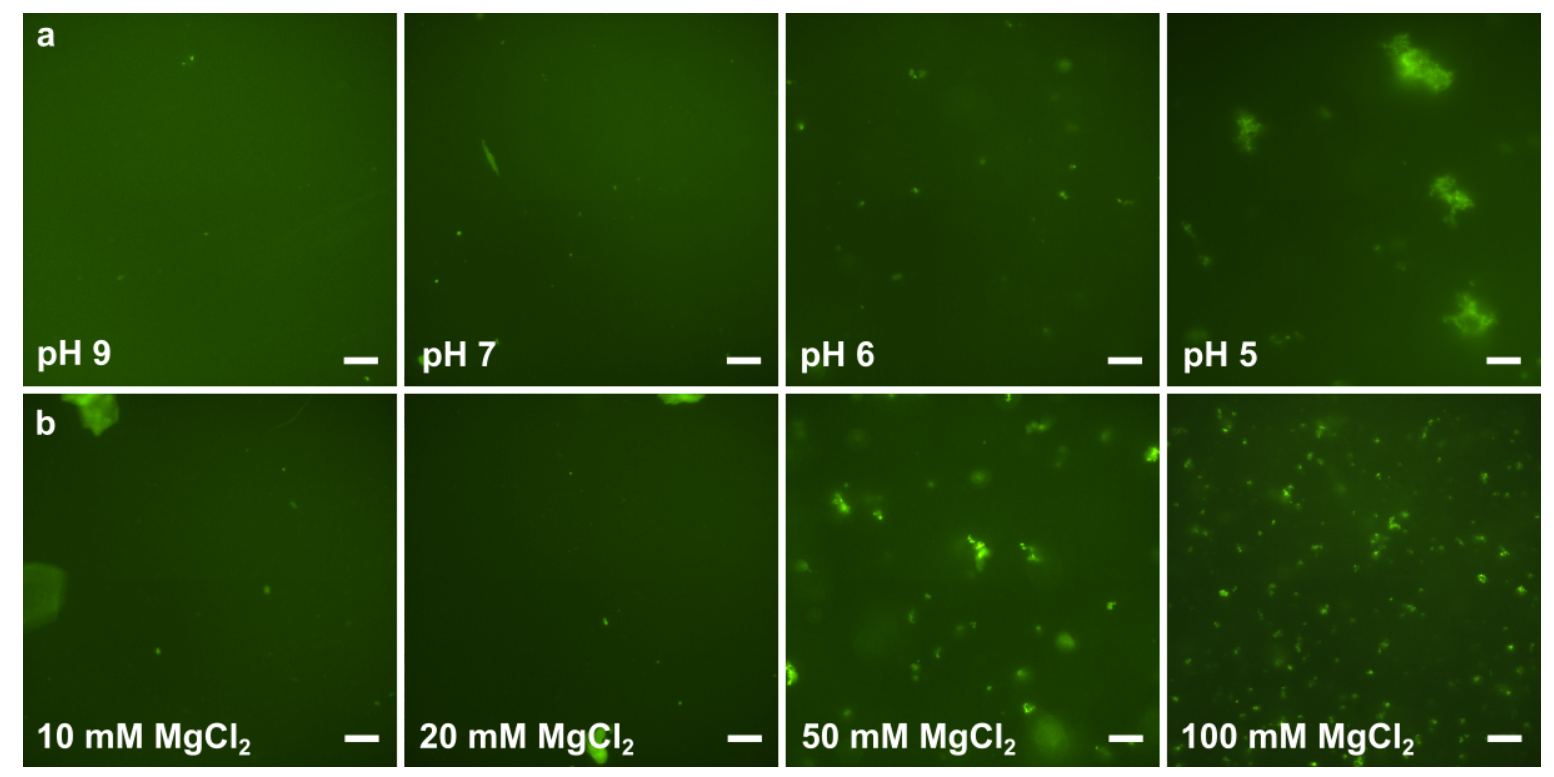

Figure S46 Fluorescence microscopy of P5T8 self-assembly under different conditions after $1 \mathrm{~h}$ at a peptide concentration of $0.5 \mathrm{mg} \cdot \mathrm{mL}^{-1}$ (a) range of $\mathrm{pH}(100 \mathrm{mM} \mathrm{HEPES}, 100 \mathrm{mM} \mathrm{NaCl}$ and $10 \mathrm{mM} \mathrm{MgCl}_{2}$ ) and (b) range of $\mathrm{MgCl}_{2}$ concentrations (100 mM HEPES, pH 7.5, $100 \mathrm{mM}$ $\mathrm{NaCl}$ ). All samples self-assembled on a glass slide, all scale bars $=20 \mu \mathrm{m}$.

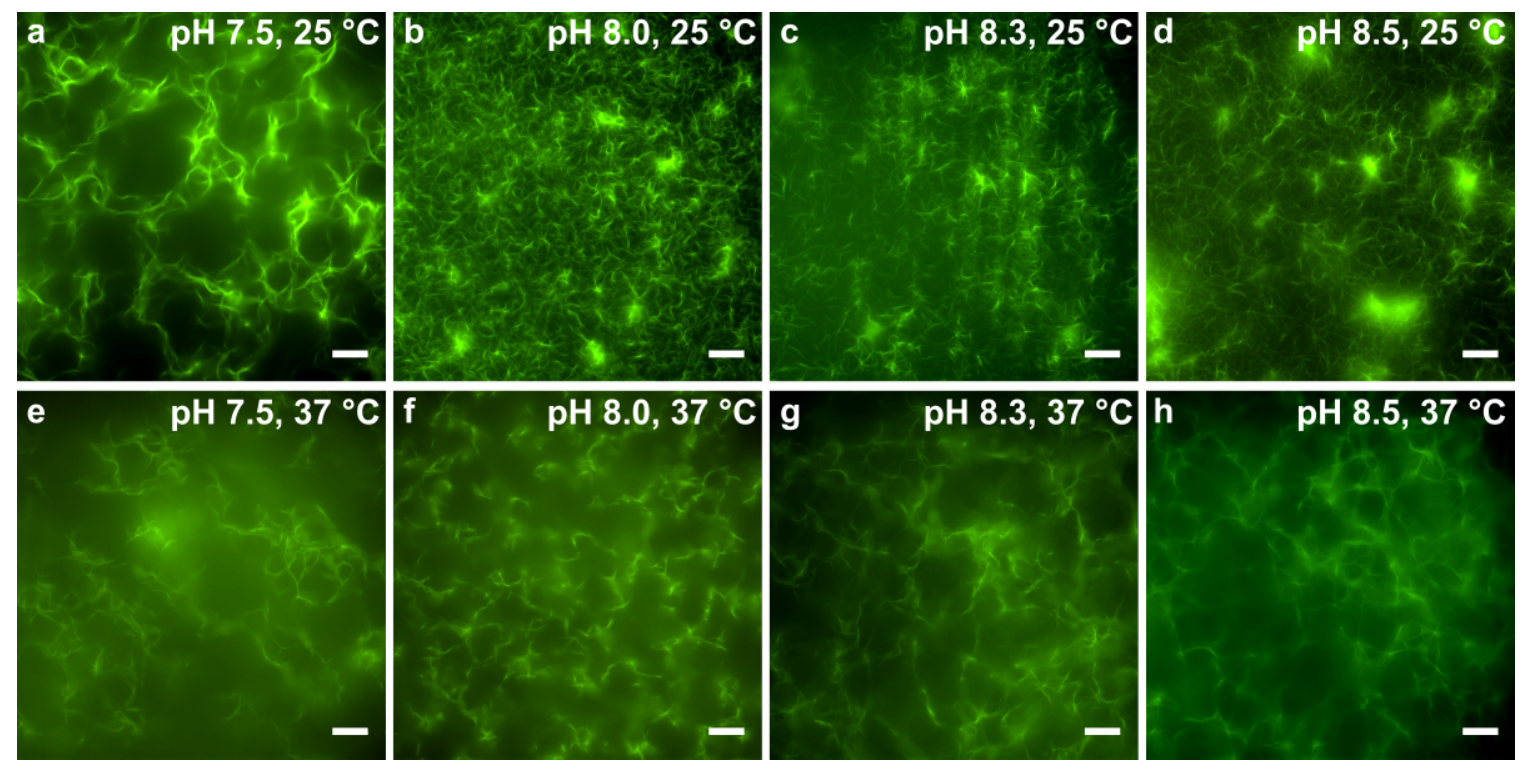

Figure S47 Fluorescence microscopy images of P5T14 $\left(0.5 \mathrm{mg} \cdot \mathrm{mL}^{-1}\right)$ prepared in $100 \mathrm{mM}$ HEPES, $100 \mathrm{mM} \mathrm{NaCl}, 10 \mathrm{mM} \mathrm{MgCl}_{2}$ at different $\mathrm{pH}$ and temperature: (a-d) at $25{ }^{\circ} \mathrm{C}$ versus $\mathrm{pH}$; (e-h) at $37{ }^{\circ} \mathrm{C}$ versus $\mathrm{pH}$. All samples self-assembled on a glass slide, all scale bars $=20$ $\mu \mathrm{m}$. 


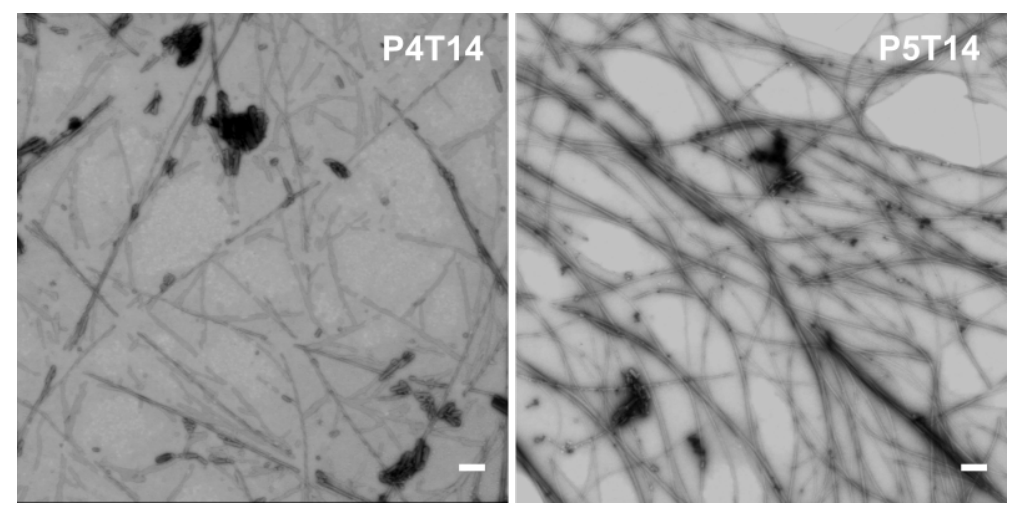

Figure S48 STEM images of P4T14 and P5T14 forming nanofibers at a concentration of 0.5 $\mathrm{mg} \cdot \mathrm{mL}^{-1}$ (100 mM HEPES, $\mathrm{pH} 7.5,100 \mathrm{mM} \mathrm{NaCl}, 10 \mathrm{mM} \mathrm{MgCl}$ ) and a self-assembly time of $10 \mathrm{~min}$ on a TEM copper grid. Scale bars $=200 \mathrm{~nm}$.

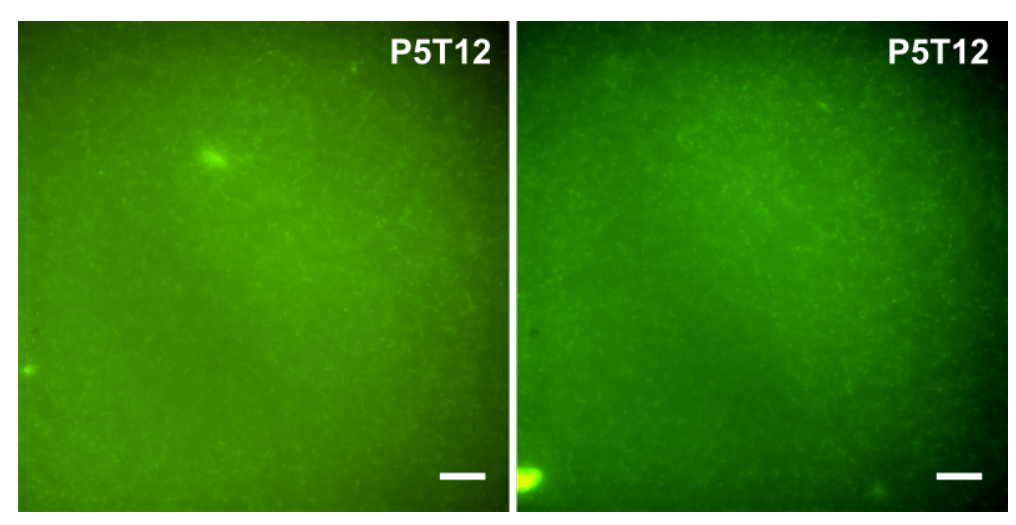

Figure S49 Fluorescence microscopy images of P5T12 forming small fibre-like aggregates at a concentration of $0.5 \mathrm{mg} \cdot \mathrm{mL}^{-1}(100 \mathrm{mM}$ HEPES, $\mathrm{pH} 7.5,100 \mathrm{mM} \mathrm{NaCl}, 10 \mathrm{mM} \mathrm{MgCl}$ ) but no micron-sized fibres. All samples self-assembled on a glass slide, all scale bars $=20 \mu \mathrm{m}$.

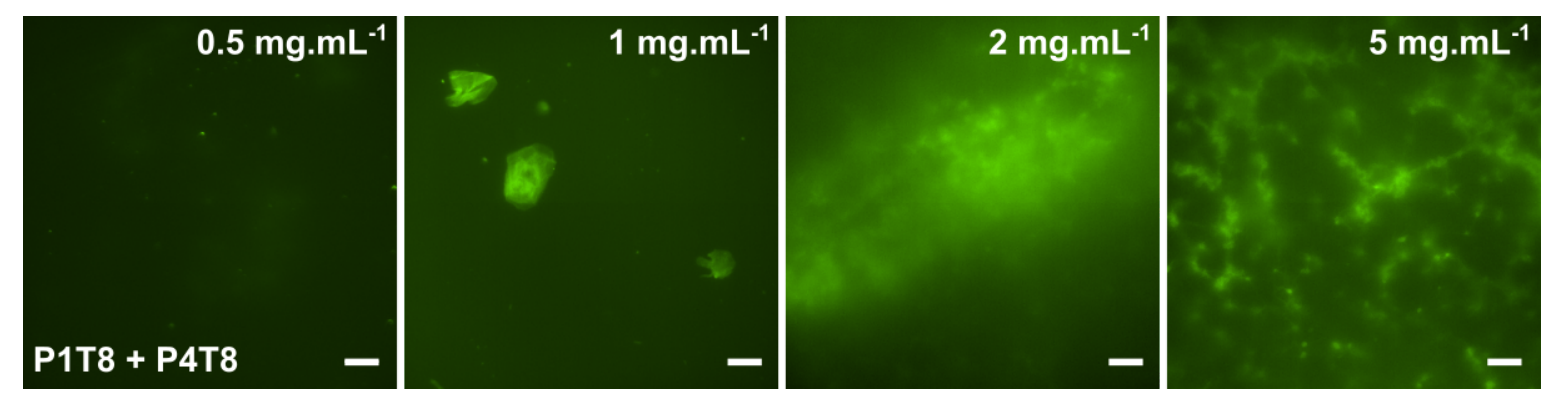

Figure S50 Fluorescence microscopy of 1:1 mixtures of cationic and anionic peptide amphiphiles (P1T8 + P4T8) with matching central sequence (GAVV) and tail (T8) after $1 \mathrm{~h}$ (100 mM HEPES, pH 7.5, $100 \mathrm{mM} \mathrm{NaCl}, 10 \mathrm{mM} \mathrm{MgCl}_{2}$ ). Final concentrations of each peptide between $0.5-5 \mathrm{mg} \cdot \mathrm{mL}^{-1}$. All samples self-assembled on a glass slide, all scale bars $=20 \mu \mathrm{m}$. 